\title{
Experimental analysis of the post-failure behavior of coal and rock under laboratory compression tests
}

Dachao Neil Nie

West Virginia University

Follow this and additional works at: https://researchrepository.wvu.edu/etd

\section{Recommended Citation}

Nie, Dachao Neil, "Experimental analysis of the post-failure behavior of coal and rock under laboratory compression tests" (2011). Graduate Theses, Dissertations, and Problem Reports. 281.

https://researchrepository.wvu.edu/etd/281

This Thesis is protected by copyright and/or related rights. It has been brought to you by the The Research Repository @ WVU with permission from the rights-holder(s). You are free to use this Thesis in any way that is permitted by the copyright and related rights legislation that applies to your use. For other uses you must obtain permission from the rights-holder(s) directly, unless additional rights are indicated by a Creative Commons license in the record and/ or on the work itself. This Thesis has been accepted for inclusion in WVU Graduate Theses, Dissertations, and Problem Reports collection by an authorized administrator of The Research Repository @ WVU. For more information, please contact researchrepository@mail.wvu.edu. 


\title{
EXPERIMENTAL ANALYSIS OF THE POST-FAILURE BEHAVIOR OF COAL AND ROCK UNDER LABORATORY COMPRESSION TESTS
}

\author{
Dachao (Neil) Nie \\ Thesis submitted to the \\ College of Engineering and Mineral Resources \\ at West Virginia University \\ in partial fulfillment of the requirements \\ for the degree of \\ Master of Science \\ in \\ Mining Engineering
}

Approved by

Brijes Mishra, Ph.D., Committee Chairperson

Yi Luo, Ph.D.

Felicia F. Peng, Ph.D.

Department of Mining Engineering

Morgantown, West Virginia

2011

Keywords: Coal/Rock specimen, post-failure behavior, control modes, load control, axial strain control, lateral strain control, UCS, triaxial tests 


\title{
ABSTRACT \\ EXPERIMENTAL ANALYSIS OF THE POST-FAILURE BEHAVIOR OF COAL AND ROCK UNDER LABORATORY COMPRESSION TESTS
}

\author{
Dachao Nie
}

A major aspect of coal mine design is the structural stability of the mine. For establishing structural stability, the strength of the strata is determined by recovering the cores. The strength is determined through various methods and one method in particular is the Uniaxial Compressive Strength of the rock, which is commonly adopted as the standard strength indicator. However, insitu behavior by past researchers have shown that rock and coal show significant residual strength contrary to the failure path observed in a conventional compression tests. Researchers in past had used stiff system for generating the post failure behavior of the rock and the results produced from these tests were applied to tunneling and hard rock mining. In addition, with the advent of computing system, geotechnical software is extensively used for mine stability analysis. They require correct inputs for producing practical and meaningful results. An extensive amount of literature is available in tunneling and hard rock mining, however, there is a dearth of literature in coal and coal measure rocks on post-failure behaviors. In addition, limited information is available on the proper method to be employed for understanding such behavior.

This thesis seeks to address this issue by performing various tests on rock and coal samples obtained from mines in West Virginia, Utah and sandstone quarries in Tennessee. Six different types of rocks (Berea sandstone, medium-grained sandstone, and coarse-grained sandstone, massive sandstone with coal streaks, grey shale and black shale) were tested in the rock mechanics laboratory. Two feedback-control modes: axial strain control and lateral strain control modes was adopted to study the post-failure behaviors of those samples. Load control was used for comparing the results with the other adopted methods. Results from these experiments show that using axial strain control and lateral strain control, the complete pre and post failure curve can be suitably obtained which are similar to the in-situ rock and coal behavior. In addition to the above finding, a possible mechanism of coal bump is also proposed which, will advance further experimental work in this area. 


\section{ACKNOWLEDGMENTS}

I wish to thank the members of my thesis advisory committee, Dr. Yi Luo, Dr. Felicia Peng, for their support, contributions, and encouragement.

Dr. Brijes Mishra, my thesis advisor, and the Chairman of the advisory committee, who provided me invaluable instructions and kind encouragement in this entire process of research. His broad knowledge and his questions encouraged me to perform better, to be a better graduate student in Mining Engineering department. His guidance has been invaluable to the completion of my thesis, and is greatly appreciated.

I am also grateful to Dr. Syd S. Peng, for accepting my graduate application, guiding my first year's study, and also the great opportunity he offered to work with Simon H. Prassetyo, a Fullbright scholar from Indonesia to learn all the basic rock/coal tests in the rock mechanics laboratory of West Virginia University. Without all the basic and foremost important skills, my thesis can never be completed.

The author also expresses sincere appreciation to his fellow graduate students and staffs of the Mining Engineering Department for their selfless help.

Forever, I am indebted to my father, Q. Q. Nie, my mother, C. X. Lu and my brother, Yin Nie, who gave me the strong support and the courage of my study here. Their care, patience, understanding, support, and most of all love make it possible for me to complete this thesis. Also to my wife, Lixia Ma, who has been patiently staying with me here in Morgantown and keeping the love between us during the last two years.

A special thank is addressed to Redbone Mining Company Inc., for their help in providing me the coal samples for this study. Thanks are also due to William J. 'Bill' Comstock, the technician in Mining Engineering Department at WVU, for his supporting my experimental work and also for repairing all the rock/coal sample preparation equipment. Without their contributions, this research could not have been smoothly completed. 


\section{TABLE OF CONTENTS}

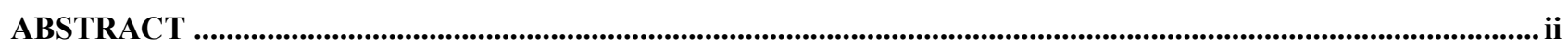

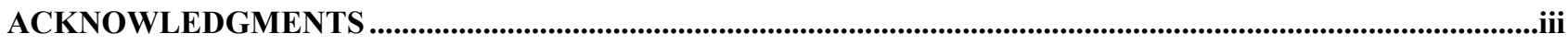

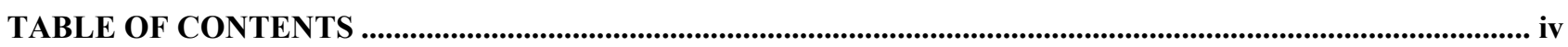

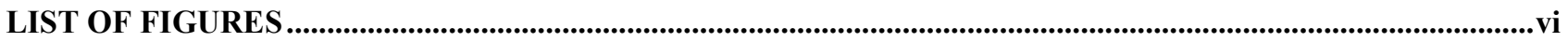

LIST OF TABLES

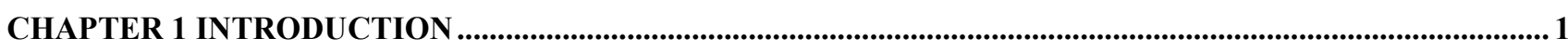

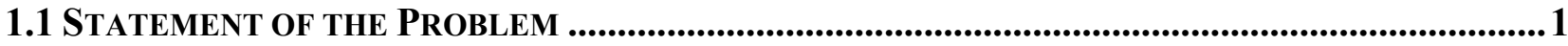

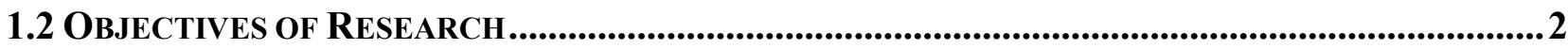

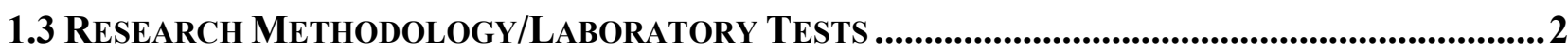

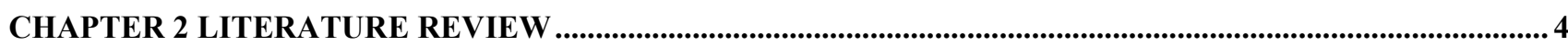

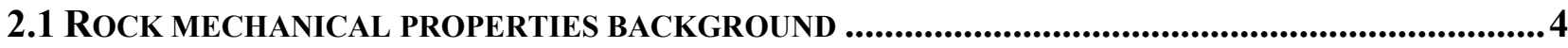

2.1.1 Uniaxial and Triaxial Compression Test …………............................................................................. 4

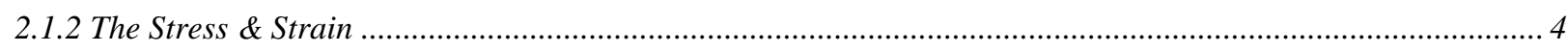

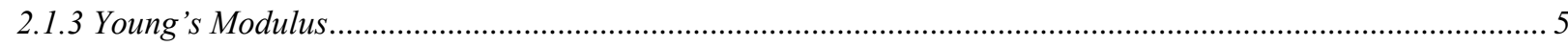

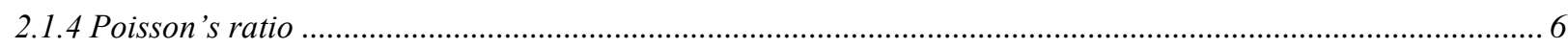

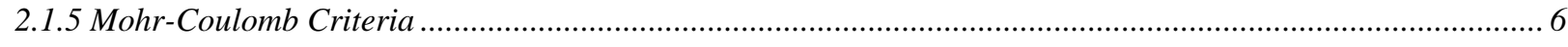

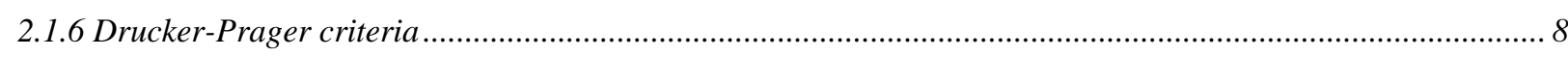

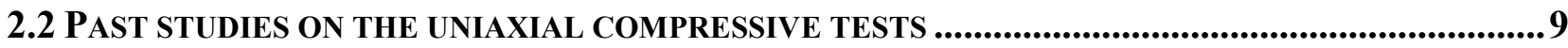

2.2.1 Stress-Strain Curve under UCS test condition ........................................................................................

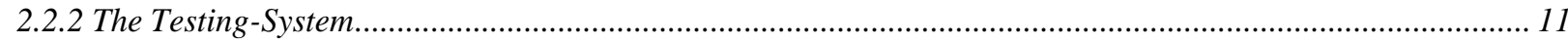

2.3 PAST RESEARCH ON THE POST-FAILURE BEHAVIORS OF ROCK SAMPLES ..............................15

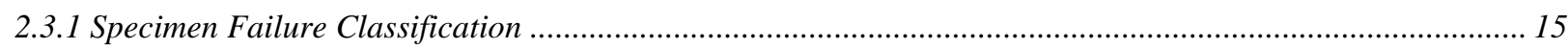

2.3.2 Previous studies on the post-failure behavior of coal and rocks............................................................... 17

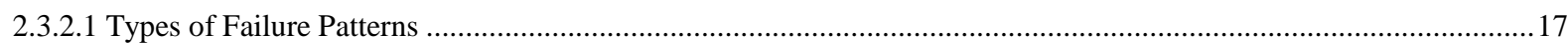


2.3.2.3 Features of Class II behavior of rocks.

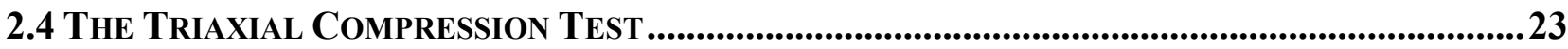

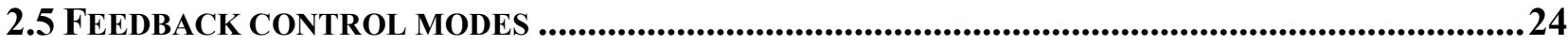

CHAPTER 3 LABORATORY TESTS

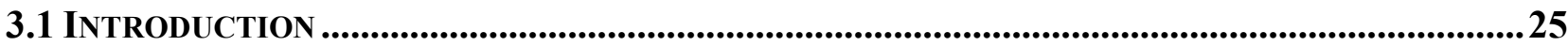

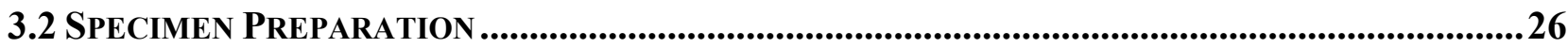

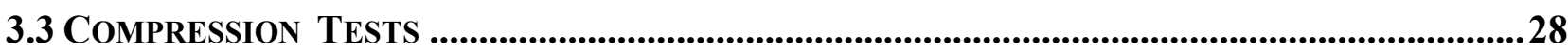

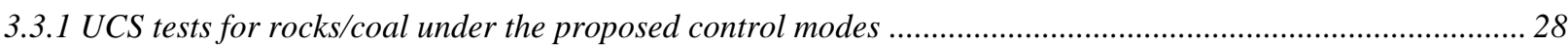

3.3.2 Triaxial compression test for coal under lateral strain control mode ...................................................... 32

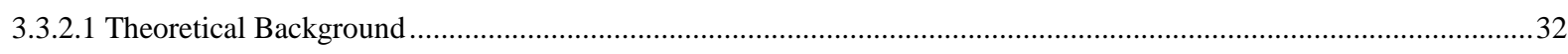

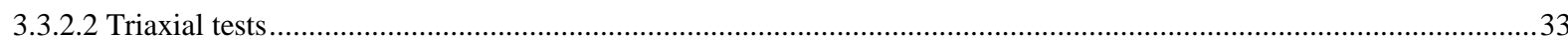

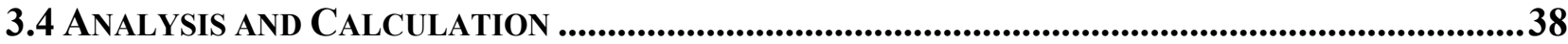

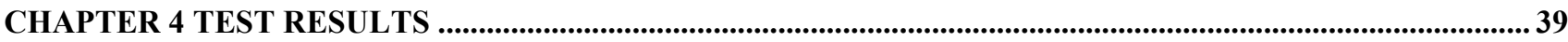

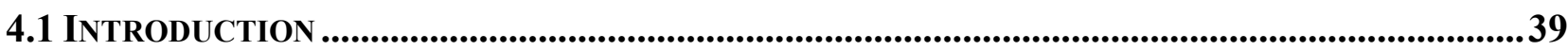

4.2 RESULTS OF THE UCS TEST FOR ROCK AND COAL UNDER THE PROPOSED CONTROL MODES 39

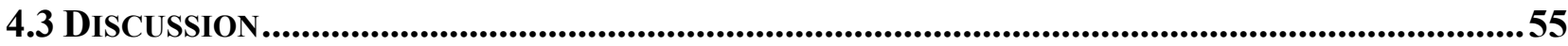

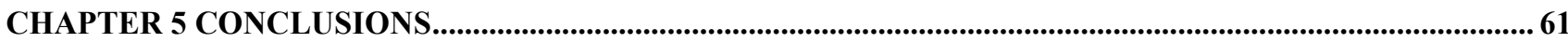

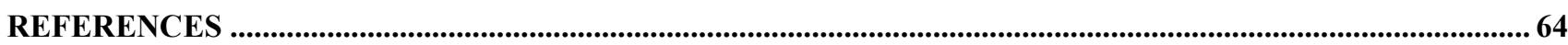

APPENDIX A: STRESS-STRAIN CURVES OF TESTED ROCK/COAL SPECIMENS ..................................... 67

APPENDIX B: ROCK/COAL SPECIMENS TESTED UNDER VARIOUS CONTROL MODES, BEFORE AND

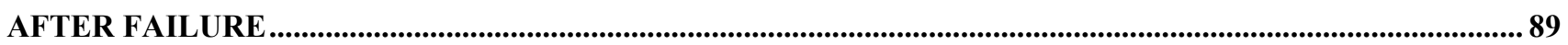

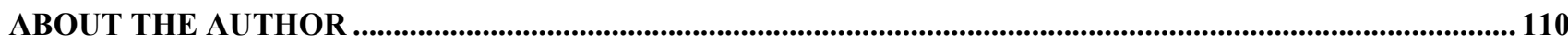




\section{List of Figures}

Figure 2.1. The Mohr-Cloulomb failure criteria and the Mohr's failure envelope.............................8

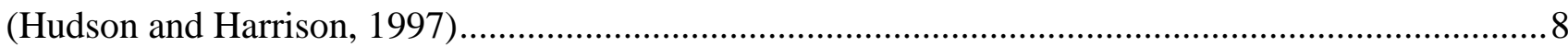

Figure 2.2. Complete stress and strain curve of rock deformation. ...............................................11

Figure 2.3. Stress and Strain curve of the uniaxial compressive strength tests. .............................12

(a)The elastic region of the stress-strain curve; (b) The complete stress-strain curve........................12

Figure 2.4. Load distribution of the specimen and testing machine during uniaxial compressive

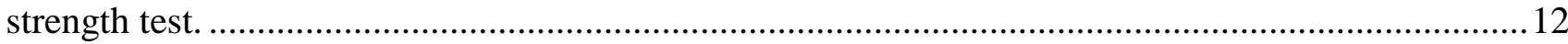

Figure 2.5. Post-peak unloading using machines that are (a) soft, and (b) stiff, with respect to the

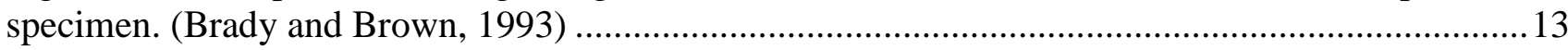

Figure 2.6. Principle of closed-loop control (after Hudson et al., 1972b) ......................................... 14

Figure 2.7. Uniaxial stress-strain curves for six different rock types showing both Class I and Class II failure behavior (after Wawersik and Fairhurst, 1970)............................................................... 16

Figure 2.8. Failure classification of specimen tested under uniaxial compression........................... 16

Figure 2.9. Stress-strain curves and failure pattern of coal and rock samples. (a), (b) are tested under displacement control mode; (c), (d), (e), (f) are tested under lateral strain control mode (Rao et al., 2010)

Figure 2.10. Normalized stress-strain curve of five different types of rocks under uniaxial compression showing elastic strain $\varepsilon_{\mathrm{e}}$ and non-elastic strain $\varepsilon_{\mathrm{p} .}$ (He and Okubo, 1990).....

Figure 2.11. Elastic and non-elastic strains of granite in the post-failure region under the confining pressure (He and Okubo, 1990). 20

Figure 2.12. Complete stress-strain curve obtained from the simulation with different control methods. (Left) Axial strain control, (Right) Lateral strain control (Hiroyuki, 2010) .21

Figure 2.13. Complete stress-strain curves with different homogeneity of rocks, $\mathrm{m}$ is the homogeneity indices (Pan and Hudson, 2006)

Figure 2.14. (a) Complete stress-strain curves of heterogeneous rocks with Drucker-Prager yield criterion. (b) Complete stress-strain curves of rocks with the same homogeneity index and different yield criterion (Pan and Hudson, 2006). .22

Figure 3.1. Vernier Caliper used for measuring specimen dimensions. .......................................26

Figure 3.2. Sample preparation in different stages. ..................................................................2 28

Figure 3.4. Coal sample with lateral extensometer and a transparent plastic-glass shield................29

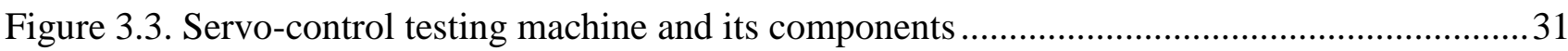


Figure 3.5. Triaxial Testing Machine .34

Figure 3.6. Pictorial setup for the triaxial compression test ….........................................................35

Figure 4.1. Stress-strain curves of six roof/floor rock samples tested under load control..... .40

Figure 4.2. Stress-strain curves of six Berea sandstone samples tested under lateral strain control. .42 Figure 4.3. Stress-strain curve of six different types of rock samples tested under lateral strain control. .45

Figure 4.4. Stress-strain curves of six different rock samples tested under axial strain control. .45

Figure 4.5. Stress-strain curves of six coal samples (Pittsburgh seam) tested under lateral strain control 46

Figure 4.6. Stress-strain curves of six coal samples (Pitt. seam) tested under axial strain control .....48 Figure 4.7. Stress-strain curves of four coal samples (Hiawatha seam) tested under lateral strain control

Figure 4.8. Stress-strain curves of four coal samples (Hiawatha seam) tested under lateral strain with low confining pressure 52

Figure 4.9. Maximum strength, Young's modulus, and Poisson's ratio versus the applied confining pressure for Hiawatha seam coal samples under lateral strain control. .53

Figure 4.10. Stress-strain curves of 12 coal samples tested under lateral strain control. .54

Figure 4.11. Typical stress-strain curves of rock samples tested under load control .55

Figure 4.12. Class I failure behavior curves of different rock samples tested under lateral strain control (Berea Sandstone). .56

Figure 4.13. Class II failure behavior curve of different rock samples tested under lateral strain control (Black Shale).

Figure 4.14. Class II failure behavior of coal samples from different seams tested under lateral strain control and the failed specimens (Pittsburgh coal seam). 58

Figure 4.15. Stress-strain curves of sandstone and Pittsburgh seam coal tested under axial strain control and the failed specimens. .59

Figure 4.16. Stress-strain curve of the Utah coal specimen under low confining pressure 60 


\section{List of Tables}

Table 3.1 Specific information of each different control mode 29

Table 3.2 Coal/Rock sample information used in this experiment .................................................30

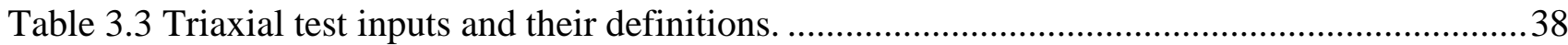

Table 4.1 The properties and results of the six rock samples tested under load control ....................40

Table 4.2 Test results of six Berea sandstone samples tested under lateral strain control mode.........41

Table 4.3 The basic information and test results of six different types of rock samples tested under lateral strain control mode. .43

Table 4.4 The basic information and test results of six different types of rock samples tested under axial strain control mode. .44

Table 4.5 The basic information and test results of six coal samples from Pittsburgh seam tested under lateral strain control mode

Table 4.6 Test results of six coal samples from Pittsburgh seam under axial strain control .47

Table 4.7 Test results of four coal samples from Utah seam under lateral strain control mode...... .48

Table 4.8 The basic information and test results of four coal samples from Hiawatha seam tested under lateral strain control with low confining pressure .51 


\section{CHAPTER 1 INTRODUCTION}

\subsection{Statement of the Problem}

This thesis addresses two problems: post-failure deformation behavior studies on both coal and rocks under various control modes and a new insight offered on future pillar failure study.

Mechanical properties of both coal and rocks such as Young's modulus (E), Poisson's ratio $(v)$, ultimate/failure strength $\left(\sigma_{f}\right)$, cohesive strength $(C)$, and the friction angle $(\varphi)$, etc. are often required to be input to some numerical models for predicting and analyzing the stability of the mine pillars and overburden strata. In addition, most of the models require the post-failure properties to predict the initial failure and the subsequent path of the complete failure.

Extensive researches (Rao, 2010; Simon, 2003; Rin, 2008) and field investigations were conducted to explore the roof/floor rock and coal properties and behaviors. However, majority of the commonly performed Uniaxial Compressive Strength (UCS) test on rocks and coal is by load control mode feedback, which usually produces a violent and explosive failure. A Feedback control is a control mechanism that uses information from measurements to manipulate a variable to achieve the desired result. It is possible to control an experimental variable automatically, continuously, and precisely by using a feedback control system (Hudson, et al. 1972). In addition, some field observations of roof, pillar and floor indicate that they even exhibit residual strength feature, which is not shown by the UCS test.

Surprisingly, compression tests using lateral strain control mode on coal samples, has been neglected by ground control researchers, and therefore limited information is available. Thus to the knowledge of the author there is no available literature that entails any research on the effect of different control methods on the post-failure deformation characteristics of coal and rock samples. 
This study focused on a series of uniaxial experiments on:

(1) Six randomly selected roof and floor rocks tested under load control mode

(2) Six Berea sandstone samples under lateral strain control mode

(3) Six different type of rocks (Berea sandstone, medium-grained sandstone, coarse-grained sandstone, massive sandstone with coal streaks, grey shale and black shale) tested under both axial strain control and lateral strain control and,

(4) Two groups of coal samples tested (from both the Pittsburgh seam and Hiawatha seam) to study the post-failure behaviors under two different control methods (axial strain control, and lateral strain control). Additionally, a group of four coal specimens was tested under lateral strain control with low confining pressure to study the effect of pillar confinement on failure of the cores.

\subsection{Objectives of Research}

The main objective of this study was to: (1) investigate the influence of various feedback control modes on the post-failure deformation behaviors of both coal and rocks under uniaxial testing condition; (2) Propose a hypothesis on coal bump mechanism using lateral strain control under triaxial compression with low confining pressure to study the pillar failure and the mechanisms of bumps.

\subsection{Research Methodology/Laboratory Tests}

To perform this research, a test matrix was developed which involved, a total of twenty four rock samples from both a quarry (only for Berea sandstones) and Cumberland mine, and twenty coal samples from both Pittsburgh seam and Hiawatha seam were prepared in the laboratory. The samples were then divided into eight different groups which were tested under the following conditions.

1. Six rock specimens were tested under load control mode. 
2. Six samples of Berea sandstone were tested under lateral strain control mode.

3. The specified six different types of rock specimens were tested uniaxially under lateral strain control mode.

4. The specified six different type of rock samples were tested uniaxially under axial strain control mode.

5. Six coal specimens from the Pittsburgh seam was tested uniaxially under lateral strain control mode.

6. Six coal specimens from the Pittsburgh seam was tested uniaxially under axial strain control mode.

7. Four coal specimens from the Hiawatha seam were tested uniaxially under lateral strain control mode.

8. Four coal specimens from the Hiawatha seam was tested under lateral strain control in a triaxial state with low confining pressure. 


\section{CHAPTER 2 LITERATURE REVIEW}

\subsection{Rock mechanical properties background}

\subsubsection{Uniaxial and Triaxial Compression Test}

The uniaxial compressive strength (UCS) test is usually performed to determine the ultimate strength of the rock. In addition with the strain gages it can measure Young's modulus, and Poisson's ratio. By applying confining pressure to the rock, parameters such as internal friction angle, cohesive strength and the failure envelope can be obtained. There were two types of triaxial tests: the biaxial (traditional compression) test where $\sigma_{1}>\sigma_{2}=\sigma_{3}>0$ and polyaxial (true triaxial compression) test where $\sigma_{1}>\sigma_{2}>\sigma_{3}>0\left(\sigma_{1}, \sigma_{2}, \sigma_{3}\right.$ are the principal stresses $)$. The ultimate strength of the material also depends on the amount of confining pressure $\left(\sigma_{2}, \sigma_{3}\right)$ applied to the specimen. Also, the properties obtained from uniaxial and triaxial compressive strength tests are regularly used as input parameters for mine design.

\subsubsection{The Stress \& Strain}

In the rock mechanics, stress analysis is performed on structures that are designed to withstand a variety of load. For example, stability of coal and hard rock mines, slope stability of open pit mines and various other structures involve designs to withstand various stresses which are naturally or artificially applied to them. The applied stress may be tensile, compressive and shear. When a load is applied to a mechanical member, it will induce internal forces within each member and when they are acting on any cross sectional area they are termed as stress. This stress when applied on a material will deform the material. In rock mechanics the standard method is to measure the deformation of a cylindrical specimen along axial and lateral directions. The strain produced 
under the axial load $\left(\sigma_{1}\right)$ is called axial strain $\left(\varepsilon_{\mathrm{a}}\right)$ and the strain developed in the direction normal to the axial load is called the lateral strain $\left(\varepsilon_{1}\right)$. For understanding the complete deformation behavior of rock, another property which is commonly calculated is the volumetric strain. It is defined as the ratio of the change in volume of the specimen body to the deformation to its original volume. If $\mathrm{V}$ is the original volume and $\mathrm{d}_{\mathrm{V}}$ is the change in volume occurred due to the deformation, the volumetric strain $\varepsilon_{\mathrm{v}}$ induced is given by $\varepsilon_{\mathrm{v}}=\mathrm{d}_{\mathrm{V}} / \mathrm{V}$, which is also the sum of the linear strains in three mutually perpendicular directions given by $\varepsilon_{\mathrm{v}}=\varepsilon_{\mathrm{a}}+2 \varepsilon_{1}$ (one axial and two laterals). Therefore, the yield strength of a rock refers to the point on the engineering stress-strain curve (as opposed to true stressstrain curve) beyond which the specimen experiences deformations that will not be completely reversed upon removal of the loading. The ultimate strength refers to the point on the engineering stress-strain curve corresponding to the stress that produces fracture.

\subsubsection{Young's Modulus}

Young's modulus is a measure of the stiffness of an elastic material and is a quantity used to characterize materials. It is determined from the stress-strain curve. In rock mechanics, the slope of the stress-strain curve is calculated at 50\% of the peak strength, and the stiffness obtained is called the tangent modulus. For an isotropic material the stiffness will remain same in all the directions. However, in anisotropic materials, Young's modulus will vary with the change in the direction. In this thesis, all the Yong's modulus calculated are the average young's modulus. It was calculated by the slope of the determined straight line as

$\mathrm{E}=\Delta \sigma_{\mathrm{A}} / \Delta \varepsilon_{\mathrm{A}}$ 


\subsubsection{Poisson's ratio}

When a material is compressed in one direction, it usually tends to expand in the other two directions perpendicular to the direction of compression. This phenomenon is called the Poisson effect. Poisson's ratio $v$ is a measure of the Poisson effect. The Poisson's ratio is the ratio of the lateral expansion divided by the axial compression, it may be calculated as

$$
\nu=-\frac{d \varepsilon_{\text {trans }}}{d \varepsilon_{\text {axial }}}=-\frac{d \varepsilon_{\mathrm{y}}}{d \varepsilon_{\mathrm{x}}}=-\frac{d \varepsilon_{\mathrm{z}}}{d \varepsilon_{\mathrm{x}}}
$$

Where $v$ is the Poisson's ratio,

$\varepsilon_{\text {trans }}$ is transverse strain (negative for axial tension (stretching), positive for axial compression)

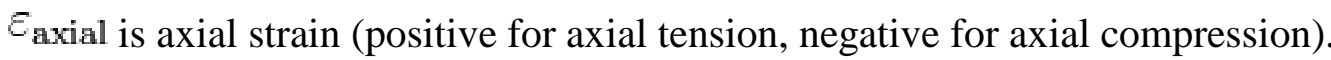

Possion's ratio characterizes the radial expansion induced by the axial load. Both E and $v$ are affected by the confining pressure in the triaxial test.

\subsubsection{Mohr-Coulomb Criteria}

A simple and popular method to predict the failure of a rock is by using the Mohr-Coulomb criteria, initially proposed by Coulomb for metals. He observed through experiment that there is a linear relationship between the normal and shear stress. He proposed the coulomb equation which is shown in equation 2.3. The strength of a rock, namely the friction-resistance strength equals to the summation of its internal cohesive strength and the friction produced by from the shear plane. It was considered as the shear strength criterion as follow:

$$
\begin{gathered}
\tau=\mathrm{c}+\sigma \tan \varphi \text { or } \\
\tau-\sigma \tan \varphi=\mathrm{c} . \ldots .
\end{gathered}
$$

where $\tau$ is the shear stress on the failure plane (shear strength), 
$\sigma$ is the normal stress on the failure plane,

$\mathrm{c}$ is the cohesive strength (cohesion),

$\varphi$ is the internal friction angle.

Mohr later (1990) associated Coulomb criteria with the triaxial stress state and the famous Mohr-Coulomb failure criteria was invented for the prediction of the influence of the confining pressure on the compressive strength of rocks through a single plot as illustrated in Figure 2.1. This can be done through various experiments such as the uniaxial tension, uniaxial compression, and triaxial compression test on rocks. The construction of all Mohr's plots was built by the failure stress $\left(\sigma_{1}\right)$ at different confining pressure $\left(\sigma_{3}\right)$. The tangent line of all those circles is called the Mohr's failure envelope, which can be used to estimate the stability of a rock at a certain point, by comparing the actual Mohr's circle to it. The estimated point will be unstable if the corresponding Mohr's circle is tangent or secant to the envelope line and vice versa. The envelope line can be acquired by the fitting method based on its experiment results. So far, there has been several proposed type of envelopes such as oblique straight line, cubic parabola, and hyperbola, etc. The oblique straight line one, however, agreed very well with the Coulomb criteria as indicated in the above equation.

Mohr strength theory is, in essential, a shear strength theory. For one thing, it shows a comprehensive strength characteristic of rocks and it can be applied to the failure criteria of both ductile and brittle rocks. Additionally, the feature that the tensile strength of a rock is far less than its compressive strength, which can be well approved through the plot; moreover, the characteristic that rocks will fail under triaxial tension but they will not fail under triaxial compression as indicated in the plot that the strength envelope is not close in the compression region. Therefore, this theory was widely employed in the rock engineering practices. 
However, the drawback of this criterion is that the intermediate principal stress $\sigma_{2}$ was neglected and so it sometimes disagrees with the actual experiment result. In addition, this theory is only appropriate to shear failure but not apply to dilatation or creep failure and also further research is needed as for the applicability of the tensile region.

BASIC EQUATIONS Rock fails at a critical combination of normal and shear stressex

Figure 2.1. The Mohr-Cloulomb failure criteria and the Mohr's failure envelope (Hudson and Harrison, 1997)

\subsubsection{Drucker-Prager criteria}

Drucker-Prager criteria, abbreviated as the D-P criteria, which was extended from the MohrCoulomb criteria (C-M) and the famous Mises criteria. It was given by:

$f=\alpha \mathrm{I}_{1}+\sqrt{J_{2}}-\mathrm{K}=0$ 
Where $\mathrm{I}_{1}=\sigma_{\mathrm{ii}}=\sigma_{1}+\sigma_{2}+\sigma_{3}=\sigma_{\mathrm{x}}+\sigma_{\mathrm{y}}+\sigma_{\mathrm{z}}$

which is the first invariant of stress.

$$
\begin{aligned}
J_{2} & =\frac{1}{2} s_{i} s_{i}=\frac{1}{6}\left[\left(\sigma_{1}-\sigma_{2}\right)^{2}+\left(\sigma_{2}-\sigma_{3}\right)^{2}+\left(\sigma_{3}-\sigma_{1}\right)^{2}\right] \\
& =\frac{1}{6}\left[\left(\sigma_{x}-\sigma_{y}\right)^{2}+\left(\sigma_{y}-\sigma_{z}\right)^{2}+\left(\sigma_{z}-\sigma_{x}\right)^{2}+6\left(\tau_{x y}^{2}+\tau_{y z}^{2}+\tau_{z x}^{2}\right)\right]
\end{aligned}
$$

which is the second invariant of deviator stress;

$\alpha, \mathrm{K}$ is the experimental constant related to the internal friction angle $\varphi$ and the cohesive strength $\mathrm{c}$ of rocks:

$$
\alpha=\frac{2 \sin \varphi}{\sqrt{3}(3-\sin \varphi)}
$$

$$
K=\frac{6 c \cos \varphi}{\sqrt{3}(3-\sin \varphi)}
$$

Drucker-Prager criteria considered not only the influence of the intermediate principal stress $\sigma_{2}$ but also the effect of hydrostatic pressure. Thus, this theory got over the shortcomings of the C-M criteria and was extensively used in the calculation and analysis of numerical simulation on rock and soil mechanics field worldwide (Cai M. F., 2002).

\subsection{Past studies on the uniaxial compressive tests}

\subsubsection{Stress-Strain Curve under UCS test condition}

Figure 2.2 shows the complete stress-strain curve of a typical sample under uniaxial compression tests. The curve is broken into various stages from $\mathrm{O}$ to $\mathrm{E}$ as shown in Figure 2.2 (Cai, 2002 and Skudai, 2008)). Each of the stages is as follows: 
1) Stage I (Phase OA). In stage 1, pre-existing micro-cracks of the specimen will close at low levels of stress. Also because of the non-uniform closing of microcracks there is a non-linear development of strain.

2) Stage II (Phase AC). This is a transitional stage from elastic deformation to stable crack propagation regime. The stress-strain curve is approximately linear in the stage and it can be divided into two sub-stages. In phase $\mathrm{AB}$ it is the elastic deformation period and in phase $\mathrm{BC}$ it is the stable crack propagation period.

3) Stage III (Phase CD). This is the unstable crack propagation stage and it can also be called progressive crack stage. Point $\mathrm{C}$ is an inflection point from elastic to plastic phase, i.e. when some of the deformation becomes irrecoverable at this point, which is the yield point. The corresponding stress of this point is therefore the yield stress or yield limit, the value of which is around two thirds of the ultimate strength of the specimen. In this stage, the development of the micro-cracks has a qualitative change and fractures continue to propagate until the specimen failed completely. Moreover, the axial strain and volumetric strain quickly increases and dilatancy also occurs.

4) Stage IV (Phase DE). This is the post-failure deformation behavior phase and is also what this thesis is going to focus on. The maximum bearing capacity of the specimen is reached, but it is still intact, even though the internal structure is highly disrupted. In this stage, the crack arrays fork and coalesce into macro-cracks or a fault. Thereafter, the specimen has essentially parted to form a series of blocks rather than an intact structure. These blocks slide across each other along the macro-fractures and finally the bearing capacity of the specimen sharply decreases as the deformation propagates. However, the bearing capacity does not drop to zero, since the ruptured specimen still holds a certain amount of capacity at the time the test terminates. 


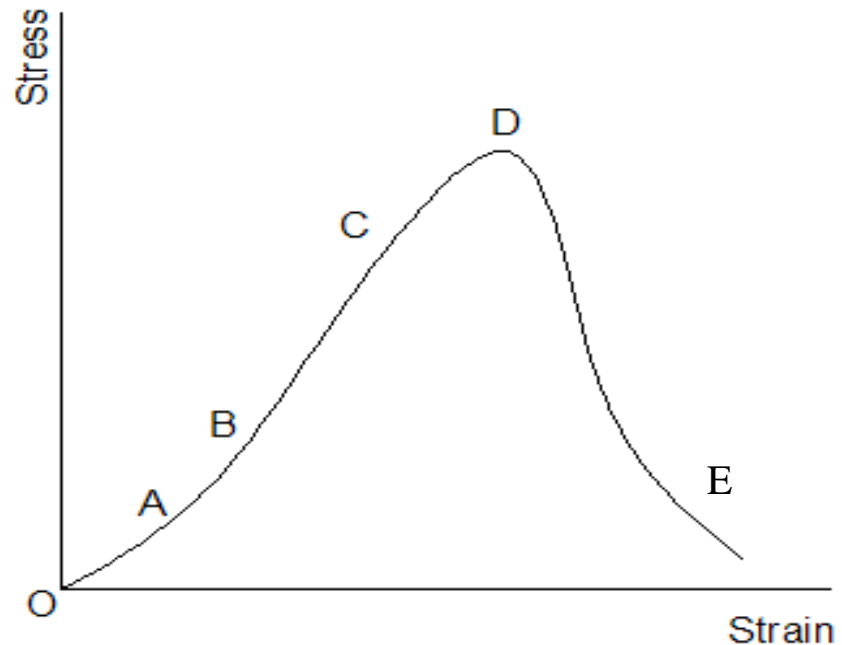

Figure 2.2. Complete stress and strain curve of rock deformation.

\subsubsection{The Testing-System}

As earlier discussed, the unixial compressive strength tests were performed in a stiff testing system. Rock and coal specimens were compressed by the continuous load from the axial actuator of the testing machine till they failed. In a standard uniaxial compression testing the sample fails immediately with the attainment of the peak stress. Figure 2.3a.shows the drop in the load once the sample has failed. Commonly when force control method is used, the stress strain curve is limited to the point of failure. Point beyond the peak stress includes the curves that are created due to the unloading of the ram. Also (Wawersik and Hudson, 1970) showed that such force-displacement curves are not the true intrinsic property of the rock. Underground rock behavior of pillars has shown that rock deforms gradually with certain residual strength, whereas using the load control method, it is impossible to see such behavior. Therefore, it is imperative that extensive research is required for understanding the mechanism of the post failure behavior of rock and coal specimen. For this reason the soft testing machine was not used for determining post failure behavior. 


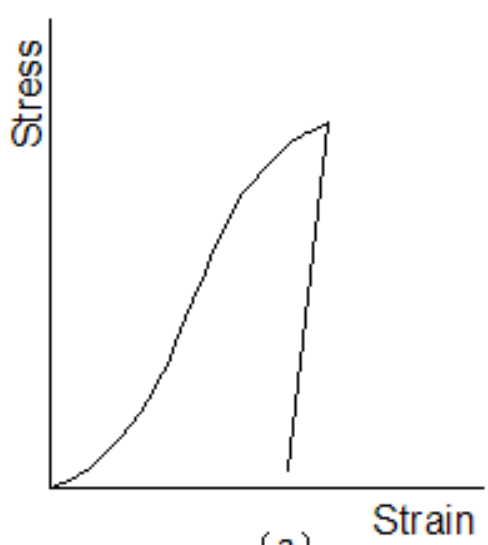

(a)

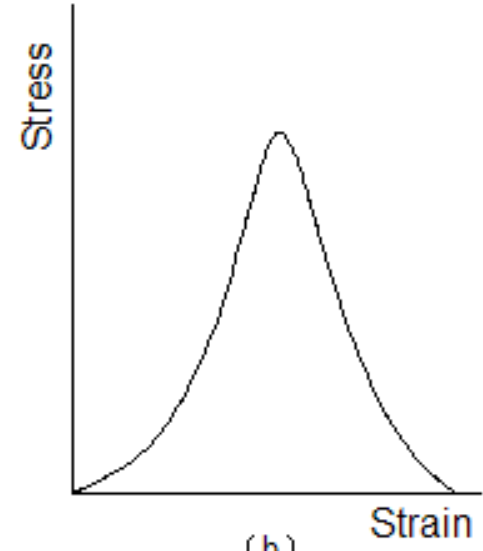

(b)

Figure 2.3. Stress and Strain curve of the uniaxial compressive strength tests. (a)The elastic region of the stress-strain curve; (b) The complete stress-strain curve.

When compression tests are performed in a soft testing machine the rock specimen fails in a sudden and violent behavior after reaching the peak strength. The reason for such behavior is the stiffness of the testing machine, which deforms with the deformation of the sample. As a result, when a sample fails it unloads the entire strain energy into the sample and forcing it to fail violently. Therefore these machines are called the 'soft' testing machine. As illustrated in Figure 2.4 that the specimen itself is compressed and the testing machine frame is extended so the elastic deformation produced by the extension is stored in the machine frame as strain energy. Obviously, the specimen may not fail in such an explosive manner if there is no sufficient stored strain energy in the frame.

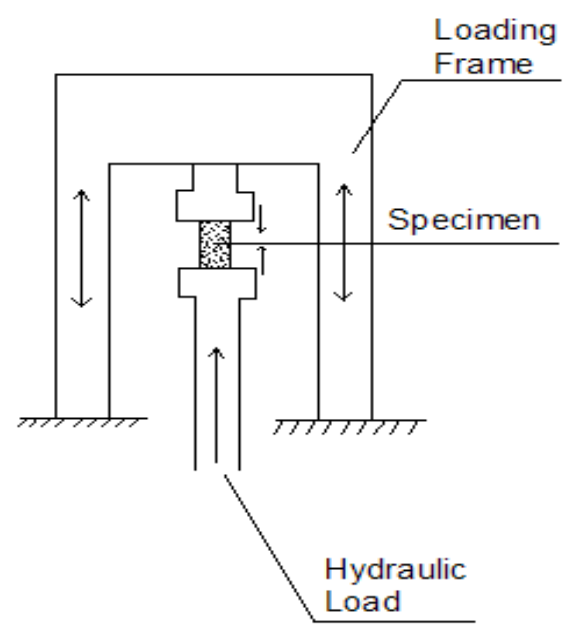

Figure 2.4. Load distribution of the specimen and testing machine during uniaxial compressive strength test. 
In order to limit the elastic deformation of the machine and the stored strain energy, the stiffness of the machine must be increased, thus a stiff testing machine was created. Therefore, the complete stress-strain curve and the characteristic of the post-peak behavior can be acquired by this new machine.

Figure 2.5 shows two different results when the same specimen was tested under (a) soft testing machine and (b) stiff testing machine (Wawersik, 1968, Brady, 1993). As shown in the curves that the specimen was loaded at the peak strength (Point A) and continued to deform axially by a small displacement $\Delta \mathrm{s}$. Accordingly, the load on the specimen was reduced from $\mathrm{P}_{\mathrm{A}}$ to $\mathrm{P}_{\mathrm{B}}$ and a certain amount of energy was assimilated as shown in the shaded area ABED. In fact, the 'soft' testing machine unloads to point $\mathrm{F}$ rather than $\mathrm{B}$ as the specimen was compressed by $\Delta \mathrm{s}$ from point A and the stored strain energy AFED was released, which is more than the absorbed energy ABED as clearly shown in curve (a). On the contrary, for those specimens tested under the 'stiff' testing machine, the released strain energy AGED is less than the absorbed energy ABED as illustrated in curve (b). Therefore, explosive failure pattern occurred shortly after the peak strength for those tested on the 'soft' testing machine and vice versa (Brady, 1993).

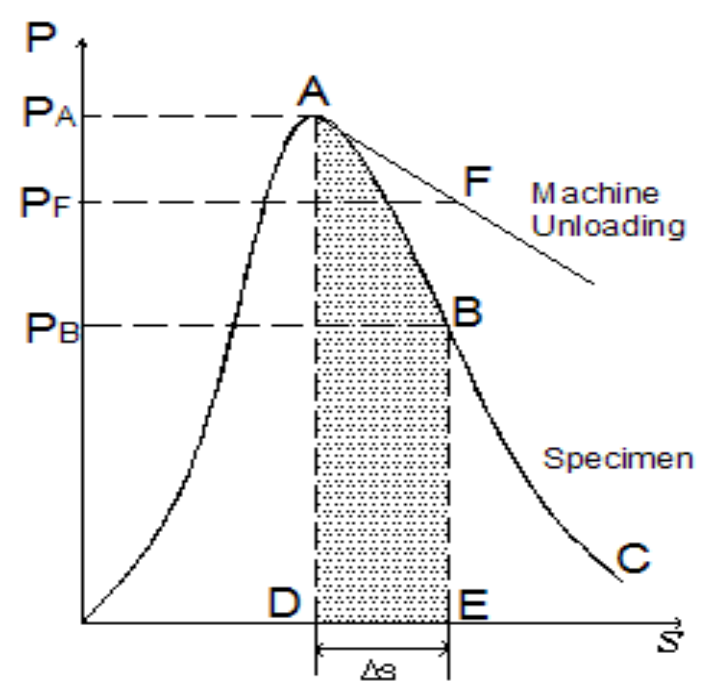

(a)

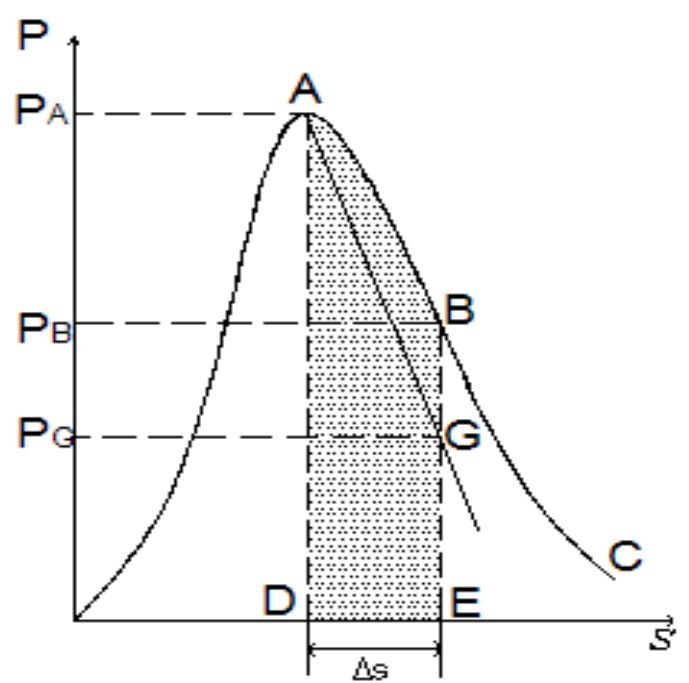

(b)

Figure 2.5. Post-peak unloading using machines that are (a) soft, and (b) stiff, with respect to the specimen. (Brady and Brown, 1993)

However, by employing only the 'stiff' testing machine is still not enough in obtaining a 
complete stress-strain curve with a controlled specimen post-failure deformation behavior for those very brittle rocks. A servo-controlled testing machine is also required. As illustrated in Figure 2.6 as for the principal of a closed-loop servo-control system. In the servo controller, composite command is applied to one input of the comparator and the feedback is applied to the other. The command signal represents the desired value of the controlled variable (load, stroke, etc.). The feedback signal represents the actual value, as sensed by the transducer. Whenever the two are not equal, the resultant error signal opens the servo-valve in a direction and by an amount which cause the actuator to correct the error. When they are equal, the error signal is reduced to zero and the servo-valve closes. The system is then in a state of equilibrium (MTS manual).

Based on what discussed above, a conclusion can be drawn that a servo-controlled stiff testing machine must be employed to acquire the complete stress-strain curve with wellcontrolled post-peak deformation behavior.

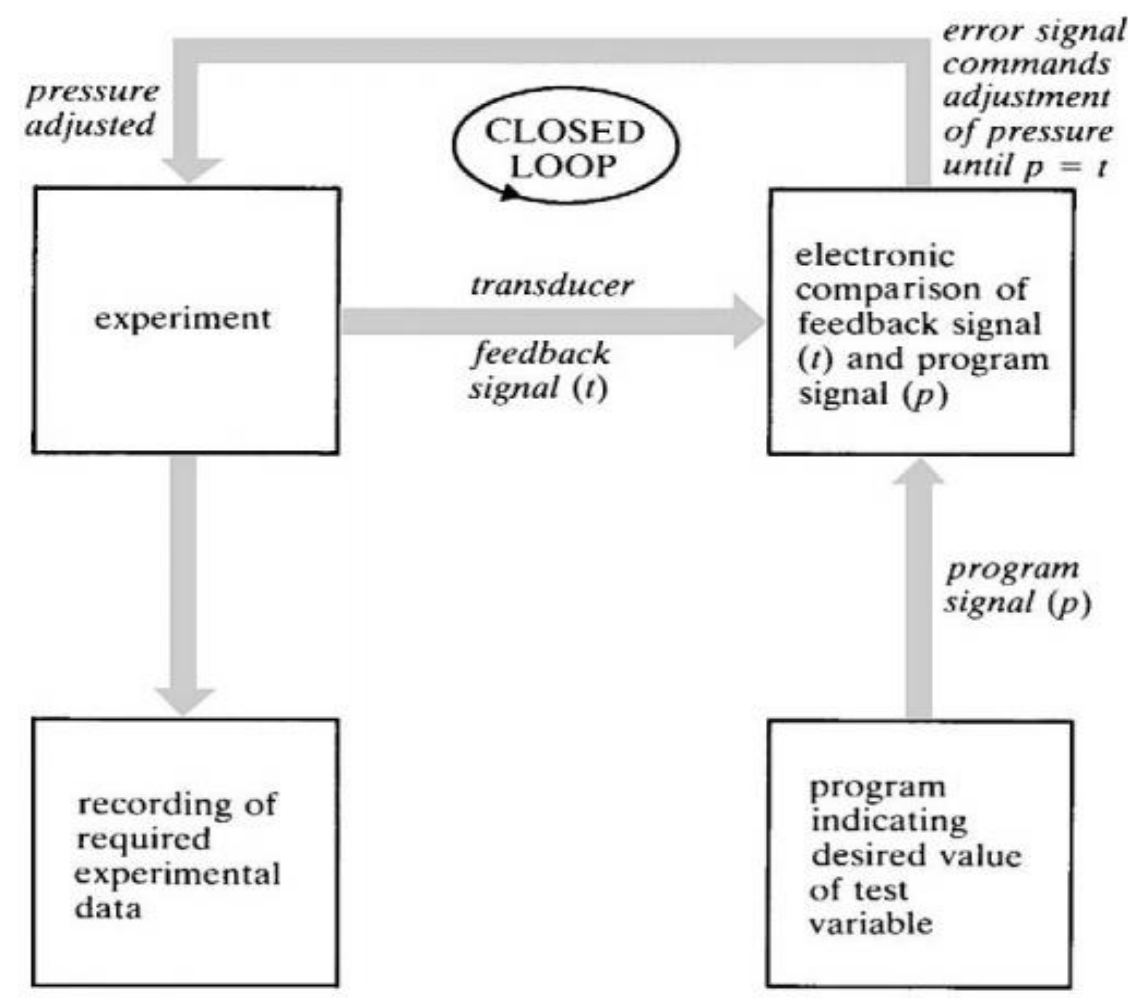

Figure 2.6. Principle of closed-loop control (after Hudson et al., 1972b) 


\subsection{Past research on the post-failure behaviors of rock samples}

\subsubsection{Specimen Failure Classification}

Wawersik (1968) conducted a series of uniaxial compressive strength tests on a variety of rock types and the complete stress-strain curves were acquired as indicated in Figure 2.7. He concluded that 'rock failure is 'stable' when energy must be added to the rock to promote further failure, and 'unstable' when energy must be extracted from the rock to prevent the violent failure'(Wawersik, 1968). It was determined that the post-failure behaviors of the specimens can be divided into two categories: Class I and Class II as illustrated in Figure 2.8, based on the failure in uniaxial compression is 'stable' or 'unstable'.

However, the Class II type of behavior represents a locus that must be found by repeatedly cycling the load, because in this case the failure process is self-sustaining even tested by 'infinitely' testing machine (Hudson, 1972). The slope of the non-accelerating or quasi-static, load-axial deformation curve in this type of failure has a positive unloading slope in the post-peak region as illustrated in Figure 2.8. This type of failure process requires that once the peak strength is reached, the loading actuator must be retracted to reduce the applied load below the value at which the failure occurs and then cycled repeatedly, increasing the load until the failure is reached again, and then reducing the load until the deformation rate stabilizes again. Thus, some form of closed-loop control that detects the onset of the failure and controls the failure process is needed in order to perform a Class II type specimen post-failure test, no matter how stiff the load frame is.

Materials that follow a Class I type of failure, on the other hand, exhibit monotonically increasing axial strain when a 'complete' stress-strain curve is obtained. (Strictly speaking, stress and strain are not the correct terms in the post-peak regions since the disintegration behavior becomes localized and far from homogeneous across the specimen.) Such materials (e.g. marble) are relatively easy to control in post-failure tests, even though the load may drop off sharply after peak load. This 
type of failure does not require retracting the actuator to maintain control of the test. For this reason, given a load frame of sufficient stiffness, a command requiring the actuator to compress the specimen at a constant rate is sufficient to fail the specimen in a controlled fashion, provided the loading rate is slow enough.

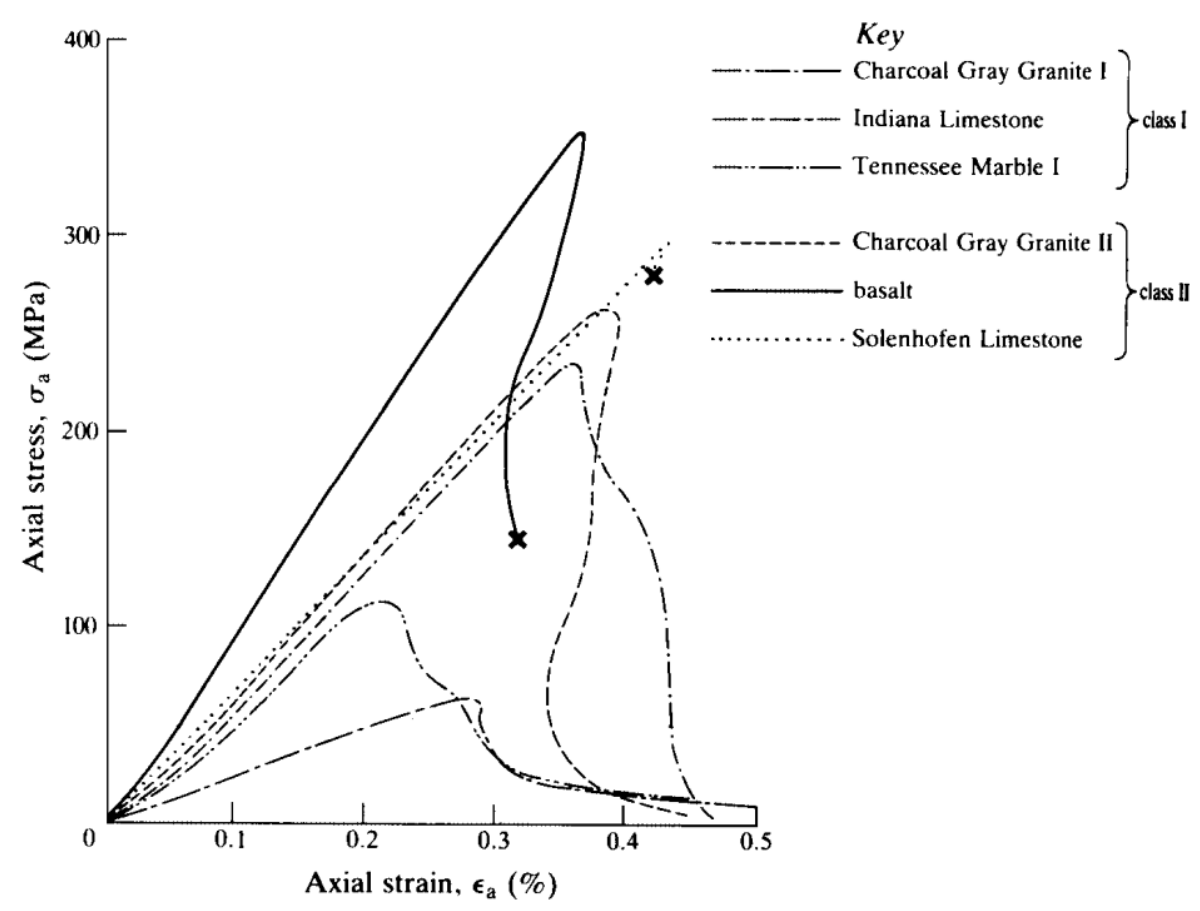

Figure 2.7. Uniaxial stress-strain curves for six different rock types showing both Class I and Class II failure behavior (after Wawersik and Fairhurst, 1970)

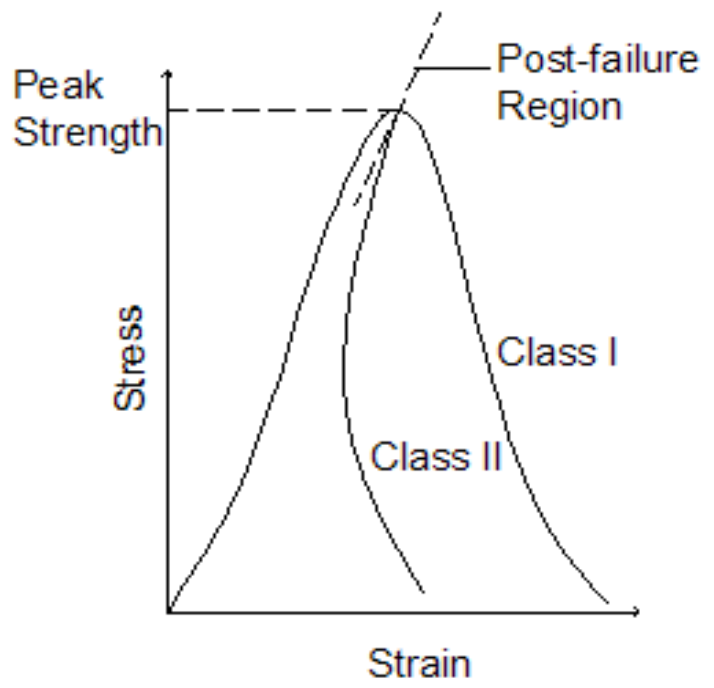

Figure 2.8. Failure classification of specimen tested under uniaxial compression. 


\subsubsection{Previous studies on the post-failure behavior of coal and rocks}

\subsubsection{Types of Failure Patterns}

Rao (2010) conducted a number of uniaxial compressive strength tests on various rocks and coal sample having UCS varying from 3480 psi to 53070 psi, for the analysis of the post-failure deformation behaviors as indicated in Figure 2.9. Among them, curve (a) and (b) are tested under displacement control while all the other four curves are tested under lateral strain control mode. He concluded that there are three types of post-deformation behavior patterns identified by using both lateral strain and displacement control method. The first type features in a steep fall in stress with only tensile cracks as shown in curve (a) and (b), type two characterizes in a rise and fall in stress with a combination of tensile and shear cracks as indicated in curve (c) and (d), while curve (e) and (f) show a gradual decrease in stress with only shear cracks which are classified as the third type of failure pattern. Class II type of behavior as introduced in the last section was not observed in his study, however. The author also concluded that all rocks may undergo post-failure behavior, the extent of which depends on the failure mechanism which combines both tensile and shear cracks.

As illustrated in the Figure 2.9, it is clear that type one and type three behavior produces a smooth stress-strain curve, while striking difference is made in the post-peak region for the second type, which typically shows plenty of 'ups and downs' in the post-failure region. It was discussed by the author that after peak strength, each 'down' period in the curve corresponds a fracture on the sample and the extent of the period totally depends on the volume of each fracture. Since the fractures did not develop in such a way that it completely crushes the sample like those tested under load or displacement control, they appear in a discrete way. Each crack is responsible for a 'fall' section in the curve and after this it rises up again till the next new failure occurs. This will never stop until the sample is totally cracked or the control limit is reached (Rao et al., 2010). 


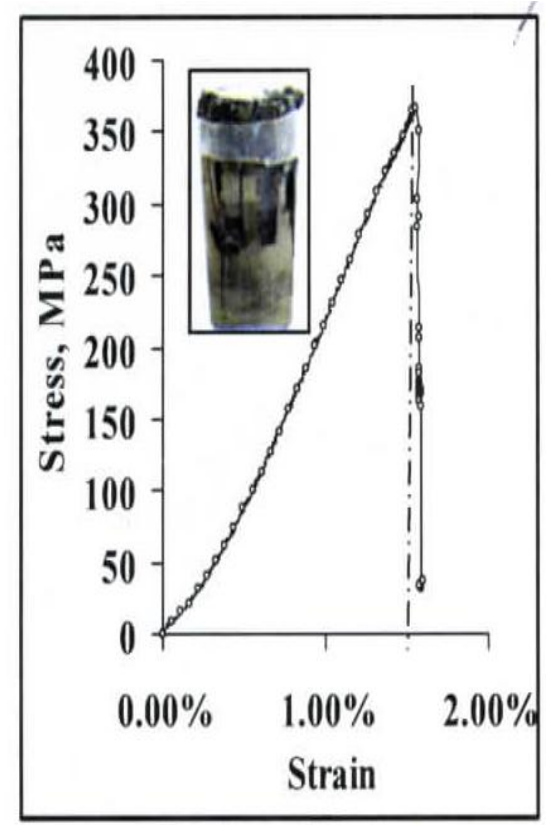

(a) Amphibolite

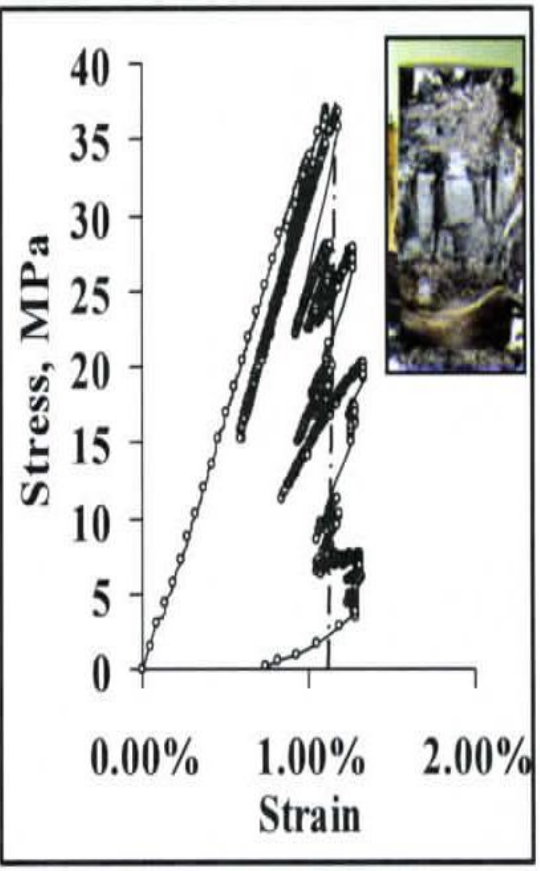

(d) Coal

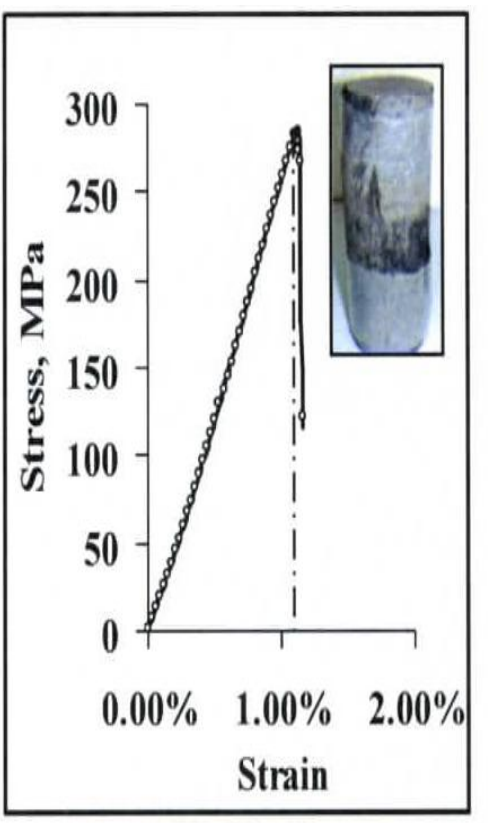

(b) Diorite

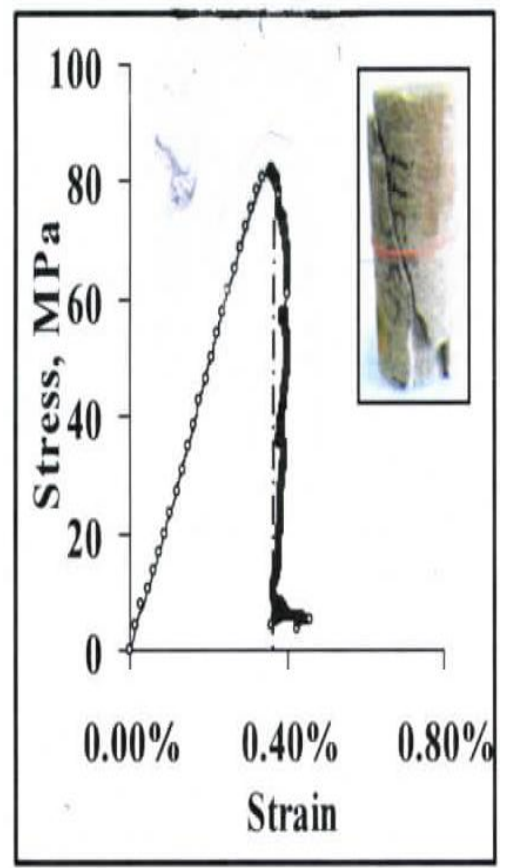

(e) Basalt

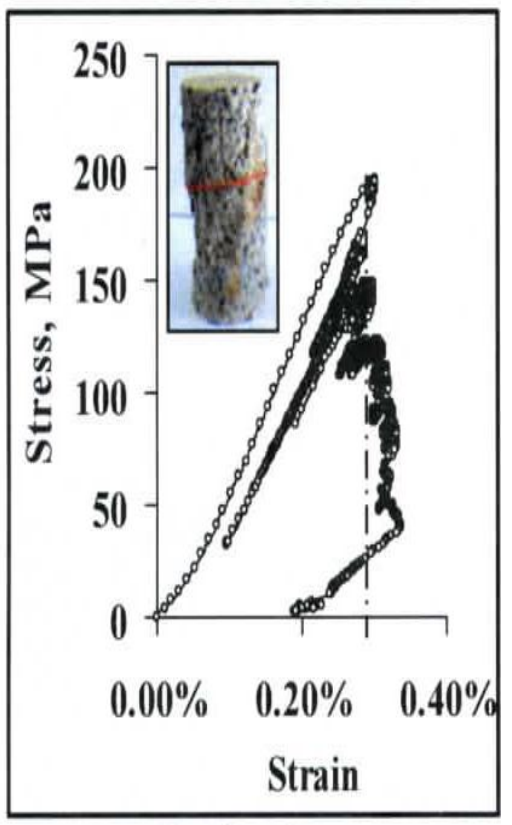

(c) Granite

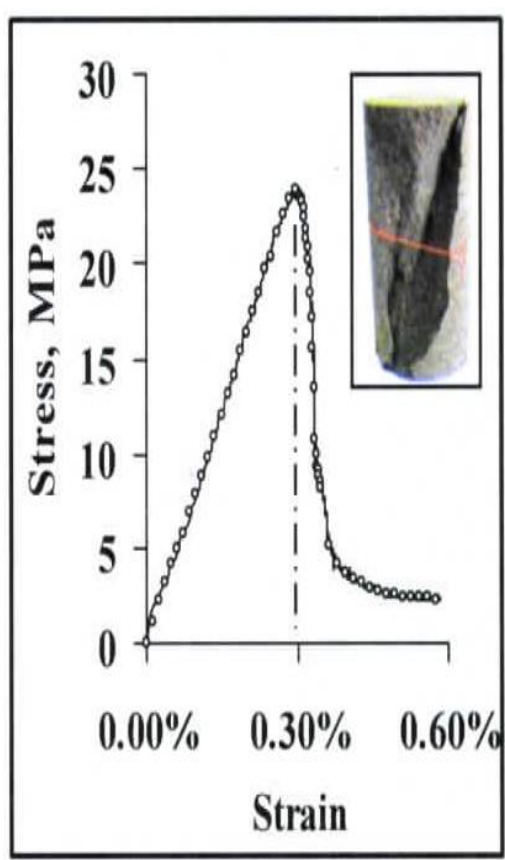

(f) Sandstone

Figure 2.9. Stress-strain curves and failure pattern of coal and rock samples. (a), (b) are tested under displacement control mode; (c), (d), (e), (f) are tested under lateral strain control mode

(Rao et al., 2010)

Hudson et al. (1970) has also recommended that 'once the peak strength is reached, the loading actuator must be retracted to reduce the applied load below the value at which the failure 
occurs and then cycled repeatedly, increasing the load until the failure is reached again, and then reducing the load until the deformation rate stabilizes again'.

\subsubsection{Factors in determining Class I and Class II behavior}

It has to be clear that it is not the rock itself that can be categorized as Class I or Class II but its behavior in the post-peak region. Therefore, it was found that there are several factors influencing the post-failure behavior of the rocks. They are presented as below:

- The relationship between elastic and non-elastic strain.

It was found that the non-elastic strain determines the slope of the post-failure region. Whenever the non-elastic strain increases slower than the elastic strain decreases, the specimen shows Class II behavior and vice versa, as indicated in Figure 2.10. However, the non-elastic strain significantly increases, the value of which is faster than the elastic strain decreases in the post-failure region under certain confining pressure. This, in turn, shows Class I behavior. Therefore, rocks which show Class II behavior under uniaxial compression may indicate Class I behavior under certain confining pressure as illustrated in Figure 2.11(He and Okubo, 1990).

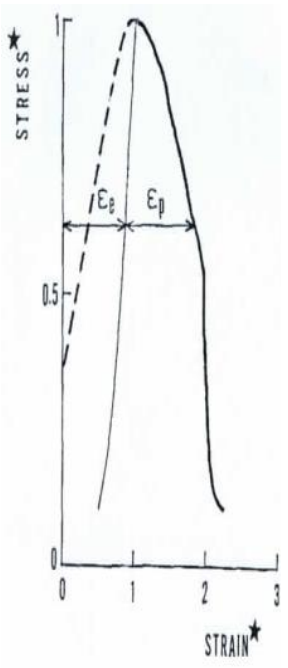

(a) Marble

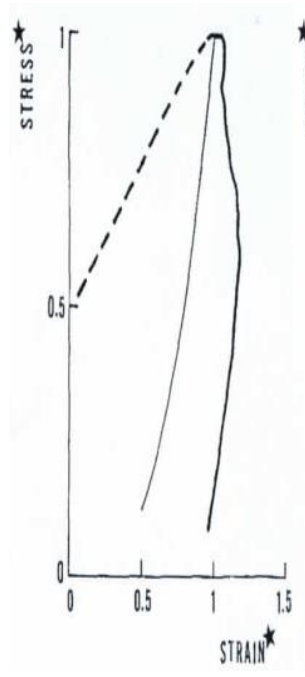

(b) Andesite

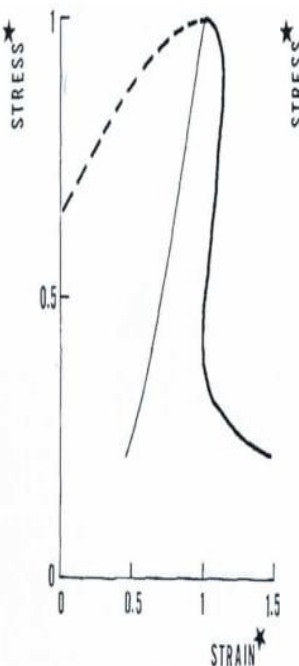

(c) Tuff

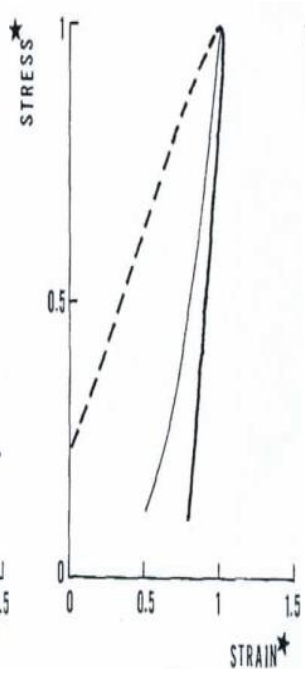

(d) Granite

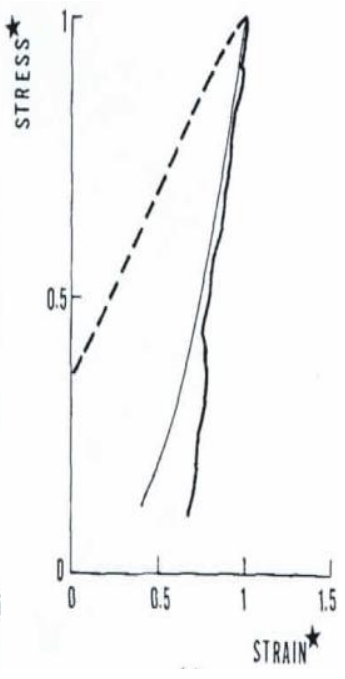

(e) Sandstone

Figure 2.10. Normalized stress-strain curve of five different types of rocks under uniaxial compression showing elastic strain $\varepsilon_{\mathrm{e}}$ and non-elastic strain $\varepsilon_{\mathrm{p} .}$ (He and Okubo, 1990) 


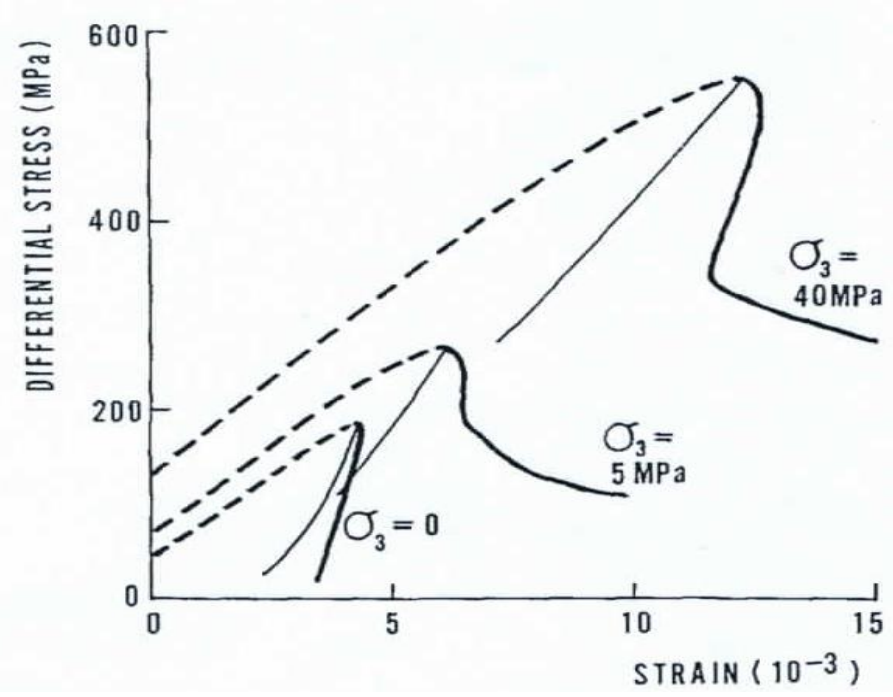

Figure 2.11. Elastic and non-elastic strains of granite in the post-failure region under the confining pressure (He and Okubo, 1990).

- The influence of the loading control method.

Hiroyuki (2010) used the Distinct Element Method (DEM) to simulate post-failure behavior from various rock tests as shown in Figure 2.12. The result of the simulation shows that axial strain increases monotonically in the post-failure region and the curve represents Class I behavior with the axial strain controlled tests as indicated on the left of the figure. On the contrary, the axial strain decreases in the post-peak region to keep the lateral strain constant and the curve shows Class II behavior with the simulation obtained from the lateral strain controlled test. Therefore, the loading control methods play significant roles in the post-failure behavior and the failure mechanisms even though the pre-failure process was almost the same under both loading modes. However, not all rocks tested under lateral strain control show Class II behavior as discussed previously. 

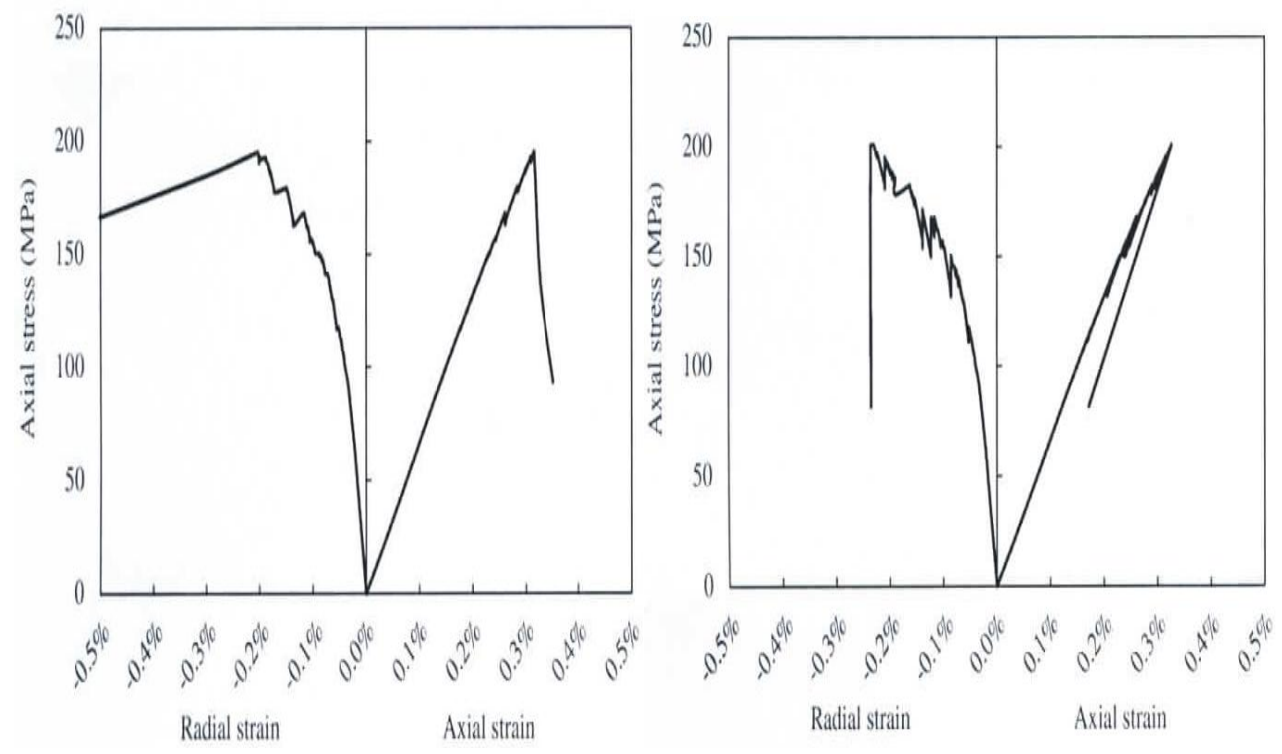

Figure 2.12. Complete stress-strain curve obtained from the simulation with different control methods. (Left) Axial strain control, (Right) Lateral strain control (Hiroyuki, 2010)

- The influence of the homogeneity of rocks.

Pan and Hudson (2006) employed an elasto-plastic cellular automaton (EPCA) as numerical simulations and a combination of stress and strain as the control variable to both types of behaviors of rocks. They found that the heterogeneity of rocks play a significant role in the complete stressstrain curves, especially in the post-failure region. Figure 2.13 shows that the higher the homogeneity indices, the easier the stress-strain curve will behave as Class II behavior. For the failure of the cell elements in the post-peak region, which will in turn lead to a rapid dropping of the specimen bearingcapacity. On the other hand, the stress-strain curves tends to behave as Class I behavior for the specimens with low homogeneity indices, for the failure of cell elements occurred greatly before the post-peak region and therefore less failed in the post-peak region from the simulation. On the other hand, acoustic emission will be produced for the specimens with higher homogeneity, which agreed with the numerical simulation very well that there are more failure of cell elements in the post-peak region and the loading-capacity decreases quickly and it's more prominent for those rocks behave as Class II (Pan and Hudson, 2006). 


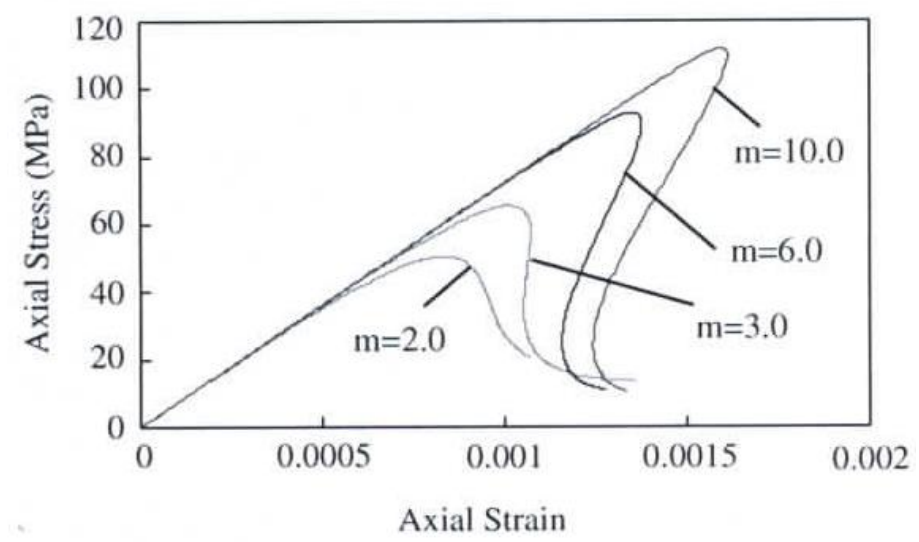

Figure 2.13. Complete stress-strain curves with different homogeneity of rocks, $m$ is the homogeneity indices (Pan and Hudson, 2006)

- The influence of the yield criterion.

Using the same numerical model as previously discussed conditions, Figure 2.14(a) indicates that rocks with higher homogeneity indices tend to represent Class II behavior with higher ultimate strength under the same yield criteria, yet Figure 2.14(b) indicates that for rocks with the same heterogeneity, the curve behaves as Class I with the Mohr-Columb criterion but Class II with the Drucker-prager criterion. So an appropriate yield criterion must be selected in the simulation process for the desired results.

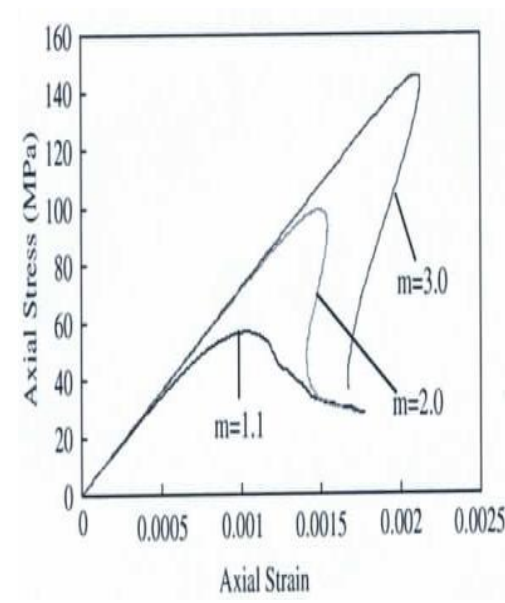

(a)

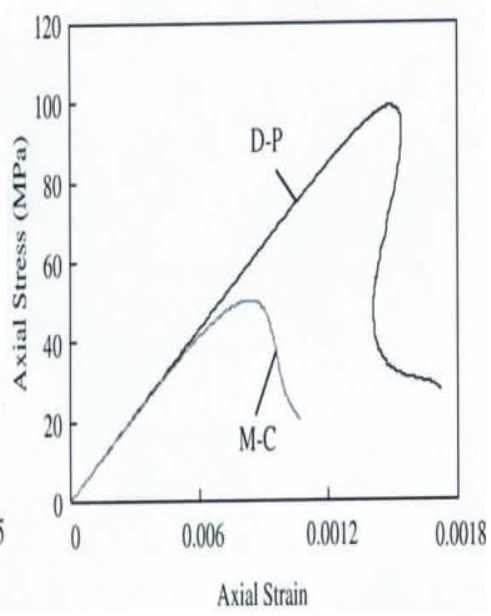

(b)

Figure 2.14. (a) Complete stress-strain curves of heterogeneous rocks with Drucker-Prager yield criterion. (b) Complete stress-strain curves of rocks with the same homogeneity index and different yield criterion (Pan and Hudson, 2006). 


\subsubsection{Features of Class II behavior of rocks}

- Hudson et al.(1972) pointed out that 'in many cases Class II behavior is probably caused by non-uniform failure in the (heterogeneously loaded) specimen; as one region of the specimen is loaded and fails, the rest of the specimen remains intact and is elastically loaded and unloaded'. In addition, some other researchers also suggested that the non-uniform failure or localization of failure is the main characteristics of Class II behavior from the experimental observations (He, 1990; Rao, 2010).

- Numerical simulation on the spatial distribution of all the cracks in both pre-peak and postpeak regions under both axial strain and lateral strain control modes show that the formation of 'shear bands', which are many shear cracks with relatively large energy were connected along a line in the post-failure, play a remarkable role in the post-peak region. Those shear bands appeared remarkably from the simulation in the axial strain controlled test while they didn't show a lot in the lateral strain controlled uniaxial compression test. This is because the formation of the shear band cannot grow sufficiently under lateral control mode in order to keep the lateral strain constant in the post-peak region (Shimizu, 2010).

\subsection{The Triaxial Compression Test}

The maximum strength that a specimen can stand under a triaxial loading state is called the triaxial compressive strength. Usually, it can be obtained from the traditional single-stage triaxial compressive strength test, where a specimen is loaded under a certain confining pressure $\left(\sigma_{2}=\sigma_{3}\right)$, then the axial stress is increased until the failure of this specimen. However, the purpose of performing the triaxial test on coal specimens in this thesis is to study the effect of the confinement on the failure of the core of the pillars and to see if the complete stress-strain curve can be obtained through the triaxial test under a certain confining pressures. 


\subsection{Feedback control modes}

In the uniaxial compressive strength test, three different control modes were employed for the six rock types and two different types of coal specimens. They are load control, axial strain control, and lateral strain control. It was found that lateral strain control, rather than the other two control modes, is a more favorable control method in controlling not only Class II behavior but also Class I type of failure. Because samples do not fail quickly and abruptly, which is much more safer for the controllers, also samples controlled by this method shows a clearer and 'step-by-step' failure process with sometimes a 'rise and fall' pattern in the post-peak region, which contributes a better understanding of the post-failure deformation behavior. 


\section{CHAPTER 3 LABORATORY TESTS}

\subsection{Introduction}

In this study, a comprehensive physico-mechanical behavior of both coal and rocks are presented. It is divided into two parts: the uniaxial test scheme and the triaxial test scheme. In the uniaxial test scheme, a number of rock and coal samples were prepared and tested under axial strain control, lateral strain control, and load control modes to investigate the influence of the different control modes on the failure mechanisms and post-failure behaviors of coal and rock samples. All the experiments were conducted under uniaxial compressive test conditions using a servo-controlled stiff compression testing machine. There are totally 22 rock samples and 16 coal samples used in this part.

It was found that load control mode is unable to provide any information in the post failure region of the rock because of the complete failure of the specimen. Axial strain control, on the other hand, is the appropriate control mode to study the post-failure behavior for some of the rocks and coal but is restricted to the Class II type of specimens, since in those cases the load/stress suddenly and sharply decreased from the peak strength to almost zero and the post-failure behavior is therefore uncontrolled. However, using lateral strain control, it was found that this mode served as a much better feedback to study the post-failure behavior of most samples, especially for those Class II types of specimens.

In addition, all specimens tested under this control mode experienced a slow, gradual, and sometimes a 'rise and fall' type of failure pattern based on all the figures obtained. We can also clearly see from Appendix A that at the time the test terminates, most of the samples tested under lateral strain control still hold a certain amount of bearing capacity or we can say they didn't fail completely and still have a certain residual strength left, while most of those samples under load and axial strain control modes failed completely and don’t have any residual strength left at all. 
In triaxial test plan, four coal specimens from the Hiawatha seam were tested with low confining pressures for studying the effect of the confinement of the pillars on the failure of the cores. Using strain control, a complete stress-strain curve was obtained which showed that with confinement the crack development is slowed and therefore the class II type of failure can be restricted to class I type.

\subsection{Specimen Preparation}

All specimens were prepared in accordance with ASTM and ISRM standards. The Length /Diameter ratio has to be maintained at 2.0 to avoid the pressure cone problem. However, in some coal specimens a ratio of 1.7-1.9 was only feasible. The diameters were measured at the top, in the middle, and the bottom of the specimen using the digital caliper as shown in Figure 3.1. The average value was then recorded for each specimen.

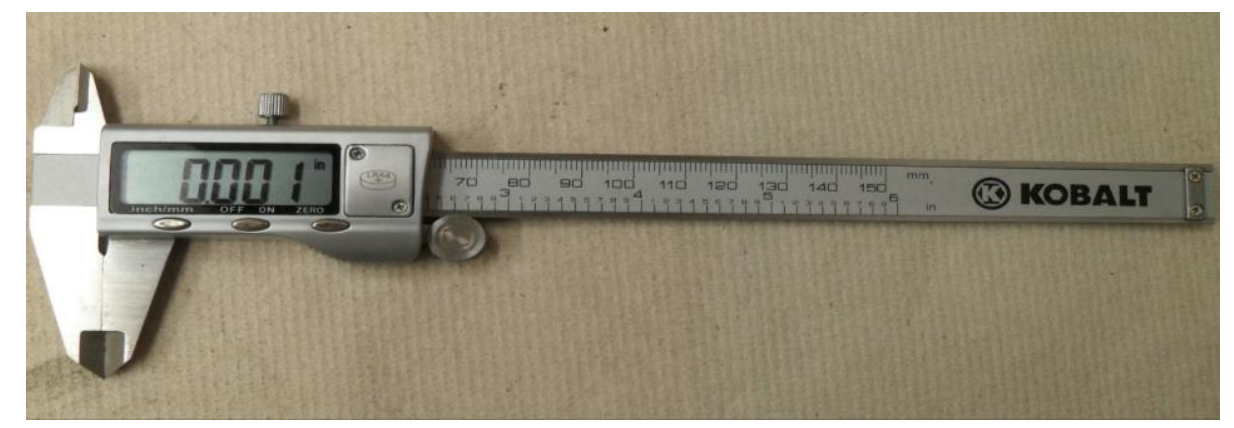

Figure 3.1. Vernier Caliper used for measuring specimen dimensions.

Again, in the uniaxial tests, three different preparation methods were used to develop rock and coal samples. The methods include drilling, cutting, and grinding. For rock the samples were cored from a Berea sandstone block as shown in Fig. 3.2 (a). For the other five different groups of rocks pertaining to this thesis, only cutting and grinding procedures were employed. These rocks were in the form of cores which were obtained from the Cumberland mine in Pennsylvania. The steps involved in the preparation process shown in Fig. 3.2 (b). For all coal specimens, coal cores 
were first drilled from the original irregular coal blocks. Then they were wrapped by engineering tapes, and their ends were flattened using an automatic grinder as shown in Fig. 3.2 (c). For coal sample preparations, this is one of the most difficult processes, because coal is extremely heterogeneous and brittle in nature and will break easily. From the completed coal specimens, only $23 \%$ was considered to be suitable for the experiment.

All coal specimens used in the triaxial test were prepared in similar manner as described in the previous paragraph, all of which were cut along the bedding planes. All samples were cut slightly larger than the predetermined thickness to allow the surface grinder to completely smooth the top and bottom of them. After the completion of grinding process, all specimens were allowed to be airdried for one week to ensure that the specimens are tested in unsaturated condition. Rock specimens were prepared with a two inch diameter cored drill, however the coal specimen was prepared with a 2.12. The variability in the diameter was due to the broken drill. Each sample was tagged based on their type, test type, and specimen number by standard office tape. Compression tests involving uniaxial and triaxial was performed in two stiff testing systems. One was MTS 440 and the other was GCTS triaxial test system. For maintaining accuracy, a set of procedure was followed for each type of test system. The entire test was preprogrammed and therefore there was no user interaction during the entire test period. Each of the equipment is described in the later sections that follow.
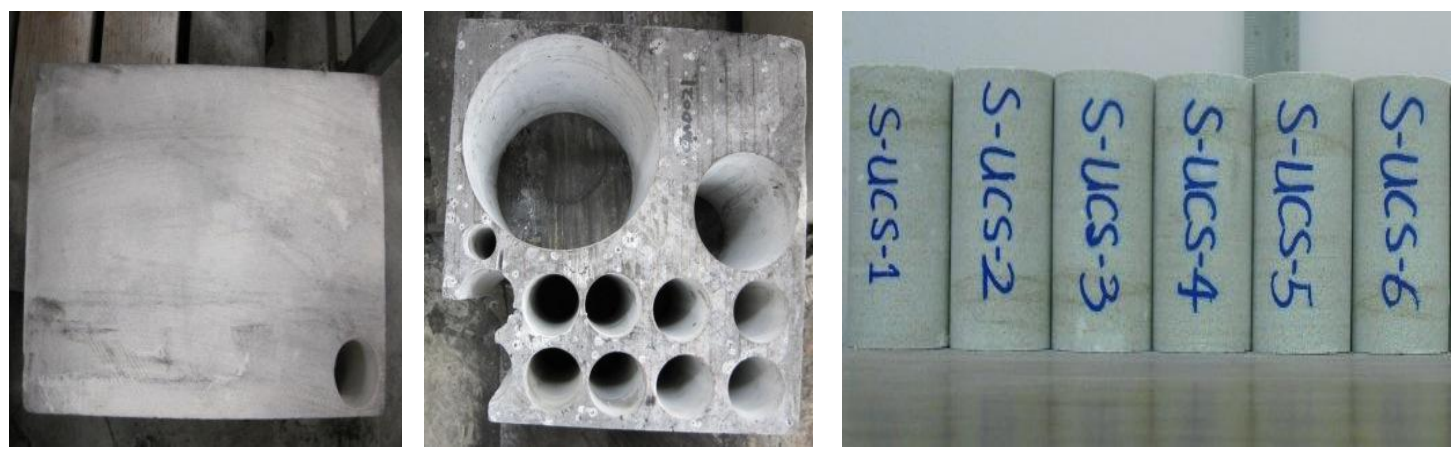

(a) Sample preparation stages: original block, drilled holes, prepared specimens. 

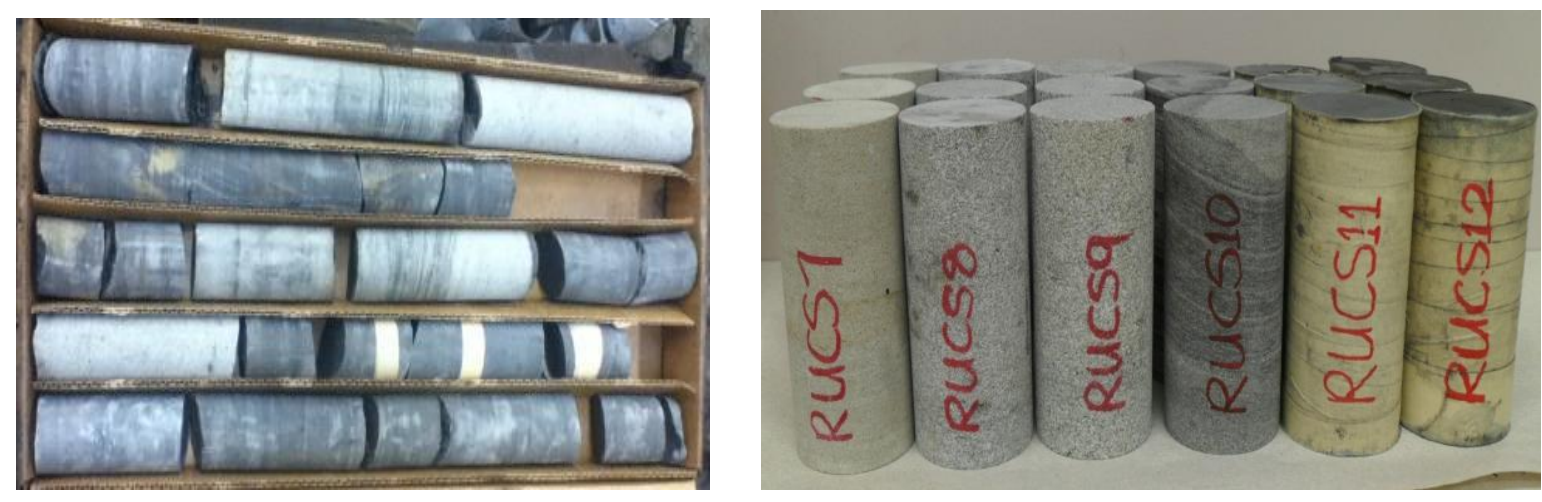

(b) Rock cores and specimens after cutting and grinding.
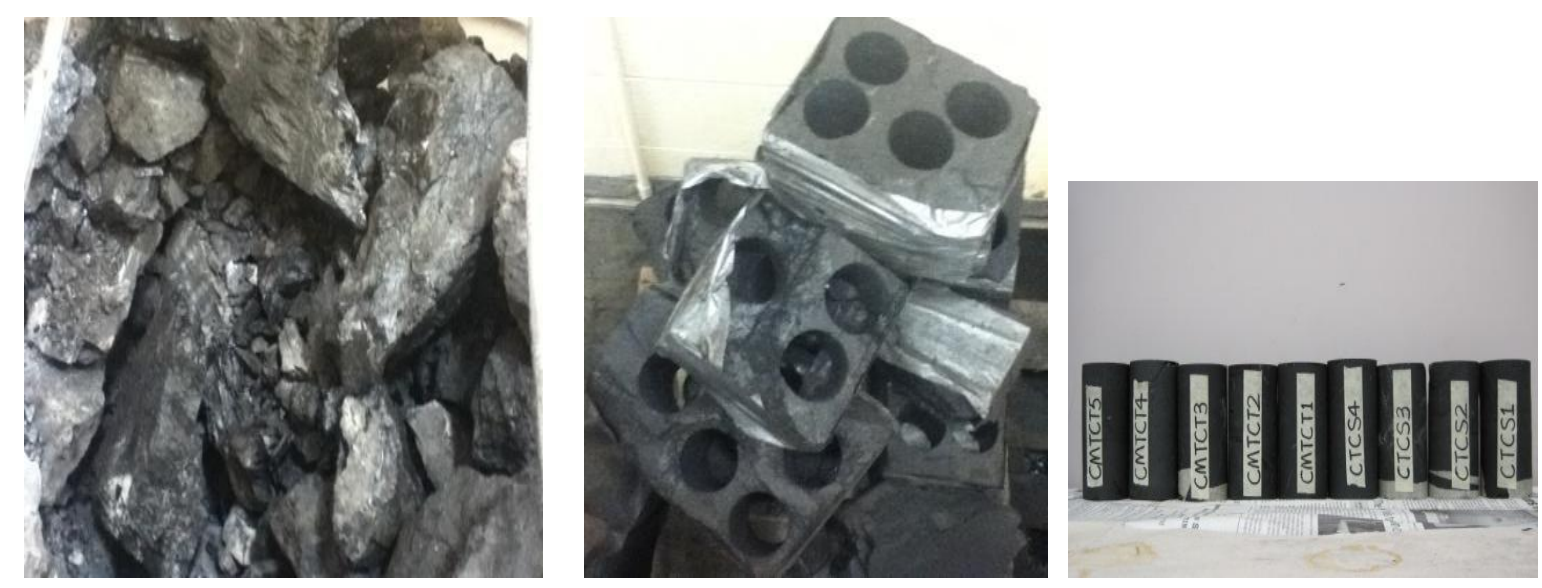

(c) Coal specimen preparation procedures: original block, drilled holes, prepared specimens.

Figure 3.2. Sample preparation in different stages.

\subsection{Compression Tests}

\subsubsection{UCS tests for rocks/coal under the proposed control modes}

This section contains description about the equipment, and sample testing methodology. For this purpose, a total of 24 different rock specimens and 16 specimens from two different coal seams were tested under various control modes to investigate the influence of the different control modes on the post-failure deformation behavior. All rock/coal specimens were conducted on a closed-loop, servo-controlled MTS testing machine (MTS 440) as indicated in Figure 3.3 with the maximum capacity of 220,000 pounds at room temperature. The axial displacement of the test was measured by 
LVDT attached to the ram of the machine. The lateral displacement or diametrical strain was measured by a circumferential extensometer. Figure.3.4 details the arrangements of the uniaxial compressive test for both rock and coal specimens (in this figure, coal specimens under lateral strain control was pictured). The information as for the feedback control mode, ramp control rate, terminal point, measurement modes of axial/lateral displacement and the time interval are shown in Table 3.1.

Table 3.1 Specific information of each different control mode

\begin{tabular}{|l|c|l|l|c|}
\hline Feedback Control & Control Rate & Measure of disp. & Terminal Point & Time interval \\
\hline Load Control & $300 \mathrm{lbf} / \mathrm{sec}$ & LVDT & $220000 \mathrm{lbf}$ & $0.05 \mathrm{sec}$ \\
\hline Axial Strain Control & $0.0001 \mathrm{in} / \mathrm{sec}$ & LVDT & $0.1 \mathrm{in}$ & $0.01 \mathrm{sec}$ \\
\hline Lateral Strain Control & $0.0001 \mathrm{in} / \mathrm{sec}$ & Extensometer & $0.1 \mathrm{in}$ & $0.05 \mathrm{sec}$ \\
\hline
\end{tabular}

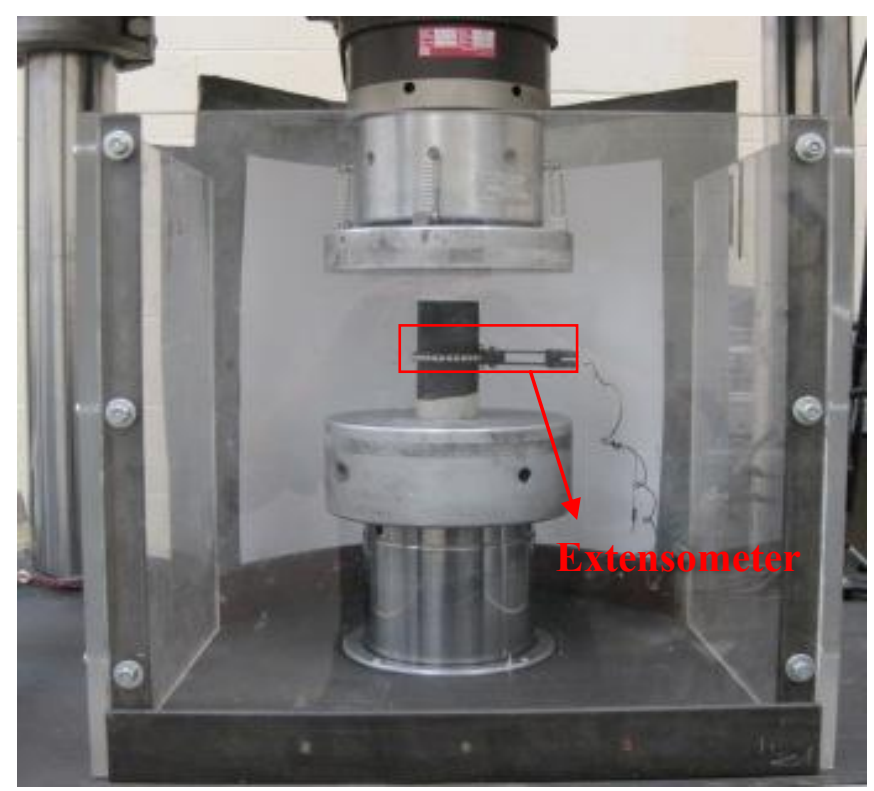

Figure 3.4. Coal sample with lateral extensometer and a transparent plastic-glass shield.

All basic information and testing properties of specimens for the uniaxial part are illustrated in Table 3.2. Bezat (1986) suggested that 'load control may be useful for testing in the elastic region of the stress-strain curve, provided that precautions are taken not to exceed the peak specimen strength. Load, however, is not a satisfactory control mode for post-failure testing of either Class I or Class II type specimens. Using load as control mode will not permit the control of tests beyond the 
maximum loading bearing capacity of the specimen. At that point, the programmed load will exceed the specimen strength and there will be a sudden failure as the actuator tries to maintain load. Continuing a test in a load control mode beyond peak strength often results in an explosive failure'. Under this circumstance, coal specimen under load control was not conducted, for preserving the specimen for any additional tests.

Table 3.2 Coal/Rock sample information used in this experiment

\begin{tabular}{|c|c|c|c|c|c|}
\hline $\begin{array}{l}\text { Types of } \\
\text { Specimen }\end{array}$ & $\begin{array}{l}\text { Diameter } \\
\text { (inch) }\end{array}$ & $\mathrm{L} / \mathrm{D}$ ratio & $\begin{array}{l}\text { Amount of } \\
\text { specimen }\end{array}$ & Control Modes & Origin of specimen \\
\hline Sandstone & 2.12 & 2.0 & 6 & Lateral Strain & A quarry \\
\hline Rock $^{1}$ & 2.00 & 2.0 & 6 & Load Control & Cumberland Mine \\
\hline Rock $^{2}$ & 2.00 & 2.0 & 6 & Lateral Strain & Cumberland Mine \\
\hline Rock $^{2}$ & 2.00 & 2.0 & 6 & Axial Strain & Cumberland Mine \\
\hline Coal $^{1}$ & 2.12 & 1.7 & 6 & Lateral Strain & Redbone Mine \\
\hline Coal $^{1}$ & 2.00 & 1.7 & 6 & Axial Strain & Cumberland Mine \\
\hline $\mathrm{Coal}^{2}$ & 2.12 & 1.9 & 4 & Lateral Strain & West Ridge Mine \\
\hline Remarks & \multicolumn{5}{|c|}{$\begin{array}{l}\text { Rock }^{1} \text { are those samples randomly selected from both roof and floor of } \\
\text { Cumberland mine; } \\
\text { Rock }^{2} \text { includes Berea sandstone, medium and coarse grained sandstone, massive } \\
\text { sandstone with coal streaks, grey shale, and black shale; } \\
\text { Coal }^{1} \text { are from Pittsburgh seam; } \mathrm{Coal}^{2} \text { are from Utah seam }\end{array}$} \\
\hline
\end{tabular}

Moreover, all axial strain was calculated by the equation that

- Average (axial LVDTs)/axial gage length

$\varepsilon_{\mathrm{a}}=\Delta \mathrm{L} / \mathrm{L}$

where $\varepsilon_{\mathrm{a}}$ is the axial strain; $\Delta \mathrm{L}$ is the average axial LVDTs; $\mathrm{L}$ is the axial gage length

All lateral strains were calculated by the following equation: 
- Circumferential strain

$$
\mathrm{C}_{\text {strain }}=-\Delta \mathrm{C} /\left(\pi^{*} \mathrm{D}\right)
$$

where $\mathrm{D}=$ Specimen Diameter

$$
\begin{aligned}
& \Delta \mathrm{C}=\pi^{*} \Delta \mathrm{L} /[\sin (\phi / 2)+(\pi-\phi / 2) * \cos (\phi / 2)] \\
& \mathrm{C}=2 * \pi^{*}(\mathrm{D} / 2+l+m) \ldots \ldots \ldots \ldots \ldots \ldots \ldots \ldots \ldots \ldots \ldots \ldots \ldots \ldots \ldots \ldots \ldots \ldots \ldots \ldots \ldots \ldots \ldots \ldots \ldots \ldots \ldots \ldots \ldots \ldots \ldots
\end{aligned}
$$

Where $l$ is the roller radius, which is assumed to be $3.048 \mathrm{~mm}(0.12 \mathrm{in}) ; m$ is the jacket thickness; $\Delta \mathrm{L}$ is the change in gage opening (raw gage output); $\mathrm{L}$ is the chain length.

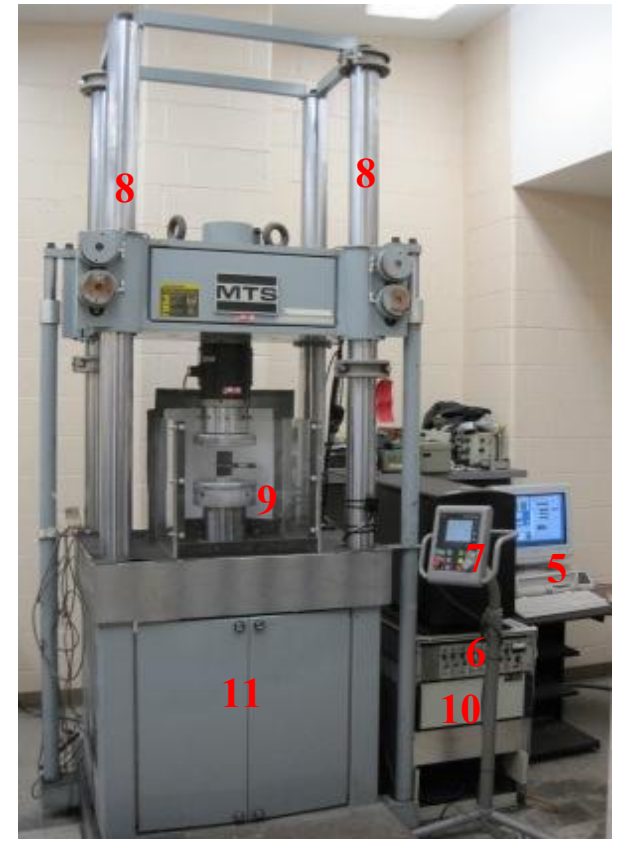

(1) Upper steel platen

(2) Lower steel platen

(3) Coal/Rock specimen

(4) Extensometer
(5) Computer connected to

MTS testing machine

(6) Data acquisition system

(7) Manual control system

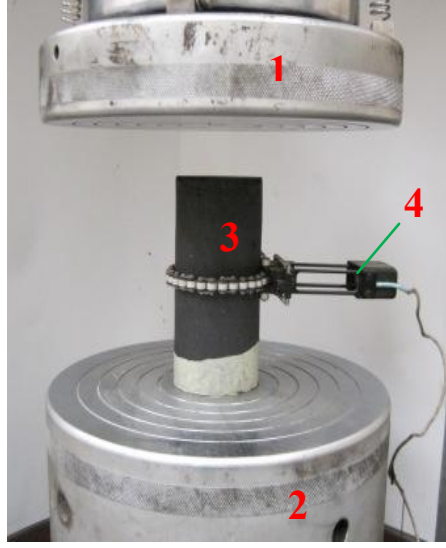

(8) Machine frames

(9) Glass Shield

(10) Strain gage controller

(11) Machine LVDT system

Figure 3.3. Servo-control testing machine and its components

In all tests the specimens were loaded directly between the loading platens of the testing machine. No 'friction reducers' were inserted between the rock/coal and the specimen platens, although lots of experiments were performed to assess the effect of different end conditions. The 
MTS rock mechanics system was used along with their extensometers for conducting post-failure experiments.

\subsubsection{Triaxial compression test for coal under lateral strain control mode}

\subsubsection{Theoretical Background}

The triaxial test is a versatile test used to determine the stress-strain-strength properties and behaviors of both coal and rocks. In a triaxial test a cylindrical specimen of rock is first subjected to confining pressure (isotropic state) in a triaxial cell vessel and then the axial stress is applied at a certain rate until the specimen fails. However, this testing condition may produce deformation characteristics very different from that in the field. Therefore, the estimated in-situ stress paths need to be closely followed in laboratory testing for more accurate prediction of the in-situ deformation behaviors and stress-strain characteristics (GCTS manual, 2010). The testing system RTX-1500 (GCTS) is the current used computer-controlled technology, which makes it possible to perform all necessary tasks to automatically accomplish accurate control for a wide variety of triaxial tests.

In this thesis, the laboratory test on the coal specimen represents an element of the underground coal pillar. The purpose of this laboratory test is to subject the specimen to stresses and/or deformations which will simulate the existing or anticipated in the field. The behavior of the field element can be predicted from the measured behavior of the laboratory test specimen. Therefore, it is desirable to use a laboratory test that will duplicate the field conditions as closely as possible. Moreover, the triaxial test can be made to approximate many field conditions. For instance, the confining pressure corresponds to the lateral pressure on the element. The axial load produces shearing stresses, which correspond to the shear stress in the field. Therefore, the triaxial test has become a popular and useful tool for determining the strength and deformation characteristics of coal and rocks. 


\subsubsection{Triaxial tests}

Four coal specimens prepared from the Hiawatha seam were tested in the triaxial compression conditions under lateral strain control mode. All tests were performed by employing the GCTS Triaxial Rock Testing System (RTX-1500) in the rock mechanics laboratory of the mining engineering department at West Virginia University. This new and advanced testing equipment was indicated as Figure 3.5 and has the following characteristics (GCTS 2010 Catalog):

- Direct closed-loop digital servo control of axial stress, average principle stress, axial strain, radial strain, and several other calculated triaxial variables.

- 1,500 KN load capacities and 1,750KN/mm stiffness.

- GCTS High Pressure Triaxial cell with internal instrumentation to measure local axial \& radial strains

- $140 \mathrm{MPa}$ servo-controlled pressure intensifier system for cell and pore pressure.

- Available options: axial \& circumferential deformation measurement system, platens with ultrasonic transducers, and high temperature control subsystem.

- Ideal for performing unconfined compression, triaxial, bending, indirect tension, fracture, creep, post failure behavior, and other compression tests.

For performing the triaxial loading of the specimen, it was placed between the base cap and the top end cap inside the triaxial cell and jacketed with polyolefin heat shrink tube. Figure 3.6 (a) shows the laboratory set up in the rock mechanics laboratory. The heat shrink tube was attached to the sample using the heat gun as illustrated in Figure 3.6 (b). In Figure 3.6 (c) an instrumented set up of the sample is shown with the lateral chain extensometer and various sensors. The last step in the 
process was to set the triaxial cell in into the test platform and connect various wires for initiation of the test.
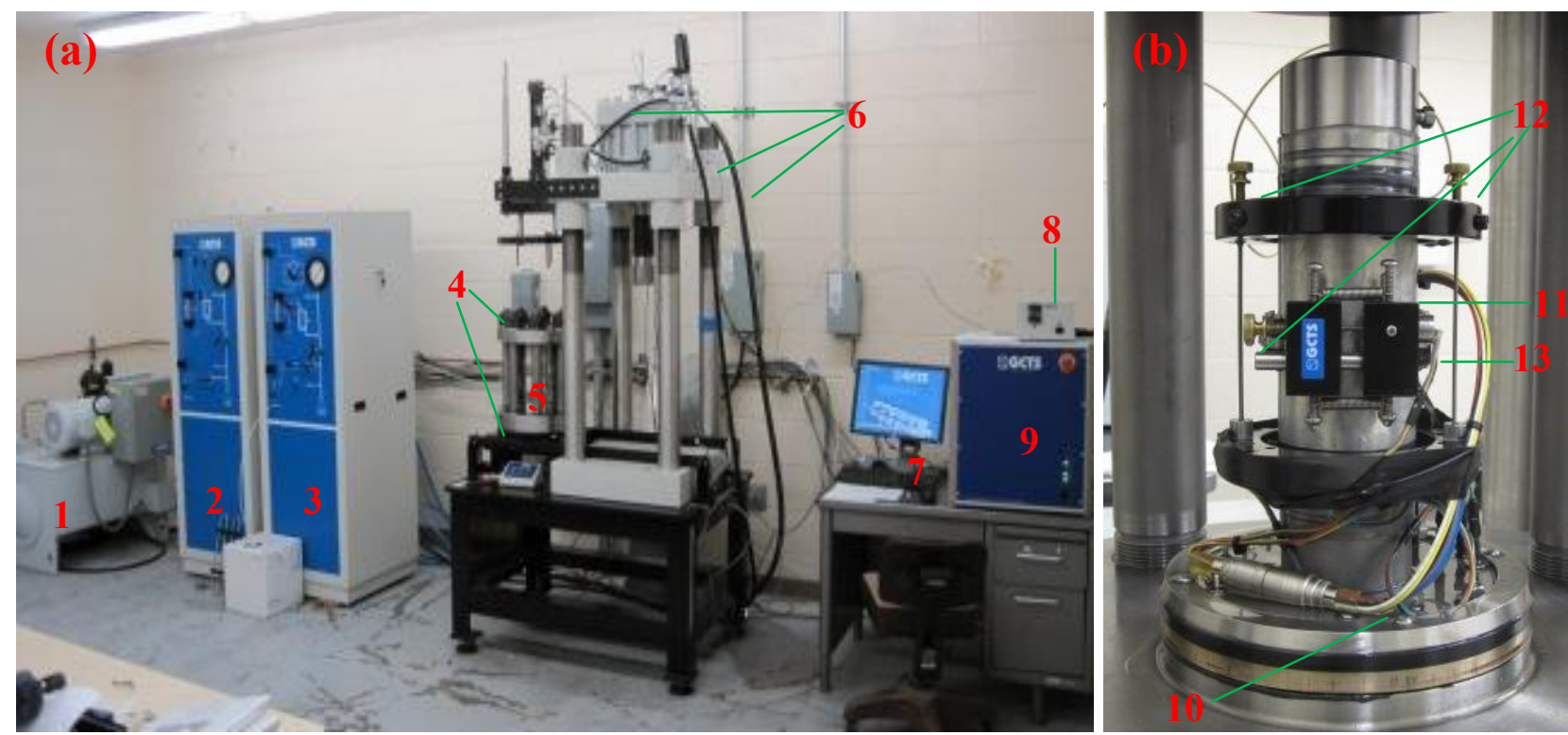

(1) Hydraulic pump

(5) Triaxial cell

(9) Digital controller

(2) Pore pressure intensifier

(6) Hoses

(10) Sensors

(3) Cell pressure intensifier

(7) Computer software

(11) Specimen

(4) Input/output cell pressure holes (8) Wall temperature meter (12) LVDT 1,2,3 (13) Chain extensometer

\section{Figure 3.5. Triaxial Testing Machine}

Figure 3.5 (a) displays the employed triaxial testing machine for coal specimen and Figure 3.5 (b) details the specimen assembly with chain extensometers and all sensors. The testing procedure for carrying out the triaxial test of the coal specimen is described as follows: 


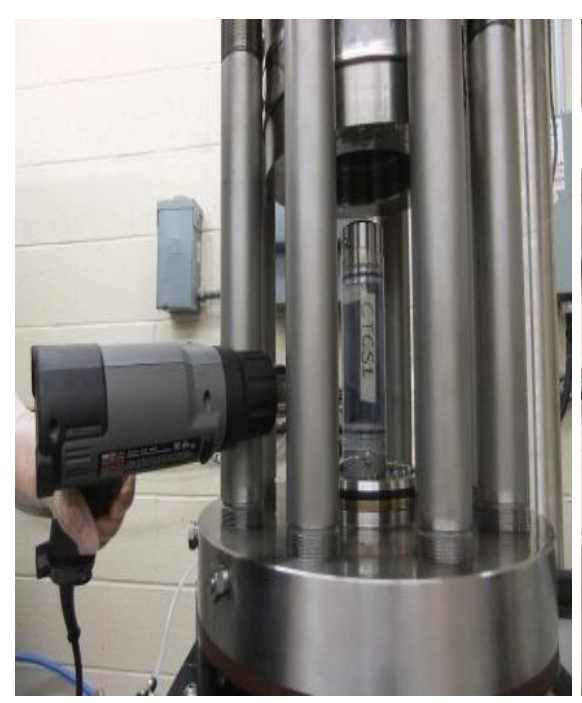

(a)

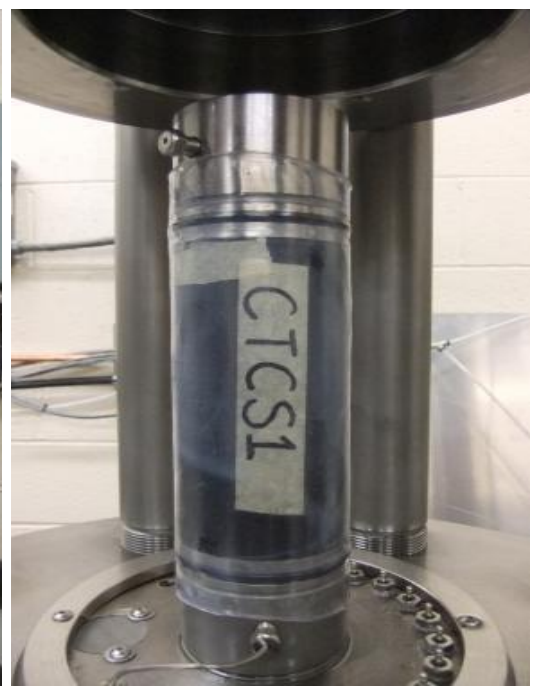

(b)

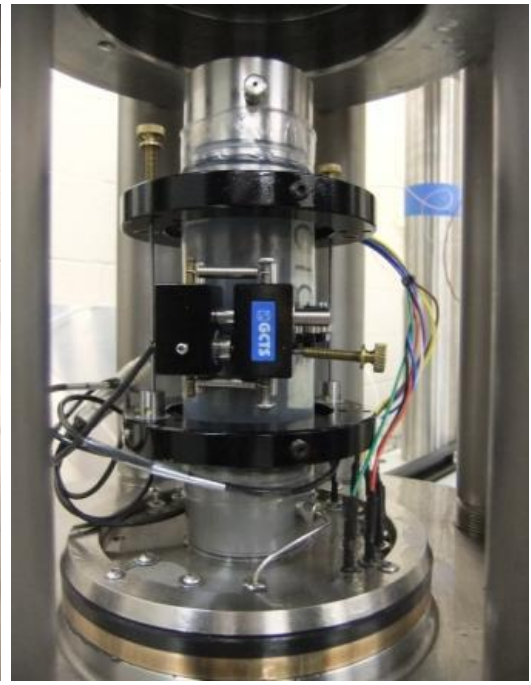

(c)

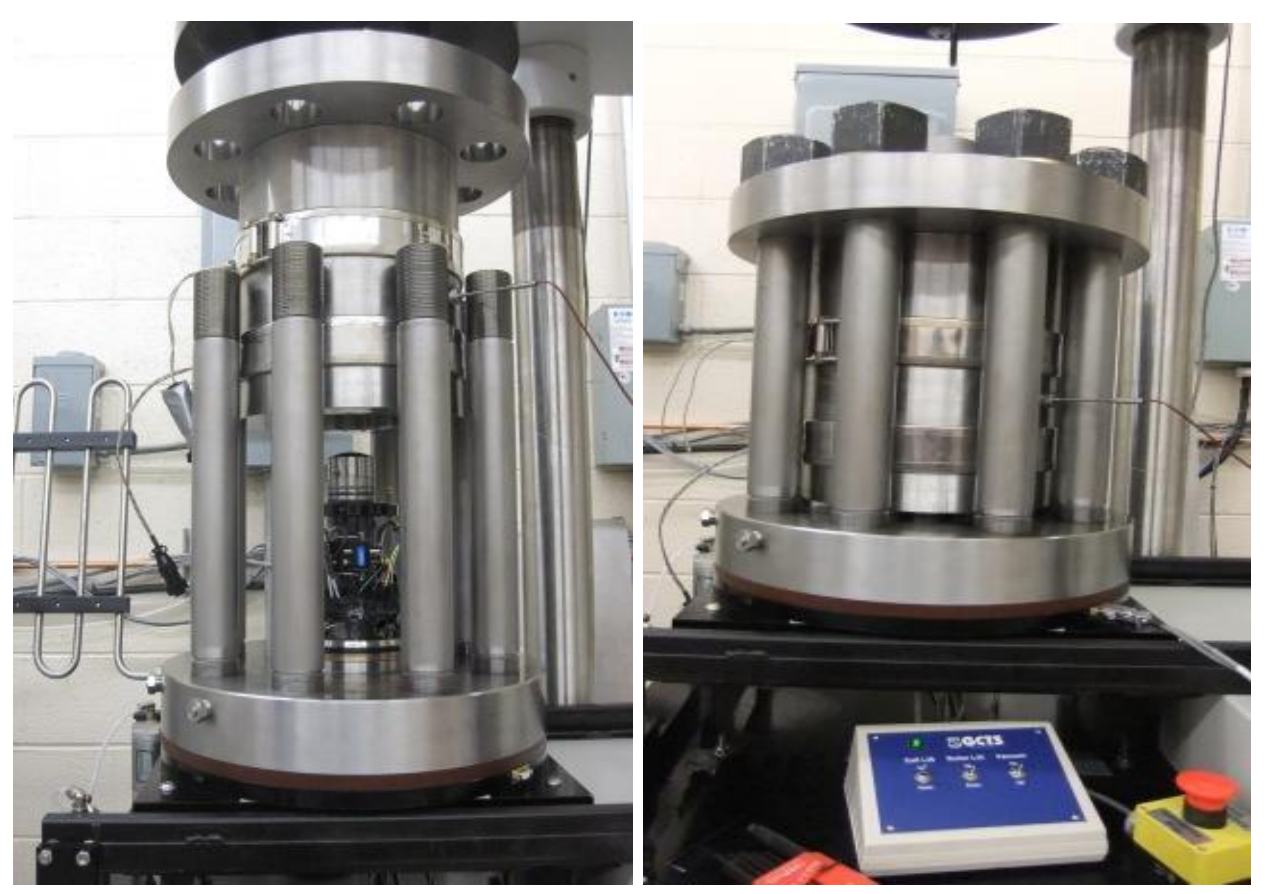

(d)

(e)

Figure 3.6. Pictorial setup for the triaxial compression test

a) Heat gun is heating the heat shrink which wrapped around the installed specimen; b) Specimen with heat shrink is ready to install extensometers and sensors; c) All sensors, chain extensometer, and LVDT 1,2,3 were installed; d) The triaxial cell is moving down through a cell lift command; e) Specimen is fully covered by triaxial cell. 
1) The specimen assembly consisting of the specimen mounted between the top and bottom end caps and gages for measuring the axial and lateral deformation is lift up by the cell lift command and then placed between the upper and lower platen in the triaxial loading frames.

2) The upper platen of the load frame is slowly moved down by dragging the displacement command in the computer software until it almost touches the top cap of the specimen assembly. A small deviator stress (instead of axial load) of $0.5 \mathrm{Mpa}$ is then applied to ensure that the specimen assembly is in good contact with the upper platen. Using the deviator stress prevents any mechanical instability (for instance, the upper platen may be pushed upwards) when the applied confining pressure exceeds the axial stress.

3) When the applied deviator stress is stable, the hydraulic fluid is ready to inject to the triaxial chamber through the connected hoses by controlling the hydraulic pump system. The fluid is pressurized to the chamber with the help of the cell pressure intensifier. This process will take probably 15-20 minutes. When the 'fill indicator' attached in the cell pressure intensifier is full of oil, the triaxial cell is also filled with oil. Within the computer software, set the 'output' versus 'feedback' to 'cell pressure' versus 'cell pressure displacement' command, then slowly drag the cell pressure displacement until the desired confining pressure is reached. Note that you will have to use the recharging cell pressure intensifier procedure if the desired value cannot be reached. More details can be seen in the GCTS manuals.

4) After applying the cell pressure, then it's time to go to the heating system. Set the 'Output versus Feedback' signal to 'Temperature versus Wall temperature', then turn on the heating controller and input the desired temperature. Note this temperature will rise up to $5^{\circ} \mathrm{C}$ per minute. This process will not be discussed further since no temperature is applied in my laboratory test. 
5) Reset all LVDT 1, 2, 3 to zero by clicking the offset button and it's is ready to execute the test. During the test, the upper platen moves downward at a predetermined constant lateral strain rate thereby increasing the load on the specimen. The axial stress and the corresponding specimen deformation are continuously measured. The axial, lateral stressstrain curves are continuously plotted on the computer screen.

6) The test is stopped when the specimen failed. This loading process will take probably 15 minutes. The axial load is then slowly reduced to a small value but not zero. A small axial load will be maintained on the top end cap.

7) Slowly open the 'recharge/dump' valve displayed on the cell pressure intensifier to drop the cell pressure inside the triaxial cell to $0 \mathrm{Mpa}$. This draining process will also take around 20 minutes.

8) The fluid is completely drained and the triaxial chamber is removed from the load frame and slipped to the original position. Open the triaxial cell and unwrap everything around the specimen.

The axial stress-axial strain curve, axial stress-lateral strain curve, and the axial stressvolumetric strain curve are generated from the raw test data and the Young's modulus, Poisson's ratio are calculated for every stage. They are all calculated from the slope of the axial stress-axial strain curve at more-or-less straight line portion for the stage. The maximum strength and the residual strength along with different confining pressures are recorded and singled out from the test data. These stress values and the corresponding confining pressures are required for the failure envelope generation. 


\subsection{Analysis and Calculation}

There are 9 test inputs need to be defined for this triaxial test. They are all summarized in the following Table 3.3.

Table 3.3 Triaxial test inputs and their definitions.

\begin{tabular}{|c|c|c|}
\hline Term & Symbol & Formula \\
\hline Axial Strain & $\varepsilon_{\mathrm{a}}$ & $\Delta \mathrm{L} / \mathrm{L}$ \\
\hline Lateral Strain & $\varepsilon_{1}$ & $\Delta \mathrm{D} / \mathrm{D}$ \\
\hline Volumetric Strain & $\varepsilon_{\mathrm{V}}$ & $\varepsilon_{\mathrm{a}}+2 \varepsilon_{1}$ \\
\hline Corrected Area & $\mathrm{A}_{\mathrm{c}}$ & $\operatorname{Ao}^{*}\left(1-\varepsilon_{\mathrm{v}}\right) /\left(1-\varepsilon_{\mathrm{a}}\right)$ \\
\hline Deviator Stress & $\sigma_{\mathrm{d}}$ & $\left(\mathrm{P}-\sigma_{\mathrm{c}} * \mathrm{~A}\right) / \mathrm{A}_{\mathrm{c}}$ \\
\hline Axial Stress & $\sigma_{\mathrm{a}}$ & $\sigma_{\mathrm{d}}+\sigma_{\mathrm{c}}$ \\
\hline Tangent Modulus & $\mathrm{E}_{\mathrm{t}}$ & $\Delta \sigma_{\mathrm{d}} / \Delta \varepsilon_{\mathrm{a}}$ \\
\hline Poisson's Ratio & $v$ & $\varepsilon_{1} / \varepsilon_{\mathrm{a}}$ \\
\hline Confining Pressure & $\sigma_{\mathrm{c}}$ & Direct Input \\
\hline Remark & \multicolumn{2}{|c|}{$\begin{array}{l}\Delta \mathrm{L} \text { is the axial deformation of the specimen } \\
\mathrm{L} \text { is the length of the specimen } \\
\Delta \mathrm{D} \text { is the measured lateral deformation } \\
\mathrm{D} \text { is the diameter of the specimen } \\
\mathrm{P} \text { is the axial load and } \mathrm{A} \text { is the area of the piston }\end{array}$} \\
\hline
\end{tabular}




\section{CHAPTER 4 TEST RESULTS}

\subsection{Introduction}

Load control, axial strain control and lateral strain control were used in the uniaxial part to study the post-failure behavior of 16 coal specimens and 24 rock specimens, wherever only lateral strain control was employed in the triaxial compression test on 4 coal specimens. This chapter enumerates the effect of the control modes on parameters such as: the ultimate strength, the residual strength, Young's modulus, and the Poisson's ratio. Each description is supported with the stressstrain that depicts the behavior of the various control modes of loading. In addition, various correlations between the parameters were analyzed and presented in the later sections of this chapter. Some relationships are summarized and discussed. Such as Young's modulus and the ultimate strength, Young's modulus vs. confining pressure, maximum strength vs. confining pressure, and Poison's ratio vs. confining pressure for the triaxial compression test. Based on all the stress-strain curves, test results and analysis, a discussion of the appropriate control mode on the post-failure behavior study is also provided at the end of the chapter.

\subsection{Results of the UCS test for rock and coal under the proposed control modes}

All specimens tested in this experiment were divided into eight different groups. In the first batch of tests, six randomly selected rock samples from both the roof and floor cores of Cumberland mine located in eastern United States and were tested under load control mode. The selected groups of samples are shown in Table 4.1. Figure 4.1 shows the stress-strain curve for the above rock 
samples. In the initial stage of the curve, there is a non-linear relationship between the applied stress and the resulting strain. This is due to the closure of cracks, micropores, etc.

Table 4.1 The properties and results of the six rock samples tested under load control

\begin{tabular}{|c|c|c|c|c|c|c|}
\hline & & & & & & \\
\hline Sample Rock Name & RLC1 & RLC2 & RLC3 & RLC4 & RLC5 & RLC6 \\
\hline Control Mode & L.C. & L.C. & L.C. & L.C. & L.C. & L.C. \\
\hline Diameter (in.) & 1.984 & 1.99 & 1.986 & 1.986 & 1.985 & 1.984 \\
\hline L/D ratio & 2.03 & 2.01 & 2.03 & 2.04 & 2.02 & 1.98 \\
\hline UCS (psi) & 17,122 & 16,633 & 16,640 & 14,311 & 8,070 & 6,151 \\
\hline $\begin{array}{c}\text { Young's modulus, } \\
\text { psi(×106) }\end{array}$ & 2.60 & 2.40 & 1.98 & 1.69 & 1.89 & 1.17 \\
\hline $\begin{array}{c}\text { Poisson's ratio } \\
\text { Remark: LC stands for Load Control Mode; }\end{array}$ & \multicolumn{2}{|c|}{ N.R. means Not Recorded } & N.R. \\
\hline
\end{tabular}

Remark: LC stands for Load Control Mode; N.R. means Not Recorded

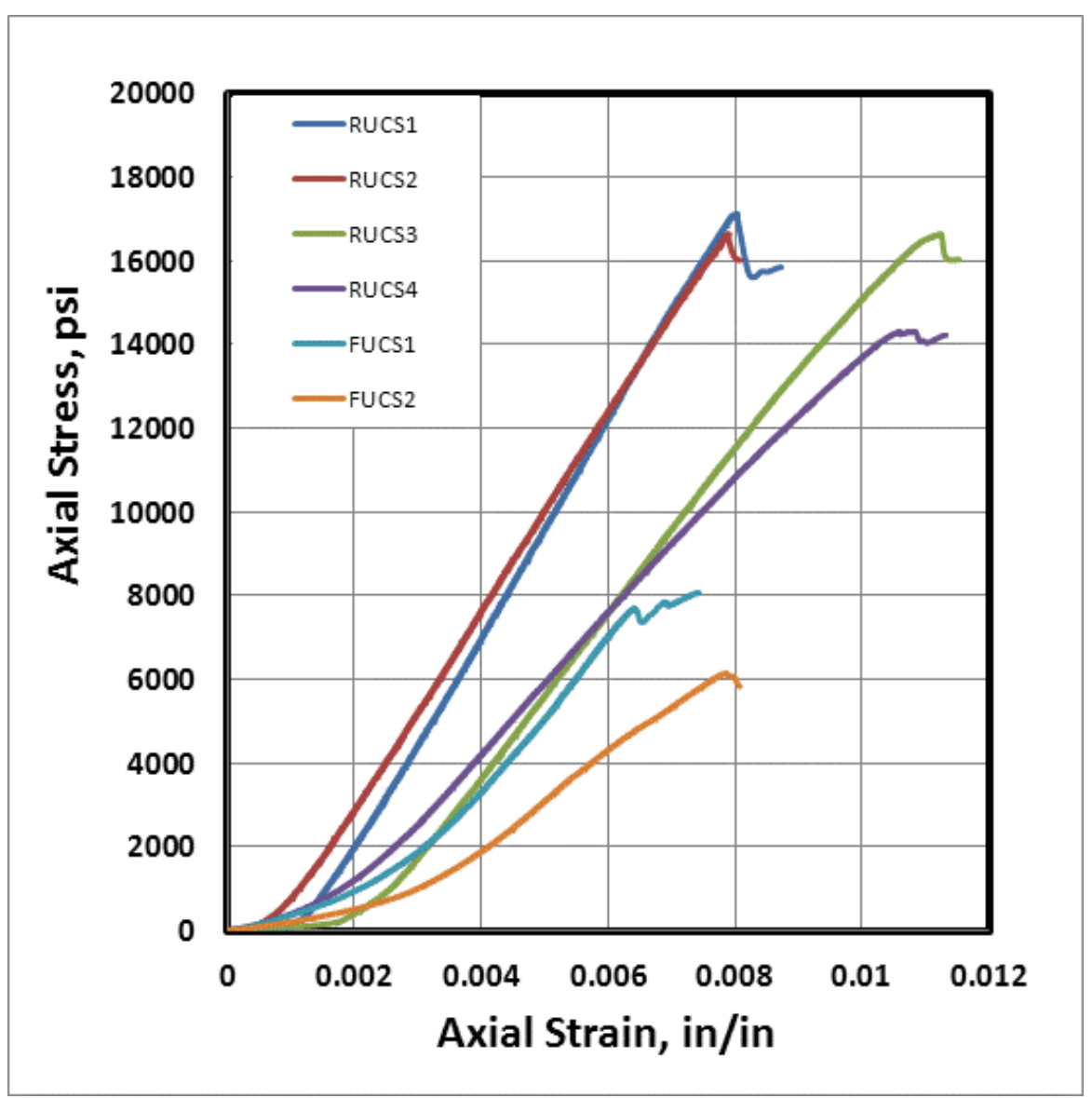

Figure 4.1. Stress-strain curves of six roof/floor rock samples tested under load control. 
For this group, the individual stress-strain curves and photographs of each specimen are shown in Appendix A (a) and B (a). All specimens failed in a shear or splitting with cone zones left at either one or two ends of the specimen. Comparing with the field observation of failure of pillars, it is uncommon that a pillar will always fail completely. For this reason it was always presumed in mid 1960's that rock do not have any residual strength. With the advent of the stiff testing machine, it was possible to observe the post-failure behavior of the rock.

Six type Berea sandstone samples were tested under only lateral strain control mode by the same testing machine. Table 4.2 shows the test results for Berea sandstone samples, which were tested under lateral strain control mode.

Table 4.2 Test results of six Berea sandstone samples tested under lateral strain control mode.

\begin{tabular}{|c|c|c|c|c|c|c|}
\hline & SUCS1 & SUCS2 & SUCS3 & SUCS4 & SUCS5 & SUCS6 \\
\hline Sample Name & 1.985 & 1.986 & 1.984 & 1.985 & 1.986 & 1.99 \\
\hline Diameter (in.) & 2 & 2 & 2 & 2 & 2 & 2 \\
\hline L/D ratio & L.S. & L.S. & L.S. & L.S. & L.S. & L.S. \\
\hline Control Mode & 8,591 & 8,433 & 8,867 & 8,773 & 8,291 & 8,693 \\
\hline UCS (psi) & 6,194 & 4,052 & 3,341 & 6,448 & 3,906 & 6,593 \\
\hline Residual Strength (psi) & $72 \%$ & $48 \%$ & $38 \%$ & $73 \%$ & $47 \%$ & $76 \%$ \\
\hline RS/UCS, \% & 2.07 & 1.99 & 2.00 & 2.02 & 2.07 & 2.07 \\
\hline Young's modulus, psi $(\times 106)$ & 0.37 & 0.32 & 0.32 & 0.32 & 0.38 & 0.37 \\
\hline Poisson's ratio & & & &
\end{tabular}

Remark: L.S. stands for Lateral Strain Control Mode, RS means Residual Strength.

Figure 4.2 shows the complete stress-strain curve for the Berea sandstone specimens. The results for each group can be summarized as:

(1) Only, Class I post-failure behavior was achieved under this control mode for Berea sandstone.

(2) The average Young's Modulus of Berea sandstone is $2.0 \times 10^{6}$ psi and the Poisson's ratio is approximately 0.35 .

(3) Unlike samples tested under load control, all specimens in this group failed in a gradual, non- 
violent manner without loud noises, even after the ultimate strength was attained, the curve still showed a slow, gradual failure process with a 'ups and downs' pattern until the test was terminated.

(4) Post termination of the test, it was found all of the specimens had not disintegrated completely and therefore can be inferred that they still have residual strength which was for $38 \%-73 \%$ of its ultimate strength.

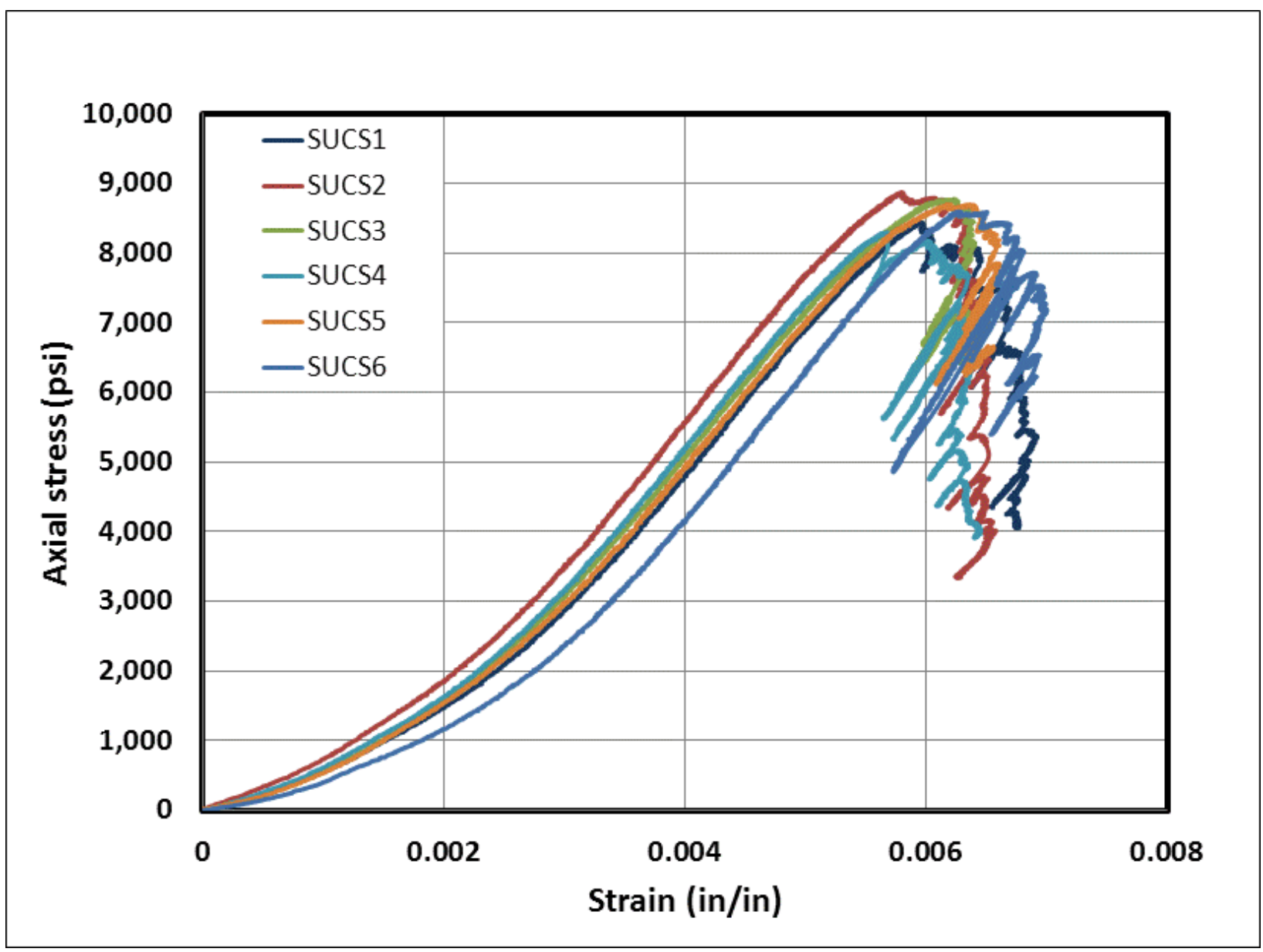

Figure 4.2. Stress-strain curves of six Berea sandstone samples tested under lateral strain control.

Both group three and four consisted of six different types of rock samples, and they were tested under both lateral strain control mode and axial strain mode. Table 4.3 and 4.4 present the complete test matrix of the rocks that were tested under lateral and axial strain control mode. The samples are Berea sandstone, medium grained sandstone, coarse-grained sandstone, massive 
sandstone with coal streaks, grey shale and black shale respectively. In these tests, both Class I (Berea sandstone, medium and coarse-grained sandstone, massive sandstone with coal streaks) and Class II (grey shale and black shale) post-failure was distinctly observed during the test. Moreover, all stress-strains curve showed a slow and gradual failure process in a non-violent manner with an 'ups and downs' curve (except for grey shale shown a sharp decrease in stress)in the post-peak region. In addition, the residual strength in this group of rocks accounts for $34 \%-86 \%$ of its UCS at the time the test stops.

Table 4.3 The basic information and test results of six different types of rock samples tested under lateral strain control mode.

\begin{tabular}{|c|c|c|c|c|c|c|}
\hline $\begin{array}{c}\text { Sample Rock } \\
\text { Type }\end{array}$ & $\begin{array}{c}\text { Berea } \\
\text { Sandstone }\end{array}$ & $\begin{array}{c}\text { Medium } \\
\text { grained } \\
\text { Sandstone }\end{array}$ & $\begin{array}{c}\text { Coarse } \\
\text { grained } \\
\text { Sandstone }\end{array}$ & $\begin{array}{c}\text { Massive } \\
\text { sandstone with } \\
\text { coal streaks }\end{array}$ & $\begin{array}{c}\text { Grey } \\
\text { shale }\end{array}$ & $\begin{array}{c}\text { Black } \\
\text { shale }\end{array}$ \\
\hline Control Mode & L.S. & L.S. & L.S. & L.S. & L.S. & L.S. \\
\hline Diameter (in.) & 1.985 & 1.985 & 1.982 & 1.992 & 1.984 & 1.977 \\
\hline L/D ratio & 2.03 & 2.02 & 2.03 & 2.00 & 1.98 & 2.03 \\
\hline R.S. (psi) & 72 & 4,297 & 5,786 & 4,862 & 8,939 & 3,508 \\
\hline UCS (psi) & 8,891 & 12,358 & 9,519 & 14,249 & 10,432 & 10,296 \\
\hline RS/UCS, \% & $1 \%$ & $35 \%$ & $61 \%$ & $34 \%$ & $86 \%$ & $34 \%$ \\
\hline & & & & & & \\
E, psi $\left(\times 10^{6}\right.$ ) & 2.2 & 3.4 & 2.8 & 3.2 & 1.6 & 1.6 \\
\hline Poisson's ratio & 0.41 & 0.30 & 0.25 & 0.20 & 0.18 & 0.06 \\
\hline
\end{tabular}

Remark: L.S. stands for Lateral Strain Control Mode, N.R. means Not Recorded, R.S. means Residual Strength, E stands for Young's modulus.

It is clear from the comparison of Table 4.3 and Table 4.4 that either the ultimate strength or the calculated Young's modulus does not have a significant difference for this group of tests under both axial strain control and lateral strain control methods, even though the ultimate strength obtained from the lateral strain control are a little bit higher than those acquired under the axial strain control mode. Moreover, some of the figures (RUCS9 \& RUCS10) show that there is a sharp fall in 
the post-peak region, which is pretty similar to those rocks tested under load control. This is probably means that axial strain control may not always be appropriate for the post-failure behavior study.

Table 4.4 The basic information and test results of six different types of rock samples tested under axial strain control mode

\begin{tabular}{|c|c|c|c|c|c|c|}
\hline $\begin{array}{c}\text { Sample Rock } \\
\text { Type }\end{array}$ & $\begin{array}{c}\text { Berea } \\
\text { Sandstone }\end{array}$ & $\begin{array}{c}\text { Medium } \\
\text { grained } \\
\text { Sandstone }\end{array}$ & $\begin{array}{l}\text { Coarse grained } \\
\text { Sandstone }\end{array}$ & $\begin{array}{c}\text { Massive } \\
\text { sandstone with } \\
\text { coal streaks }\end{array}$ & $\begin{array}{l}\text { Grey } \\
\text { shale }\end{array}$ & $\begin{array}{l}\text { Black } \\
\text { shale }\end{array}$ \\
\hline Control Mode & A.S. & A.S. & A.S. & A.S. & A.S. & A.S. \\
\hline Diameter (in.) & 1.985 & 1.986 & 1.983 & 1.990 & 1.983 & 1.986 \\
\hline $\mathrm{L} / \mathrm{D}$ ratio & 2.03 & 2.02 & 2.02 & 2.01 & 2.03 & 2.03 \\
\hline UCS & 8,694 & 10,466 & 11,028 & 14,167 & 9,316 & 8,042 \\
\hline $\mathrm{E},\left(\times 10^{6}\right), \mathrm{psi}$ & 2.1 & 3.0 & 3.0 & 2.8 & 1.6 & 1.7 \\
\hline Poisson's ratio & N.R. & N.R. & N.R. & N.R. & N.R. & N.R. \\
\hline Remark: L.S & $\begin{array}{l}\text { ands for } L \\
\text { Resic }\end{array}$ & Strength & ds for & $\begin{array}{l}\text { ans Not Rece } \\
\text { Iodulus. }\end{array}$ & $D^{2}$ & \\
\hline
\end{tabular}

The Young's Modulus, Poisson's ratio and ultimate strength varied from each different rock types in this group while the deformation behavior for each test still displayed plastic-elastic-plastic behavior during the early stage of loading followed by gradual fracturing until failure of the specimen. This indicates that under any control mode, the pre-peak region (the slope) does not change, although there is striking difference in the post-failure region. Figure 4.3 and Figure 4.4 illustrate the stress-strain curve for all the samples obtained using lateral strain and axial strain control mode. 


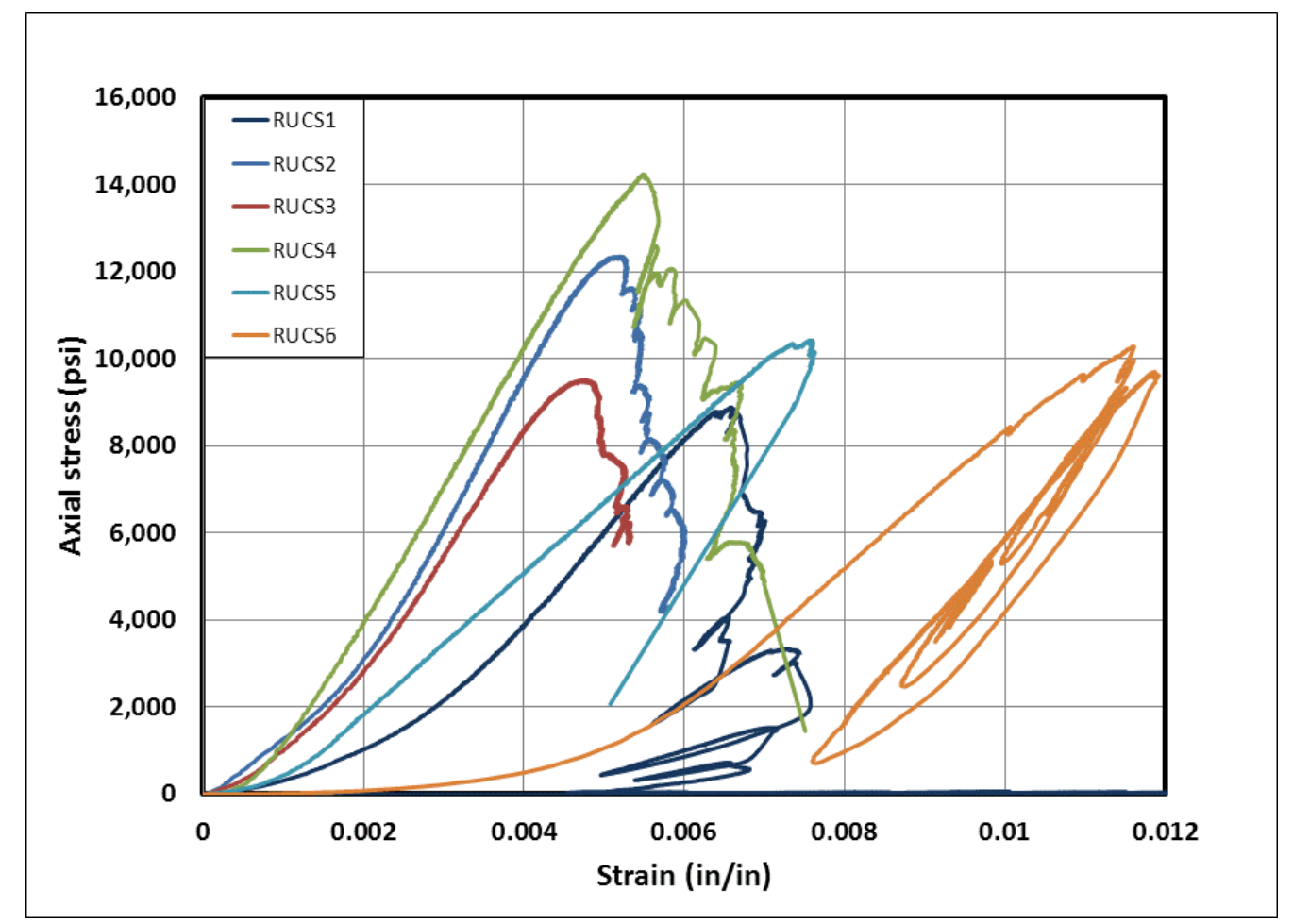

Figure 4.3. Stress-strain curve of six different types of rock samples tested under lateral strain control.

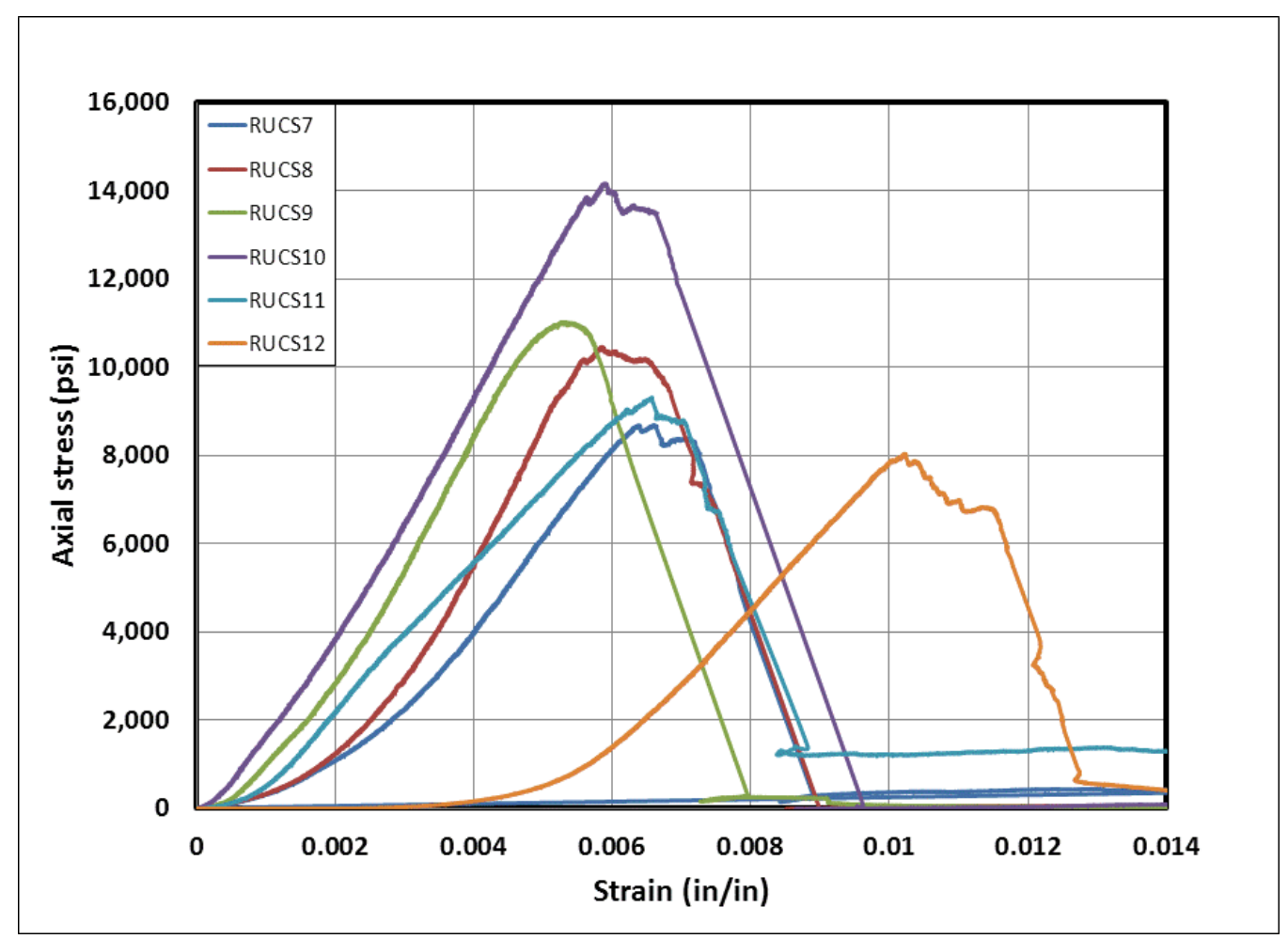

Figure 4.4. Stress-strain curves of six different rock samples tested under axial strain control. 
The results from the coal sample from both Pittsburgh and Hiawatha seams are described in the following sections. Table 4.5 and 4.6 shows the test matrix for coal samples of Pittsburgh seam. The samples were tested under lateral strain control and axial strain control mode. In figure 4.5 and 4.6 the stress strain curves for each of the specimen was obtained using the lateral and the axial strain control mode. It was noticed that different post failure behavior was observed during the compression tests. Both Class I and Class II type of behaviors was observed when axial and lateral strain control was used when the results are compared with the field observation, a close resemblance is obtained.

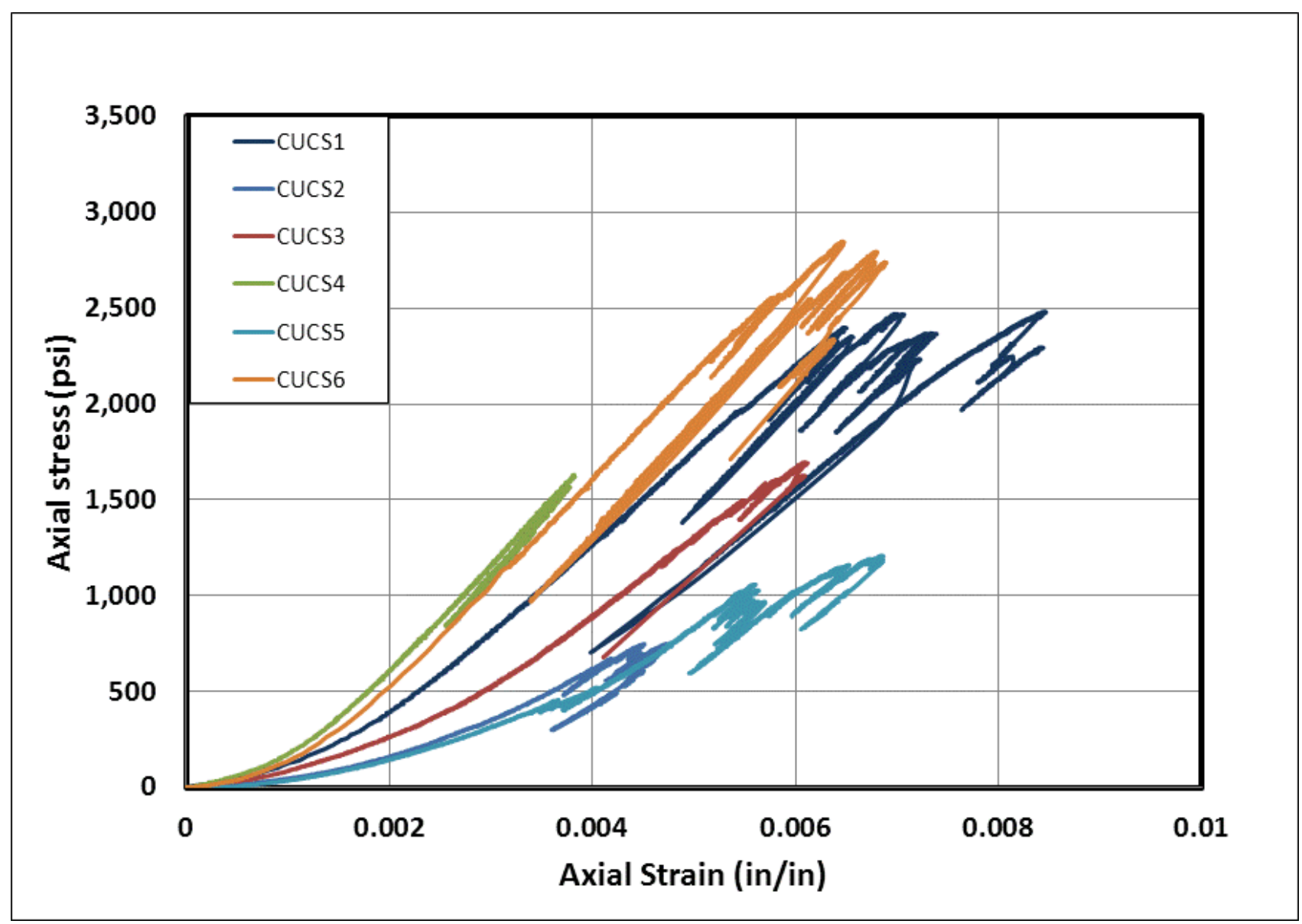

Figure 4.5. Stress-strain curves of six coal samples (Pittsburgh seam) tested under lateral strain control 
Table 4.5 The basic information and test results of six coal samples from Pittsburgh seam tested under lateral strain control mode

\begin{tabular}{|c|c|c|c|c|c|c|}
\hline $\begin{array}{c}\text { Sample Name } \\
\text { (Pittsburgh Seam) }\end{array}$ & CUCS1 & CUCS2 & CUCS3 & CUCS4 & CUCS5 & CUCS6 \\
\hline Control Mode & L.S. & L.S. & L.S. & L.S. & L.S. & L.S. \\
\hline Diameter (in.) & 2.13 & 2.12 & 2.13 & 2.12 & 2.13 & 2.13 \\
\hline L/D ratio & 1.60 & 1.70 & 1.70 & 1.70 & 1.70 & 1.70 \\
\hline $\begin{array}{l}\text { Residual Strength } \\
\text { (psi) }\end{array}$ & 2,262 & 469 & 17 & 1,414 & 966 & 1,711 \\
\hline UCS (psi) & 2,481 & $749 *$ & 1,695 & 1,629 & 1,208 & 2,847 \\
\hline RS/UCS, \% & $91 \%$ & $63 \%$ & $1 \%$ & $87 \%$ & $80 \%$ & $60 \%$ \\
\hline $\begin{array}{c}\text { Young's modulus, } \\
\text { psi }(\times 106)\end{array}$ & 0.50 & 0.25 & 0.23 & 0.52 & 0.18 & 0.56 \\
\hline Poisson's ratio & 0.45 & 0.24 & 0.32 & 0.28 & 0.26 & 0.46 \\
\hline
\end{tabular}

*Note: This low strength may due to the pre-cracks existed inside the coal specimen.

Table 4.6 Test results of six coal samples from Pittsburgh seam under axial strain control

\begin{tabular}{|c|c|c|c|c|c|c|}
\hline Sample Name & CUCS7 & CUCS8 & CUCS9 & CUCS10 & CUCS11 & CUCS12 \\
\hline Control Mode & A.S. & A.S. & A.S. & A.S. & A.S. & A.S. \\
\hline Diameter (in.) & 1.993 & 1.993 & 2.113 & 1.983 & 2.14 & 1.983 \\
\hline L/D ratio & 2.00 & 2.00 & 2.00 & 2.04 & 1.60 & 2.02 \\
\hline UCS (psi) & 3,424 & 3545 & 2,958 & 4,018 & 1,231 & 4,022 \\
\hline E, $\left(\times 10^{6}\right.$ ), psi & 0.16 & 0.19 & 0.12 & 0.75 & 0.14 & 0.16 \\
\hline Poisson's ratio & N.R. & N.R. & N.R. & N.R. & N.R. & N.R. \\
\hline \multicolumn{7}{|l|}{ Remark: A.S. stands for Axial Strain Control Mode, N.R. means Not Recorded, E stands for } \\
\multicolumn{7}{|l}{ Young's modulus. } \\
\hline
\end{tabular}




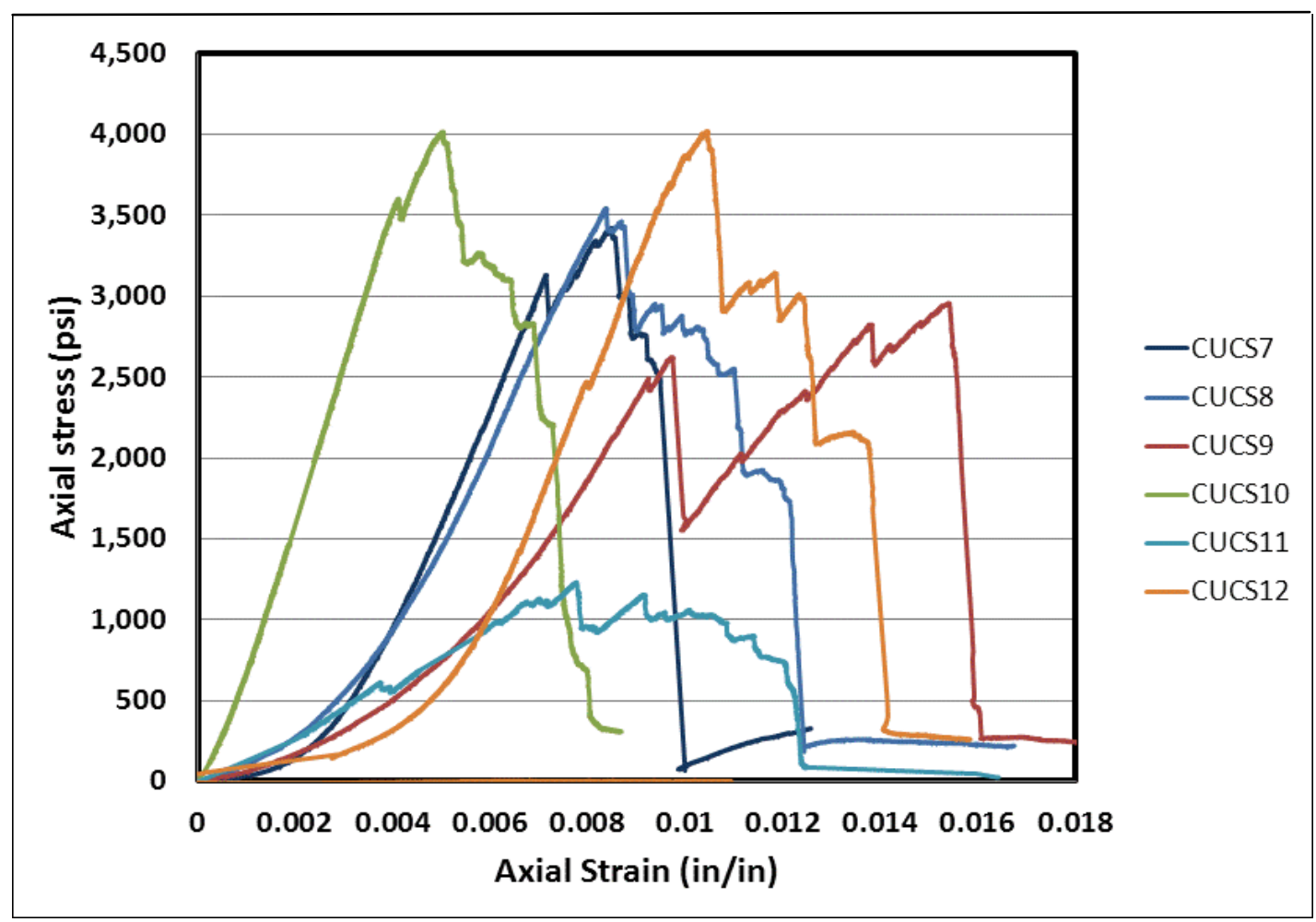

Figure 4.6. Stress-strain curves of six coal samples (Pitt. seam) tested under axial strain control

Group seven is the last group of the uniaxial test matrix. Four coal specimens from Hiawatha seam was tested under lateral strain control, as can be seen in Table 4.7 and Figure 4.7. However, a slightly different outcome was obtained under lateral strain control for coal specimens from both Pittsburgh seam and Hiawatha seam. They showed Class II behavior.

Table 4.7 Test results of four coal samples from Utah seam under lateral strain control mode

\begin{tabular}{|c|c|c|c|c|}
\hline $\begin{array}{c}\text { Sample Name } \\
\text { (Hiawatha Seam) }\end{array}$ & CLS1 & CLS2 & CLS3 & CLS4 \\
\hline Control Mode & L.S. & L.S. & L.S. & L.S. \\
\hline Diameter (in.) & 2.13 & 2.12 & 2.13 & 2.11 \\
\hline L/D ratio & 1.96 & 1.87 & 1.90 & 1.70 \\
\hline UCS (psi) & 3,094 & 2,040 & 2,184 & 1,344 \\
\hline $\begin{array}{l}\text { Residual Strength, } \\
\text { (psi) }\end{array}$ & 1,700 & 1,450 & 600 & 480 \\
\hline RS/UCS, \% & $55 \%$ & $71 \%$ & $27 \%$ & $36 \%$ \\
\hline $\begin{array}{l}\text { Young's modulus, } \\
\text { psi }\left(\times 10^{6}\right)\end{array}$ & 0.45 & 0.45 & 0.47 & 0.3 \\
\hline Poisson's ratio & 0.37 & 0.39 & 0.37 & 0.40 \\
\hline
\end{tabular}




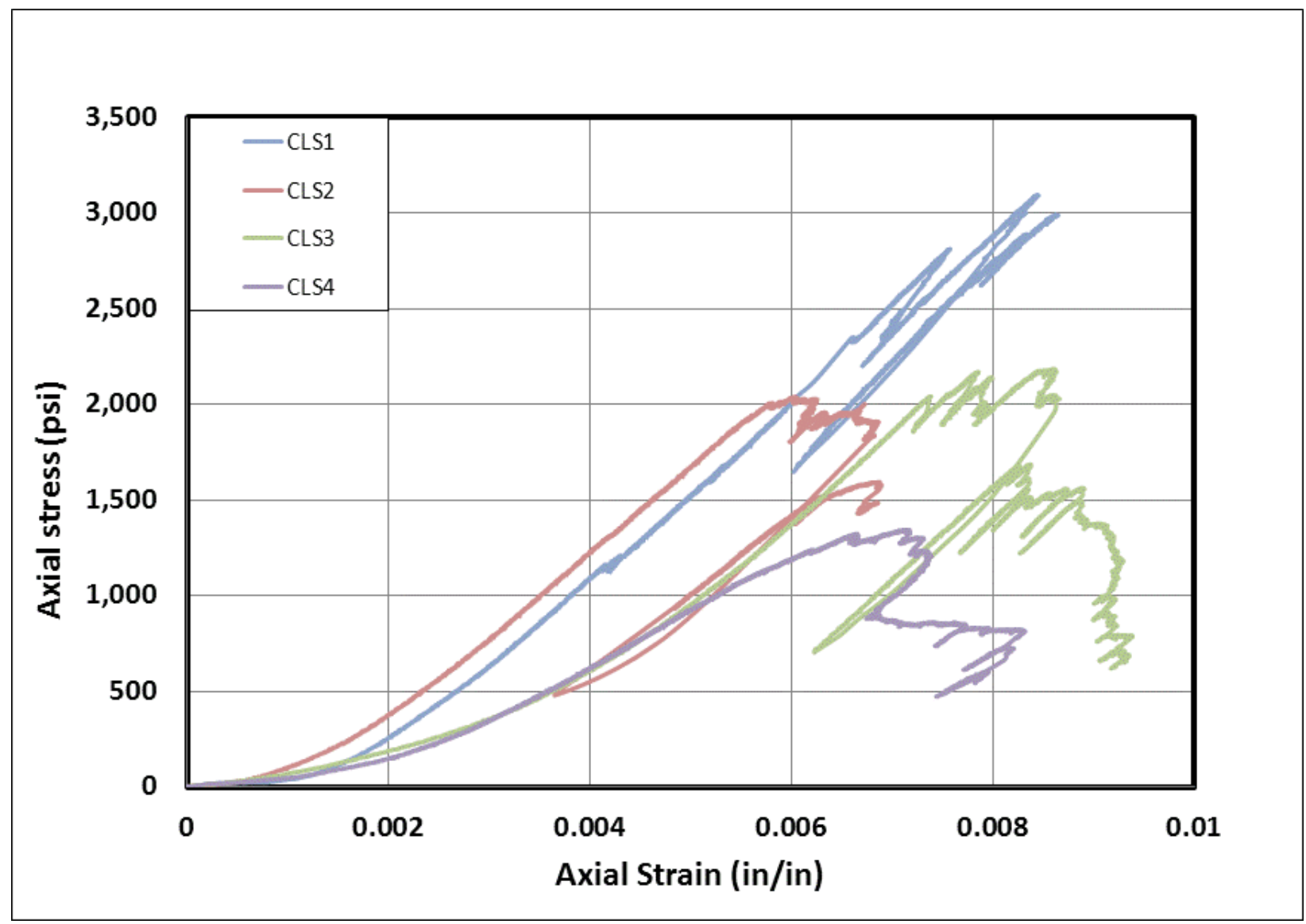

\section{Figure 4.7. Stress-strain curves of four coal samples (Hiawatha seam) tested under lateral strain control}

Here are the characteristics for these two groups: (1) Only Class II type of failure pattern are achieved under lateral control mode for coal specimens from two different fields; (2) This is actually an 'unstable' fracture development. It is a self-sustaining process, which means the fracture will propagate after the peak strength is reached without additional load. The elastic strain energy stored in the sample when the applied stress equals the compressive strength is sufficient to maintain fracture propagation until the specimen has lost virtually all strength (Wawersik, 1968). Unlike those tested under axial strain control, all specimens in this group failed in a gradual, non-violent manner without loud noises, even after the ultimate strength the curve still shows a slow, gradual failure process with a 'rise and fall' or 'ups and downs' pattern until it automatically terminates. (3) At the time the test automatically ends, all of the specimens still store energy and take certain amount of loads. It is apparent from Table 4.5 and Table 4.7 that these specimens do not fail completely and the 
residual strength accounts for half and even more of its ultimate strength through calculation. (4) It is pretty similar in the pre-peak region of all specimens tested, as far as the Young's Modulus E (0.18$\left.0.56 \times 10^{6} \mathrm{psi}\right)$, Poisson's ratio $v(0.24-0.46)$ for the Pittsburgh seam and E $\left(0.23-0.47 \times 10^{6} \mathrm{psi}\right), v$ (0.36-0.39) for the Hiawatha seam. The range of failure strain is from $0.38 \%$ to $0.84 \%$ and the UCS is around 749 to 2847 psi for the Pittsburgh seam and that range is from $0.60 \%$ to $0.86 \%$ and that UCS is from 1344 to 3094 psi for the Hiawatha seam specimens.

Group four and six are those six different rock samples and coal samples tested under axial strain control. This is the most widely used control variable for most of the numerical modelers for determining the mechanical properties and behavior of coal and rocks. However, this control variable may produce erroneous results because of the brittleness of the rock. For instance, the axial stress of sample RUCS9 drops from 10,000 psi all the way down to $100 \mathrm{psi}$; the exact same situation happened to sample RUCS10, the axial stress suddenly reduces from 13,000 psi to 0 psi as indicated in Appendix A (d). Moreover, the axial strain control will not be suitable as the control variable if the complete stress-strain curve does not monotonically increase in axial strain (the Class II behavior as described previously). Often the lateral strain control will have to be used because this does monotonically increase even if the axial strain does not (C. E. Fairhurst, J.A. Hudson, 1999). Plus, it was indicated that all twelve specimens tested under axial strain control show typical Class I failure behavior. All specimens failed in a shear or splitting pattern as shown in the bottom view of Appendix B (d) and (g). Therefore, axial strain control can be used for producing the ultimate strength and post-failure properties of the rock and coal samples in most of the cases.

Group eight is another four coal specimens from the Hiawatha seam also tested under lateral strain control but with lowing confining pressure. Table 4.8 and Figure 4.8 respectively describe the basic information, test results and the stress-strain curves of this group. 
Table 4.8 The basic information and test results of four coal samples from Hiawatha seam tested under lateral strain control with low confining pressure

\begin{tabular}{|c|c|c|c|c|}
\hline Sample Name & CTCS1 & CTCS2 & CTCS3 & CTCS4 \\
\hline Control Mode & L.S.C. & L.S.C. & L.S.C. & L.S.C. \\
\hline Diameter (in) & 2.122 & 2.121 & 2.121 & 2.121 \\
\hline L/D ratio & 2.01 & 2.02 & 2.02 & 2.07 \\
\hline Maximum Strength (psi) & $1,579.5$ & $4,174.0$ & $5,791.4$ & $4,648.5$ \\
\hline Confining pressure (psi) & 250 & 500 & 750 & 1000 \\
\hline Residual Strength (psi) & 568.5 & 2,763 & 1,628 & 2,509 \\
\hline Young's Modulus psi $\left(\times 10^{6}\right)$ & 0.66 & 0.80 & 0.86 & 0.84 \\
\hline Poisson's ratio & 0.47 & 0.47 & 0.45 & 0.45 \\
\hline \multicolumn{5}{|l}{} \\
Remark & L.S.C. stands for Lateral Strain Control with Confining Pressure \\
\hline
\end{tabular}

In this triaxial group, four coal specimens from Hiawatha seam were tested under lateral strain control mode with low confining pressure. As indicated in Figure 4.8, under the confining pressure of $250 \mathrm{psi}$ and $500 \mathrm{psi}$, the lateral deformation gradually increases and there is no unloading and reloading process in the axial direction. It is also noted that the maximum strength and Young's Modulus is proportional to the confining pressures applied in the triaxial state, even though the Poisson's ratio keeps constant under those confining pressure levels, as indicated in Figure 4.9. Another implication of this triaxial test is to simulate the influence of the confinement of the pillars on the core of the pillar system, in order to study the failure pattern of the cores and the bump mechanism. 


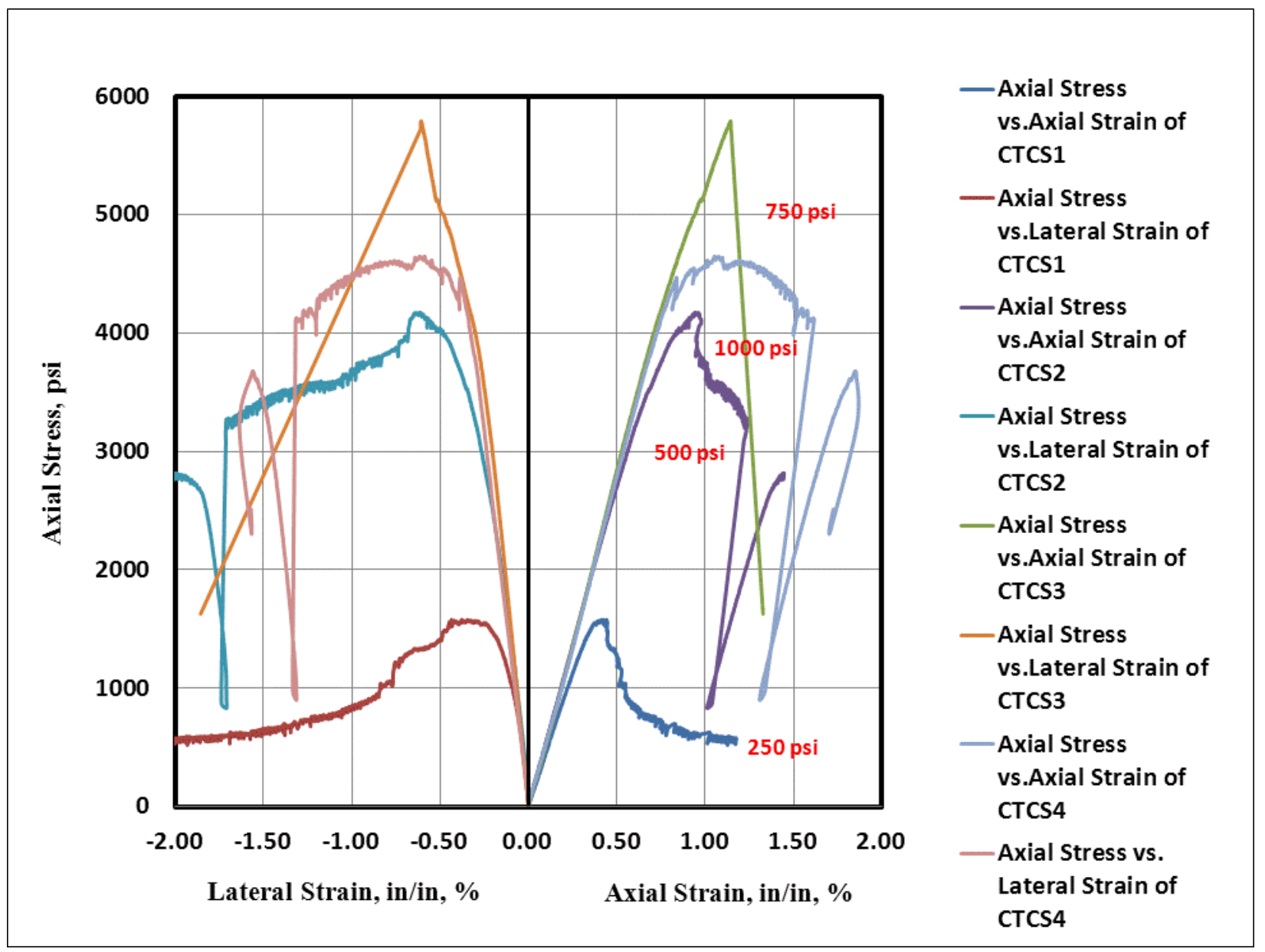

Figure 4.8. Stress-strain curves of four coal samples (Hiawatha seam) tested under lateral strain with low confining pressure

The individual stress-strain curve of each tested specimens are given in Appendix A, and the pre and after failure pictures of each specimen are compared as indicated in Appendix B. All specimens employed were collected in the form of drilled cores, which were drilled from the blocks perpendicular to bedding plane. 

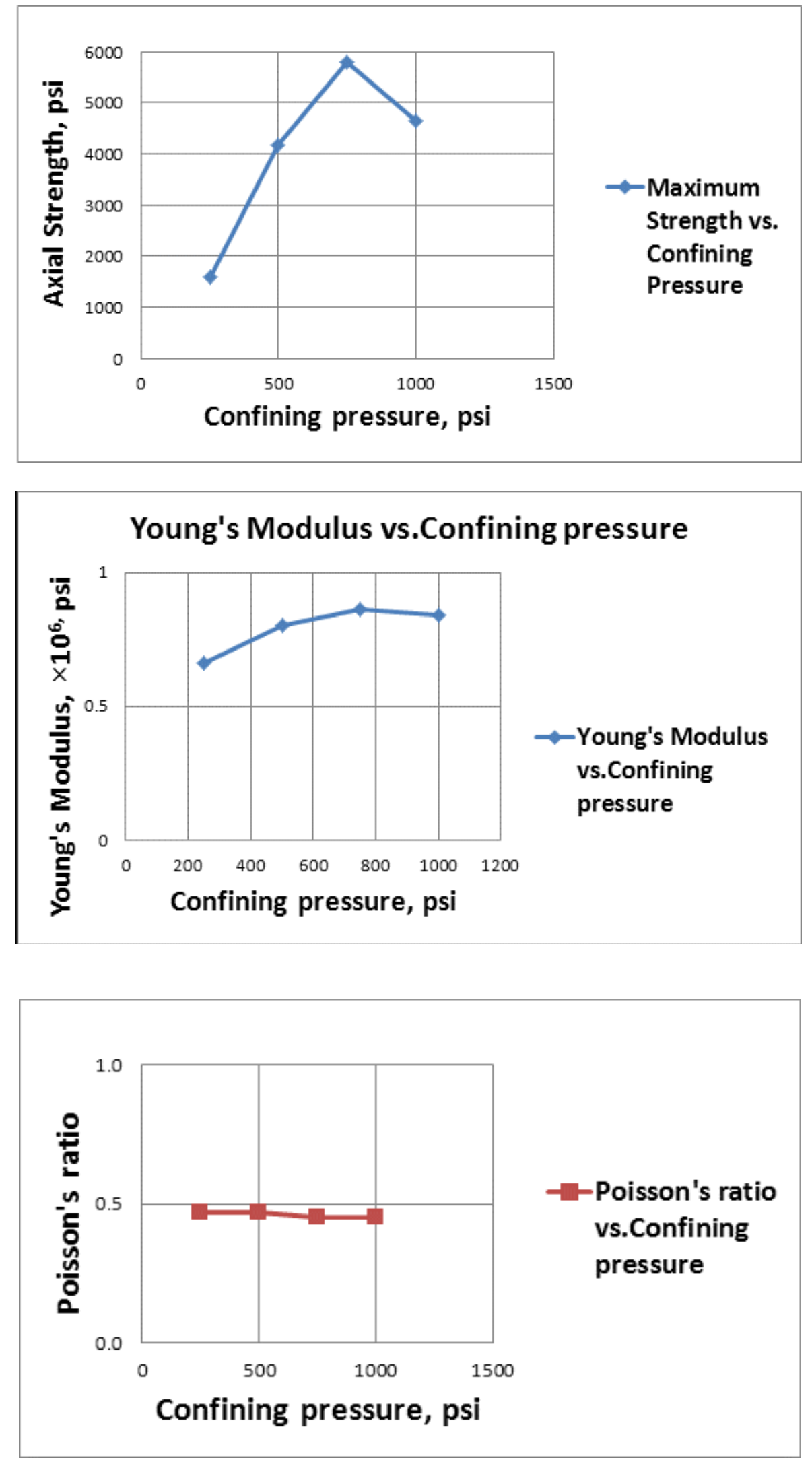

Figure 4.9. Maximum strength, Young's modulus, and Poisson's ratio versus the applied confining pressure for Hiawatha seam coal samples under lateral strain control. 
The length to diameter ratio was maintained approximately at 2.0 for all rock specimens and that was maintained at around 1.6 -2.07 for coal samples from Pittsburgh seam and 1.7-2.07 from Utah seam. All the dimensional tolerances were maintained as the ISRM suggested method, and all the samples were cut to the required length and the end faces were ground using surface grinder.

The relationship between the young's modulus and ultimate strength for each group of test can be seen in Figure 4.10. It is clear to see that the Young's modulus is in increasing trend with the increase of the ultimate strength, even though it's not constantly increased.

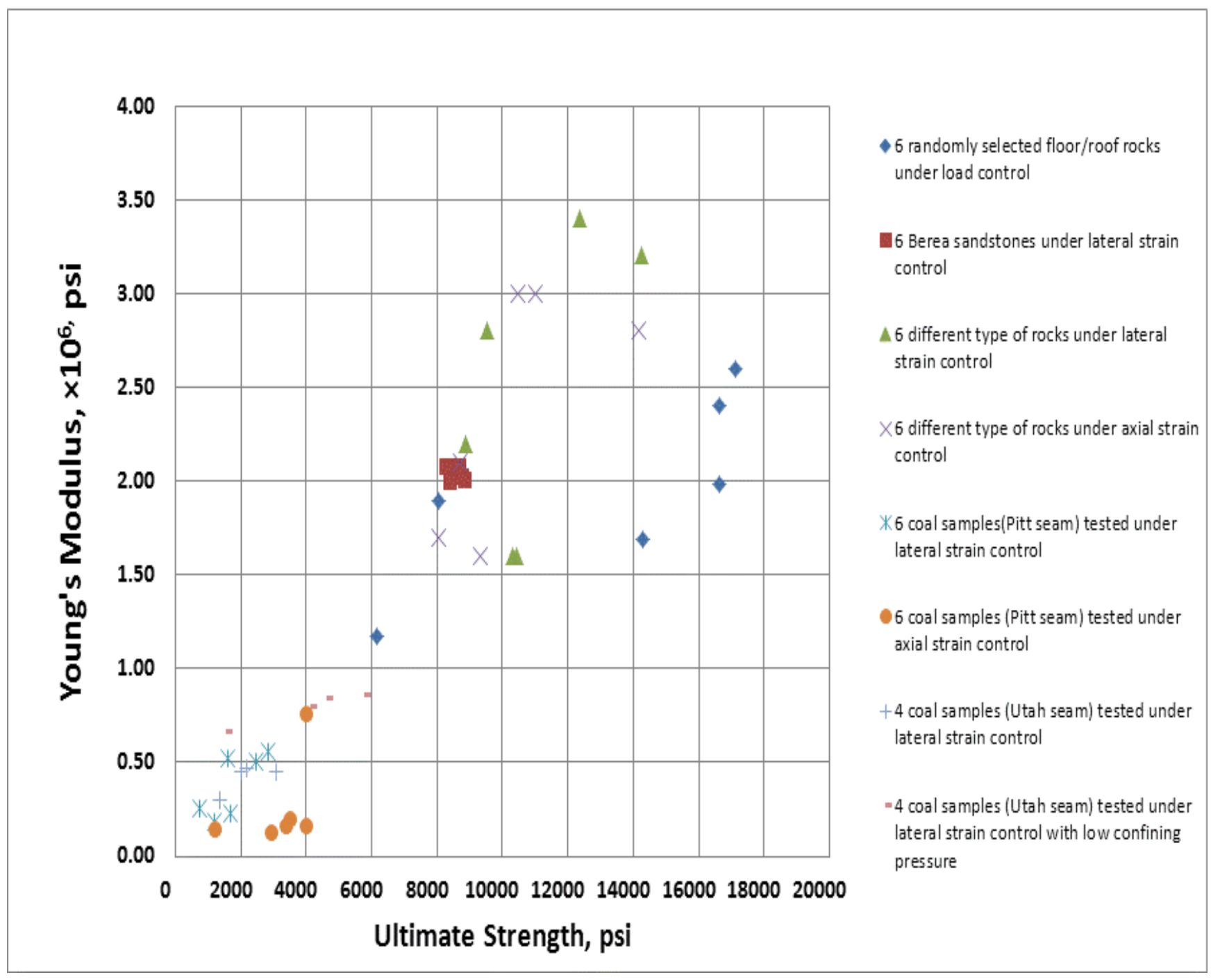

Figure 4.10. Stress-strain curves of 12 coal samples tested under lateral strain control. 


\subsection{Discussion}

For the randomly selected roof/floor rocks tested under load control, after the peak strength of the specimen was reached, the axial stress instantly dropped as indicated in Figure 4.11. This immediate process is much quicker than the response of the MTS testing machine. In fact, the slope of the post-failure curve is an indication of the machine stiffness, but not the specimen strength reduction characteristic. Suppose that the axial stress reduced by $\Delta \sigma$ from the peak to the end, and the corresponding axial strain increased by $\Delta \varepsilon$, therefore $\mathrm{A}^{*} \Delta \sigma$ is the reduced testing machine load and $\mathrm{L}^{*} \Delta \varepsilon$ is the release of the elastic deformation. Therefore, $\mathrm{K}_{\mathrm{m}}=\frac{A \times \Delta \sigma}{L \times \Delta \varepsilon}$, which is the instant stiffness of the testing equipment (You, 2007), where A is area of the tested specimen and L is the length of the specimen.

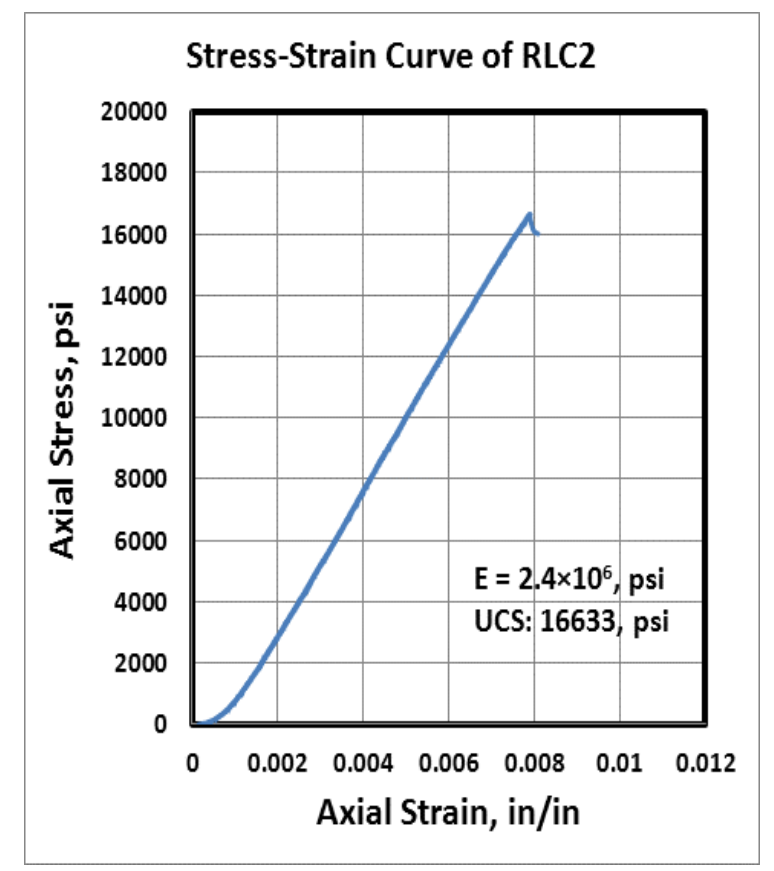

Figure 4.11. Typical stress-strain curves of rock samples tested under load control

However, Both Class I and Class II post-failure behavior was observed for six different types of rocks tested under lateral strain control as shown in Figure 4.12 and Figure 4.13. Class I postfailure behavior was shown by samples from Berea sandstone, massive sandstone, medium-grained 
sandstone and sandstone with coal intrusion. Only grey shale and black shale showed Class II behavior in the post-peak regions. For instance in Figure 4.12, it was observed that there was significant volumetric deformation. However, this is not a monotonic loading process, there are lots of unloading and reloading process occurred in the post-peak region. On the other hand, the same thing also happened with the black shale sample as shown in Figure 4.13. There was not only the unloading and reloading process which occurred in the post-failure region, but also there was localized failure generated at the top of the specimen while the bottom portion remained intact. This localized failure debris may concentrate around the chain extensometer and suddenly increase the lateral deformation. Under such circumstances, we can clearly observe that lateral strain control can provide some local confinement, which may be assumed as residual strength of the material.
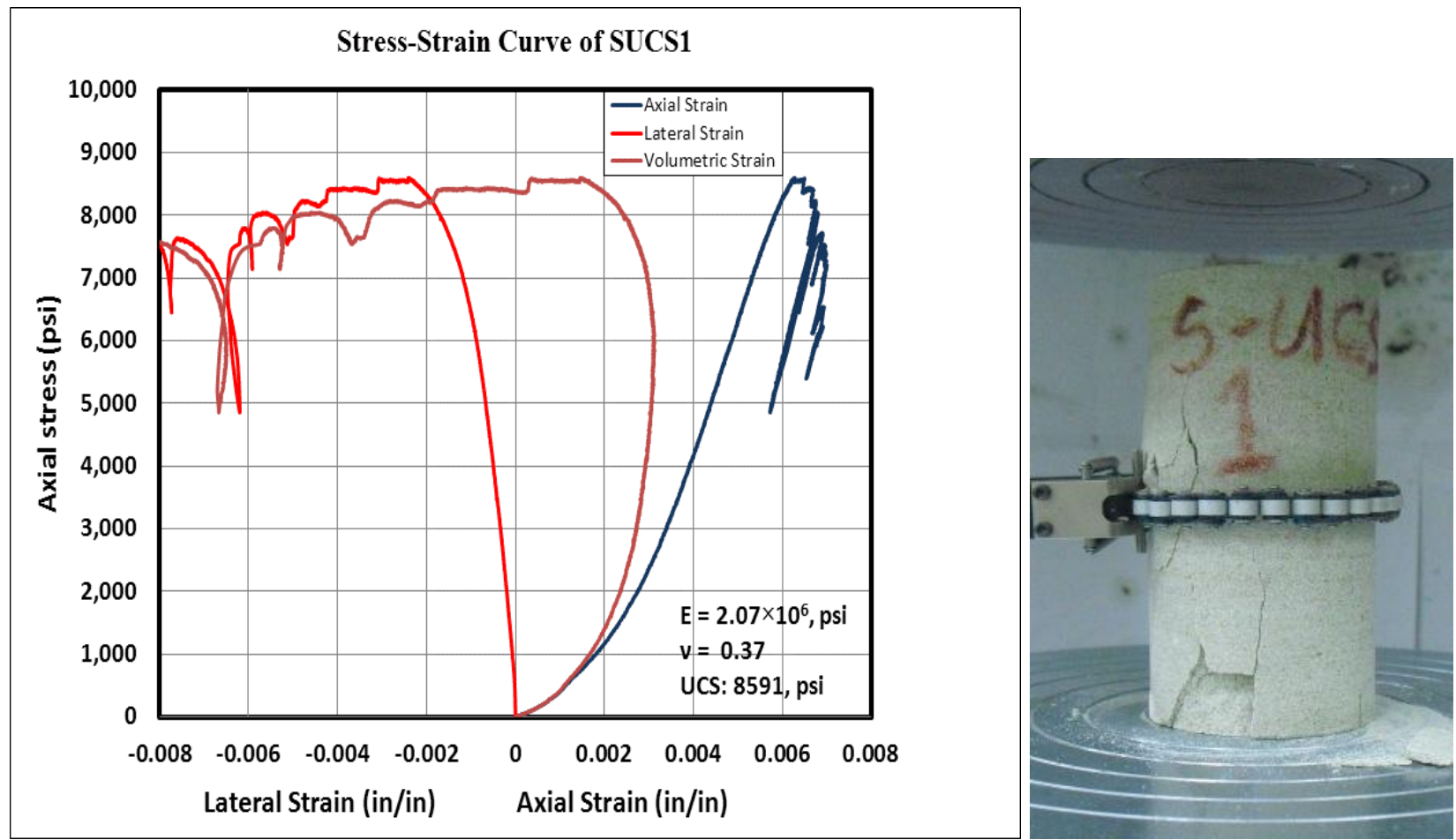

Figure 4.12. Class I failure behavior curves of different rock samples tested under lateral strain control (Berea Sandstone). 

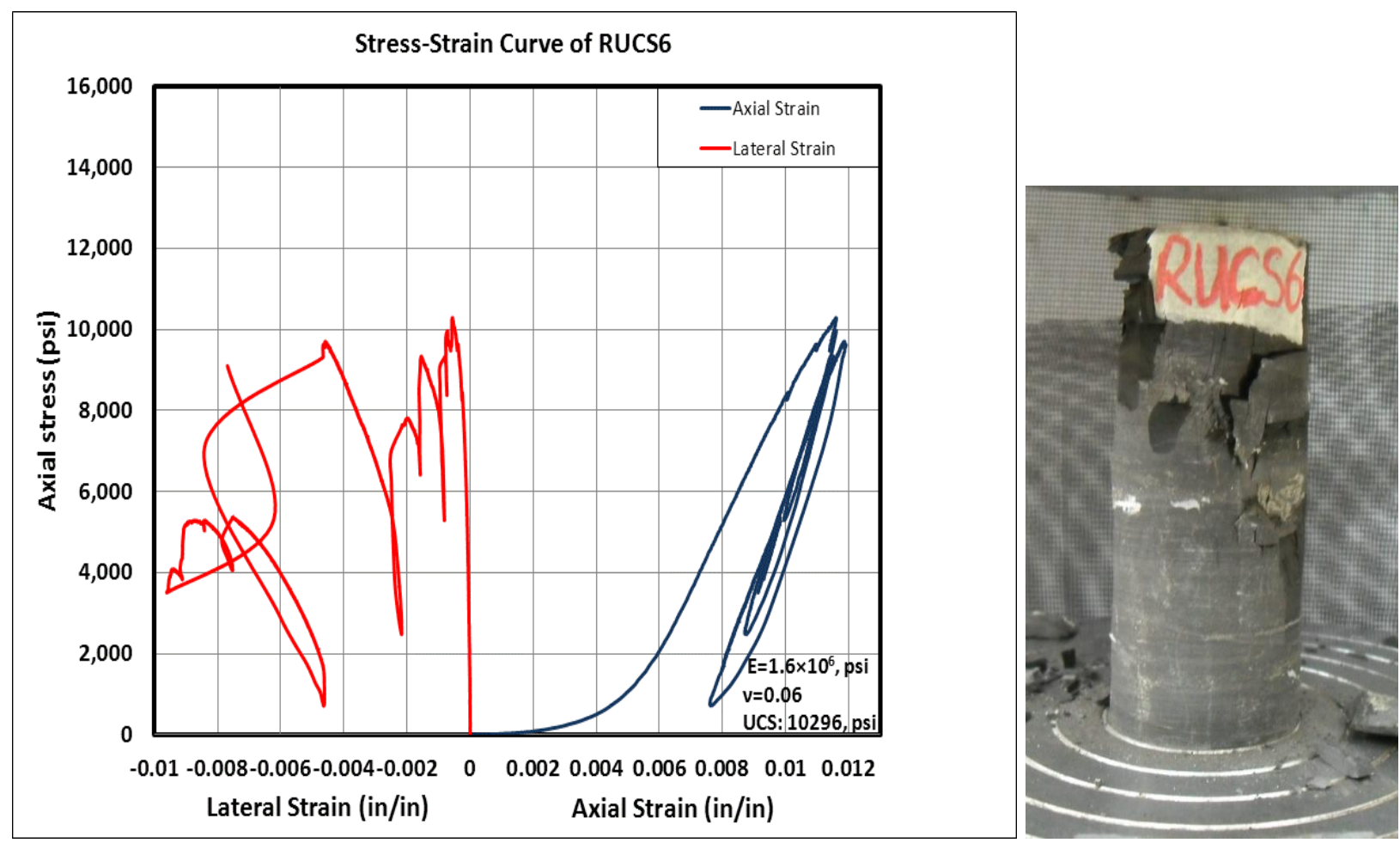

\section{Figure 4.13. Class II failure behavior curve of different rock samples tested under lateral strain control (Black Shale).}

Figure 4.14 is the stress-strain curves of coal specimens from Pittsburgh seam tested under lateral strain control mode at the same loading rate. Different from the rock samples tested under lateral strain control, all coal specimens behave Class II manner under this control mode. This is probably because of the brittleness of the coal material and the instant formation of the cracks, which may cause the servo-controlled system cannot react quickly enough to control the cracks. Therefore, the unstable failure, unloading and reloading happened in the post-peak region. As observed in the post-peak region of Figure 4.14 that there are many 'ups and downs' and with instantaneous drop in load at certain points in the post failure region. This is due to the crack development in the rock sample. As the load is further increased these crack will join to form fractures which will propagate throughout the specimen. As the lateral strain rate is maintained at a rate of $0.0001 \mathrm{in} / \mathrm{sec}$, this in turn controls the machine actuator. Therefore, the load will have to rise again to keep that value, that is why we see the 'ups' accordingly in those curves. 

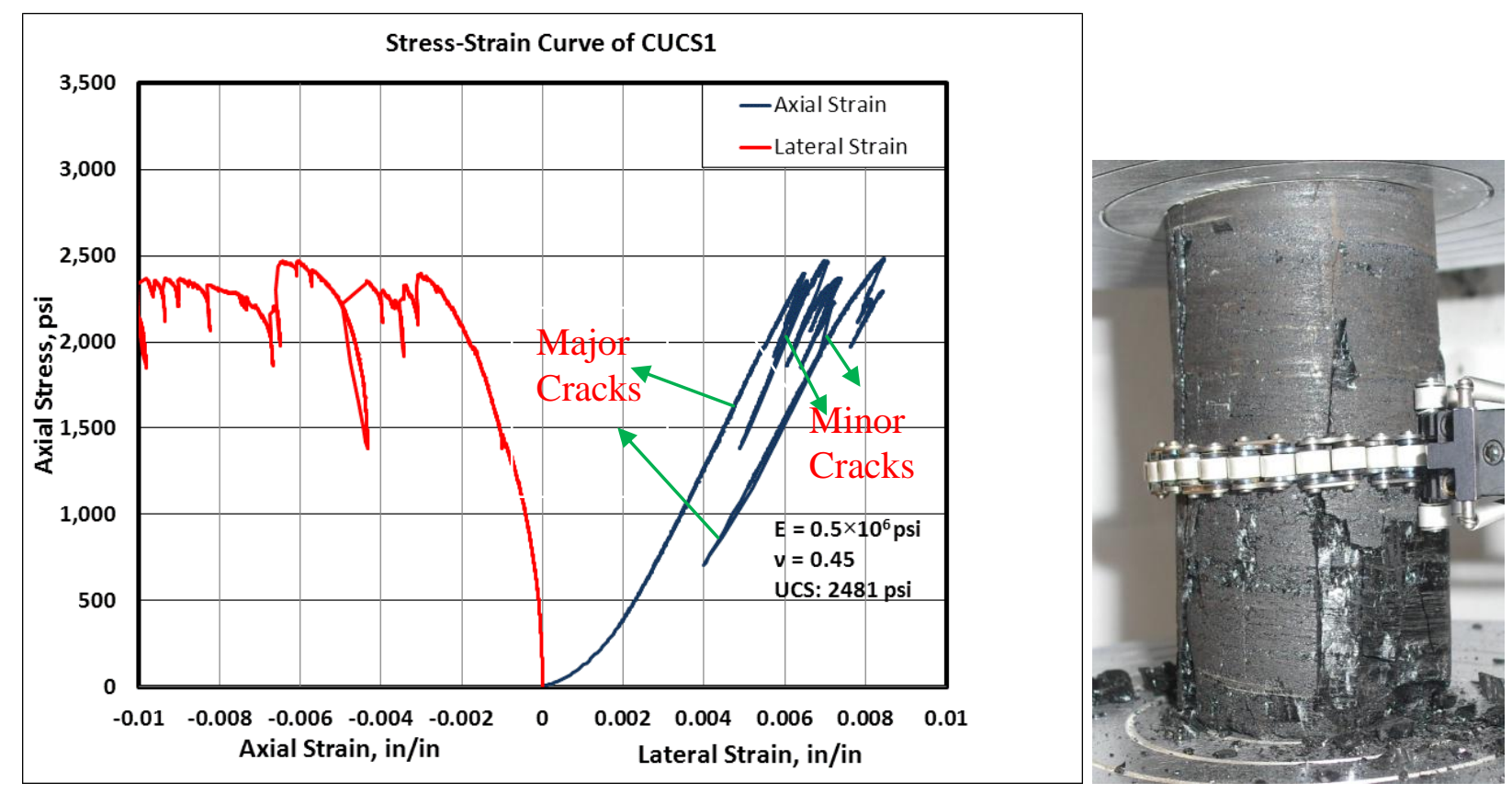

\section{Figure 4.14. Class II failure behavior of coal samples from different seams tested under lateral strain control and the failed specimens (Pittsburgh coal seam).}

Therefore, the tested specimen will have to experience many axial unloading and reloading process under lateral strain control, which means that the specimen is not failed in a continuous loading process. As Hudson (1972) pointed out that "the complete stress-strain curve for Class II situation, the locus must be found by cycling the load, because in this case the failure process is selfsustaining, even in an 'infinitely' stiff testing machine". But this control variable serves as the most sensitive means of detecting specimen failure since the formation of cracks at failure causes more lateral strain than axial displacement (Frederick A. B., 1986). Moreover, this is the only practical method for testing the Class II type of specimens without leading to a violent and unstable failure process, and this is also a good control mode for studying the residual strength characteristics of the underground coal pillars, since all specimen tested under this mode showed clear residual stress.

Axial strain control, as discussed in the last chapter, is the most widely employed control variable for determining the ultimate strength and the post-failure behaviors since a stable and controllable post-failure curve can be acquired under this mode in most cases and it has been 
successfully used in the past for detailed studies and analysis of rock failure. However, as indicated in Figure 4.15 that once the peak strength of the rock specimen is reached at point $\mathrm{B}$, a small fracture is formed at and the load slowly drops to point $\mathrm{C}$, the axial load then decreased all the way from point $\mathrm{C}$ to $\mathrm{D}$ catastrophically. Also, it is not so sensitive as lateral strain control in detecting the specimen failure process because axial strain are relatively insignificant in the initial crack formations. In addition, there will be no Class II behavior acquired under this control variable.
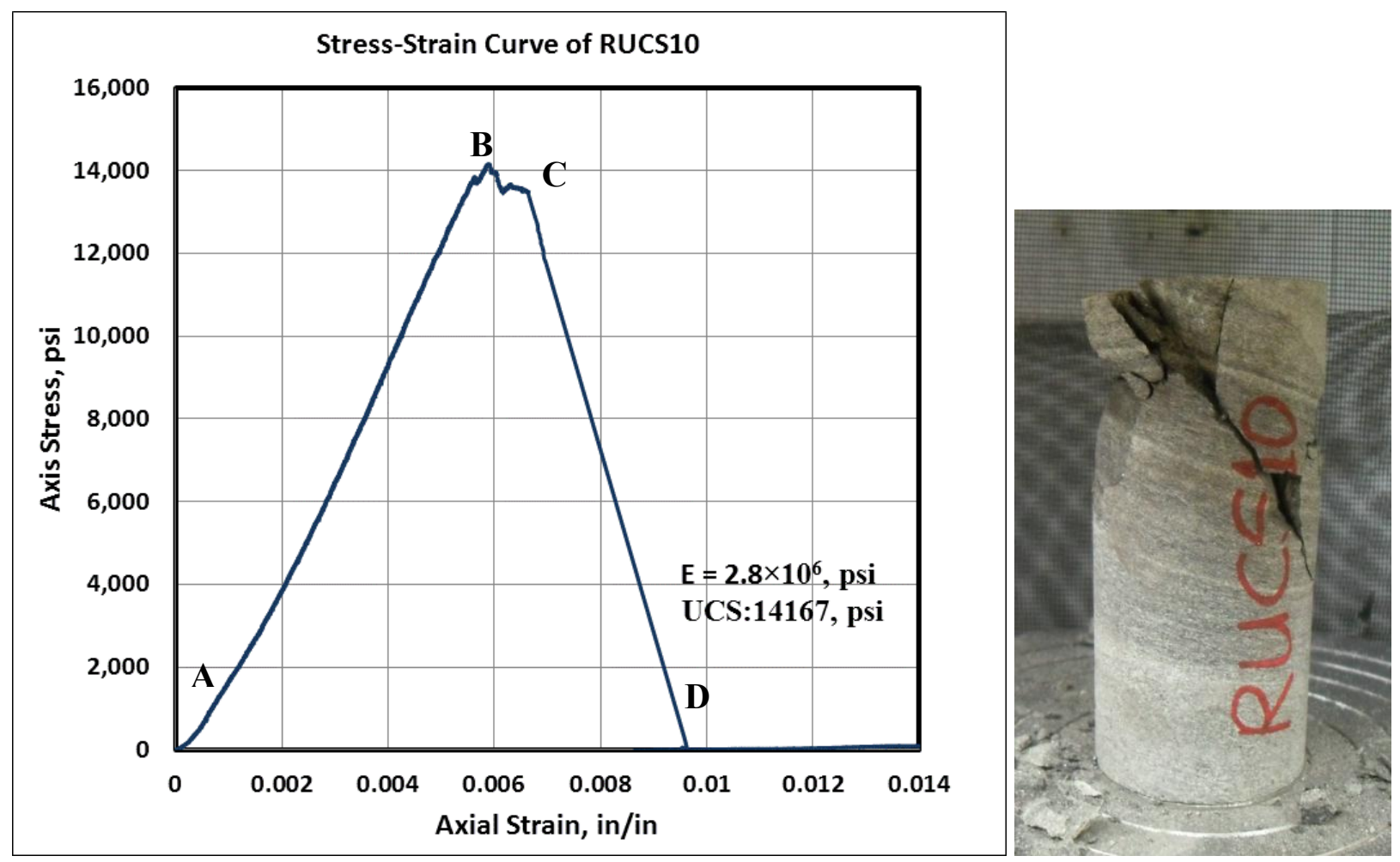

Figure 4.15. Stress-strain curves of sandstone and Pittsburgh seam coal tested under axial strain control and the failed specimens.

Under the traditional triaxial testing conditions, the lateral deformation is small and stable because of the confining pressure. Therefore, there will not be many unloading and reloading processes under lateral strain control in the triaxial testing condition. As indicated in Figure 4.16 that both the axial and lateral deformation are very stable due to the applied confining pressure, and there 
is no unloading and reloading process in the post-peak region and most importantly, it is very stable and controllable that the axial stress is reducing along with the constant increase of the lateral deformation. Therefore, in order to obtain the complete and smooth stress-strain curve, it is better to use the triaxial compression test with low confining pressure under lateral strain control.
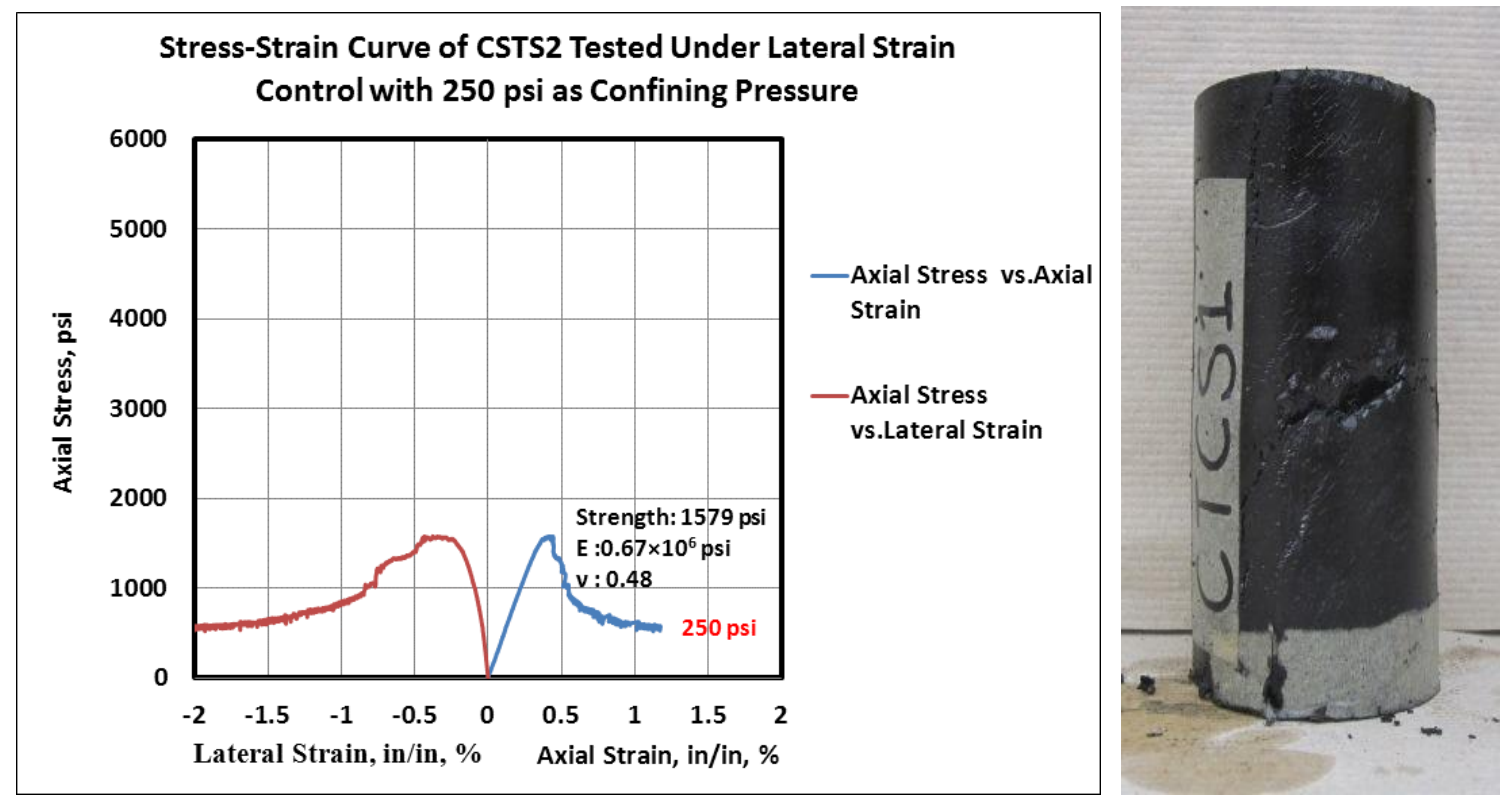

Figure 4.16. Stress-strain curve of the Utah coal specimen under low confining pressure 


\section{CHAPTER 5 CONCLUSIONS}

The methodology adopted for the forty four experimental tests on both rocks and coal used in this thesis were used to explore the best control mode in studying the post-failure behaviors of coal and rocks and also how those samples behave under different proposed control variables. These tests provided new insight into the pillar failure mechanism which is commonly termed as coal mine bumps. Three different control variables (load control, axial strain control, and lateral strain control) were adopted to evaluate the post-peak deformation behavior of both coal and rocks. Based on discussions in the previous sections, the followings are the conclusions:

- Feedback control variable significantly affected the post-failure behavior of the rock. Load control feedback, although is an universally adopted strength test control mode, however, in rock mechanics strain control should be universally used for producing correct behavior of the rock.

- Axial strain control, on the other hand, is the most widely used control variable for most of the numerical modelers for determining the mechanical properties and behavior of coal and rocks. Despite the cases where the residual strength characteristics were required.

- Lateral strain control provided the best post failure behavior of the rock. It has the following features which will help to provide a better post failure behavior (1) Samples do not fail quickly and abruptly, that is, not in an explosive and violent manner, which is much more safer for the controllers; (2) there are many 'ups and downs' and occasionally few large decrease in the post-failure region. This is because the cracks formed (usually they are the localized cracks, big or small), and the tested specimen experienced many cycling loading process, which suggests that the specimen may not fail in a continuous loading process; (3) At the time that the test automatically terminates, most sample show residual strength which is similar to field observations. For rocks tested, this value accounts for $34 \%-86 \%$ of their ultimate strength while it takes for $27 \%-90 \%$ of the corresponding ultimate strength as for 
coal samples tested in this experiment. (4) Both Class II (grey shale, black shale and all coal specimens tested) and Class I (the remaining 4 rocks) type of behavior was obtained using this control mode.

Also lateral strain control can be used under triaxial stress conditions to obtain the complete and smooth stress-strain curves of the axial deformation process of a specimen, a triaxial compression test under lateral strain control with low confining pressure is recommended. The applied confining pressure should be based on a standard that there will be not tensile fractures produced in the axial deformation, it is usually below 750 psi.

For even the same type of rock (i.e. grey shale or black shale), different failure classification type can be achieved if tested under different control modes.

When the entries are developed, the induced stresses are automatically transferred to the supported pillars both axially and laterally. Wagner (1980) suggested in a detailed study of coal pillar failure process that the failure begins at the circumference of the pillar and moves into the center. He also observed from this study that the central part (cores) of the pillar did not reach the maximum strength yet at the time, the whole pillar fails. Similar result was obtained in the laboratory when a coal specimen was tested under lateral strain control mode. It was observed that when the failure process of the specimen was progressively advancing, fragments were being ejected in all the directions. This was because of the transfer of the strain energy into kinetic energy. When the maximum preset strain was attained the coal sample continued to show residual strength.

This behavior using lateral strain control showed a unique characteristic which can provide further insight into the catastrophic pillar collapse, commonly known in mining community as bumps. If we assume a large pillar with cylindrical core at the center, then the surrounding material will provide confinement to the core. As the load on the pillar increases, this confinement will decrease, however the load transfer to the core will depend on the external material. Also the constraint along the diametrical direction controls the amount of load to be applied to the pillar. When the confining 
material around the pillar collapses, there is a sudden transfer of load on to the center of the core and thus it fails. This behavior is similar to the lateral strain control behavior in the laboratory. 


\section{REFERENCES}

1. Brady, B.H.G., and Brown, E.T.,1993, Rock Mechanics for Underground Mining, $2^{\text {nd }}$ edition, Printed in Great Britain by the Alden Group, Oxford.

2. Cai M.F.,2002, Rock Mechanics and Engineering. Science Press, Beijing, China. (In Chinese)

3. Fairhurst, C.E., and Hudson J.A.,1999, "Draft ISRM suggested method for the complete stress-strain curve for intact rock in uniaxial compression," International Journal of Rock Mechanics and Mining Science, 36, pp. 279-289.

4. Rummel, F., and Fairhurst, C.,1970, "Determination of the Post-failure behavior of brittle rock using a servo-controlled testing machine,” Rock Mechanics, 2, pp. 189-204.

5. Frederic A.B.,1986, "Recent developments in the application of closed loop servohydraulic control technology to post failure testing of uniaxially loaded cylindrical rock specimens," MTS Systems Corporation. Federal Republic of Germany.

6. GCTS 2010 Catalog.

7. Nagraja Rao, G.M., Udayakumar, S., Raju, D., and Jennifer, P.D.,2010, "Post-failure deformation behavior of coal and rocks," National Institute of Rock mechanics, Kolar Gold Fields-563 117, Karnataka, India.

8. Wagner, H., and Eng. D. (Member),1980, "Pillar design in coal mines," Journal of the South African Institute of Mining and Metallurgy.

9. He, C., Okubo, S., and Nishimatsu, Y.,1990, "A study on the Class II behavior of rock," Rock Mech. Rock Eng., 23, pp. 261-273.

10. Hiroyuki, S., Tomofumi, K., and Tsuyoshi, I.,2010, "Distinct element analysis for Class II behavior of rocks under uniaxial compression," Int. J. Rock Meth. Min. Sci., 47, pp. $323-$ 
333.

11. Husdon, J.A., Crouch, S.L., and Fairhurst, C.,1972, "Soft, Stiff and Servo-controlled Testing Machines: A Review with Reference to Rock Failure,” Engineering Geology, 6, pp. $155-189$.

12. Hudson, J.A. and Harrison, J.P.,1997, Engineering rock mechanics. An introduction to the principles, Tarrytown, NY: Pergamon, pp. 444.

13. You, M.Q.,2007, "Mechanical Properties of Rocks" Geologocal Publishing House, Beijing, China (In Chinese).

14. Kovari, K., Tisa, A., Einstein, H.H., and Franklin, J.A.,1983, "Suggested methods for determining the strength of rock materials in triaxial compression: revised version," Int. $J$. Rock Mech. Min. Sci., 20 (6), pp. 283-290.

15. MTS reference manual.

16. OKUBO, S., and NISHIMATSU, Y.,1985, "Uniaxial compression testing using a linear combination of stress and strain as the control variable," International Journal of Rock mechanics, Vol.22, No.5.

17. Pan, P.Z., Feng, X.T., and Hudson, J.A.,2006, "Numerical simulations of Class I and Class II uniaxial compression curves using an elasto-plastic cellular automation and a linear combination of stress and strain as the control method" International J. of R.M. \& M.S. 43, pp. 1109-1117

18. Peng, S.S.,2008, Coal Mine Ground Control ( $3^{\text {rd }}$ edition), Morgantown, WV: Syd, S. Peng.

19. Simon, R., Aubertin, M., and Deng, D.S.,2003, "Estimation of post-peak behavior of 
brittle rocks using a constitutive model for joint," $56^{\text {th }}$ Canadian Geotechnical Conference. $4^{\text {th }}$ joint IAH-CNC/CGS Conference. 2003 NAGS Conference.

20. Salamon, M.D.G.,1974, "Rock Mechanics of Underground Excavations," Proceedings of the $3^{\text {rd }}$ Congress of the International of Rock Mechanics, Denver, Colorado.

21. Rin, A., and Mohd, A.,2008, "Verification of post failure behavior of rock using closedcircuit servo-controlled testing machine" Geological Society of Malaysia, Bulletin 54, pp $1-4$.

22. Wawersik, W.R.,1968, "Detailed analysis of rock failure in laboratory compression tests" $\mathrm{PhD}$ thesis, University of Minnesota, Minneapolis.

23. Wawersik, W.R. and Fairhurst, C.,1970, "A study of brittle rock fracture in laboratory compression experiments, ” Int. J. Rock Meth. Min. Sci., 7(5), pp. 561-575.

24. Wawersik, W.R., Brace, W.F.,1971, "Post-failure behavior of a granite and diabase". Rock Mechanics Vol. 3(2), pp. 59-85. 


\section{Appendix A: Stress-strain curves of tested rock/coal specimens}

(a) Stress-strain curves of the six rock specimens tested under load control
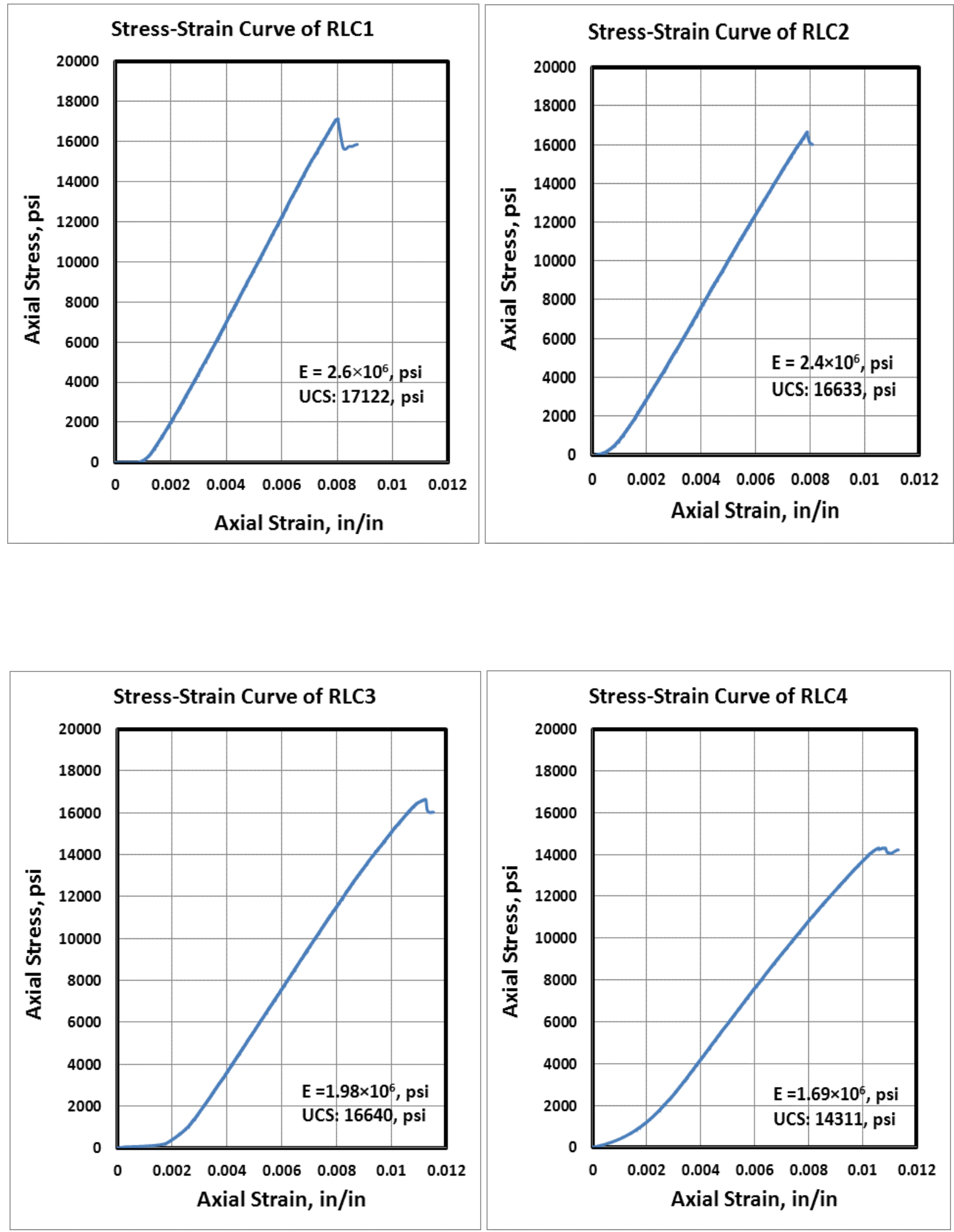

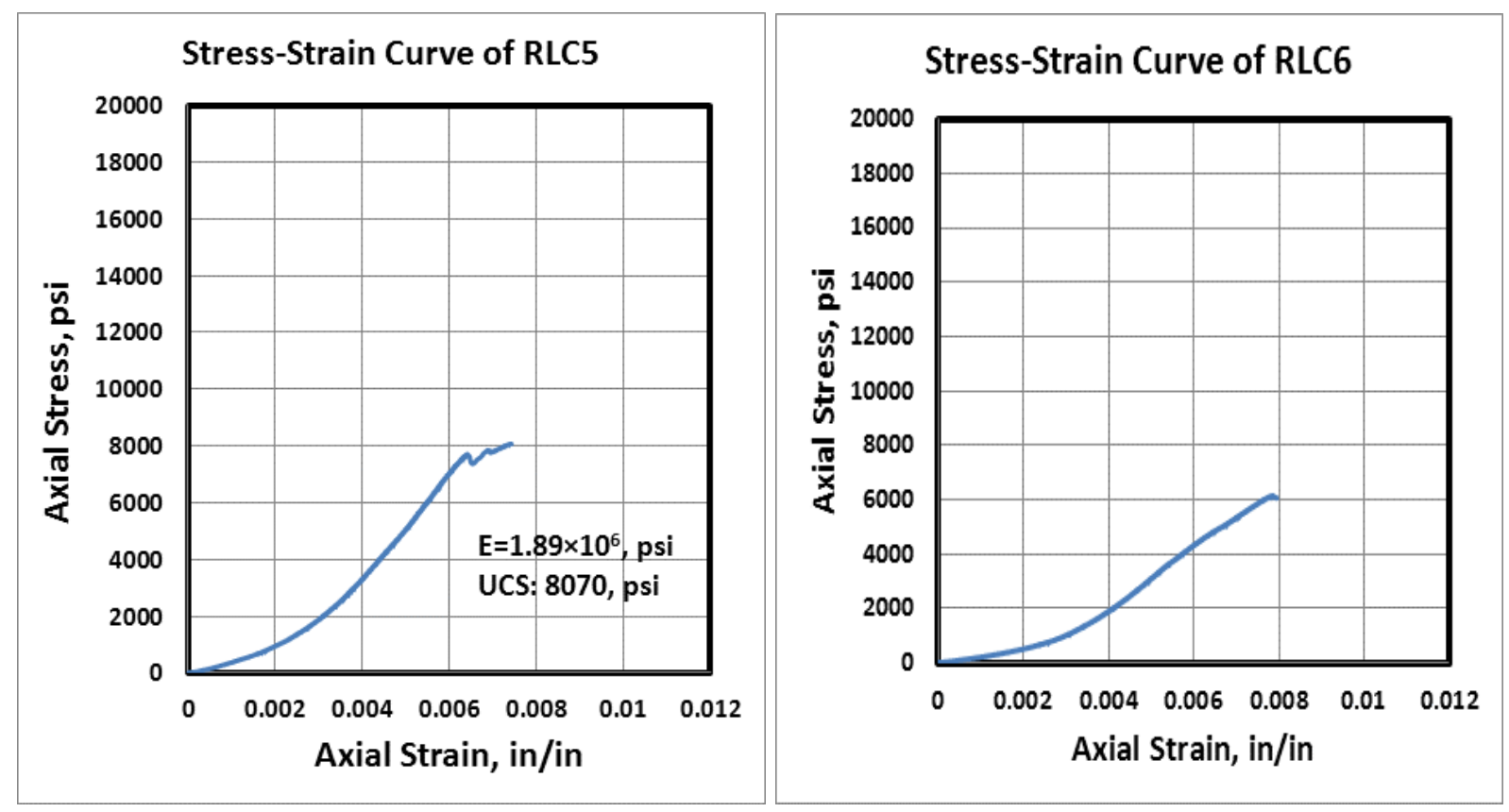
(b) Stress-strain curves of Berea sandstone specimens tested under lateral strain control
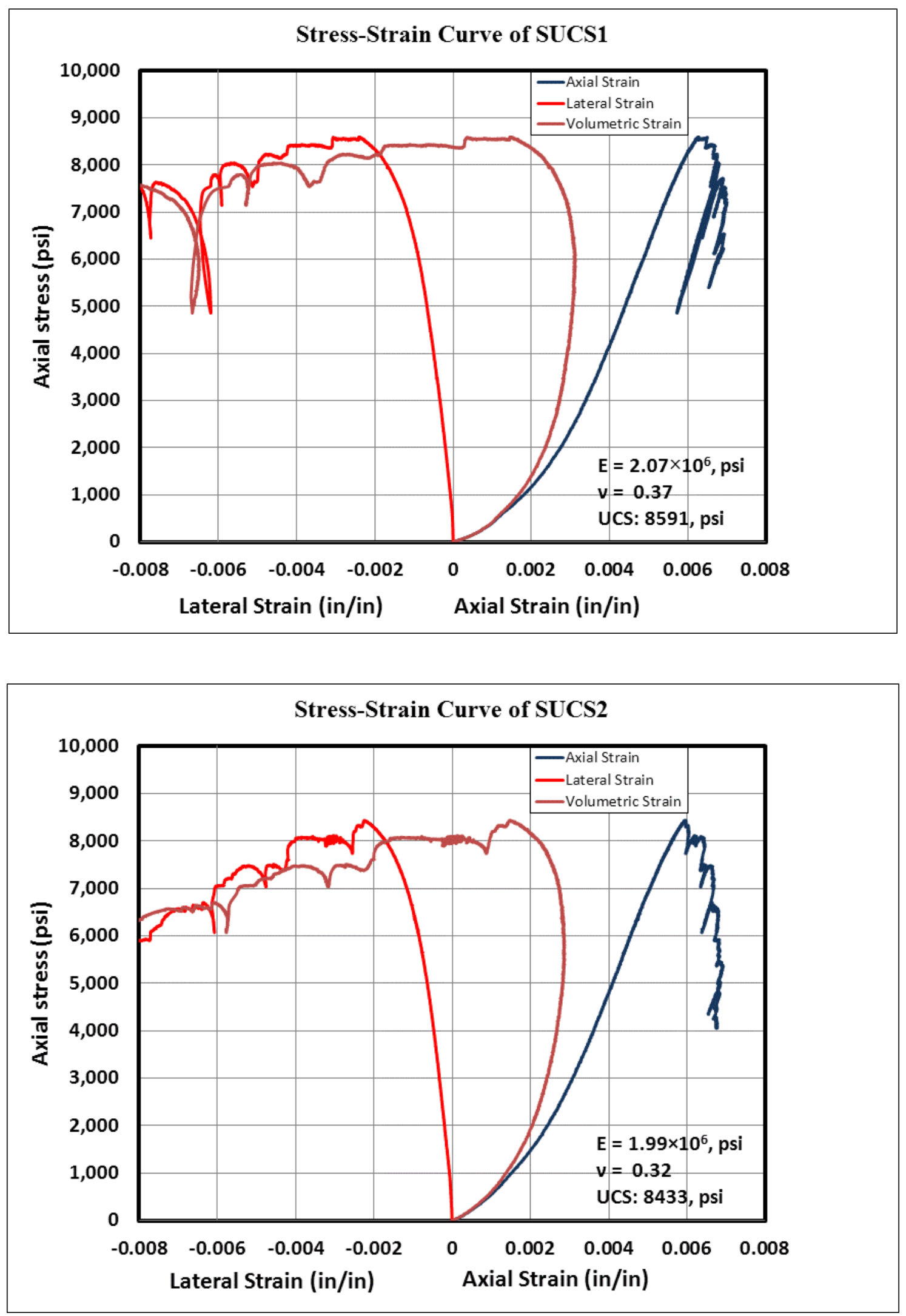

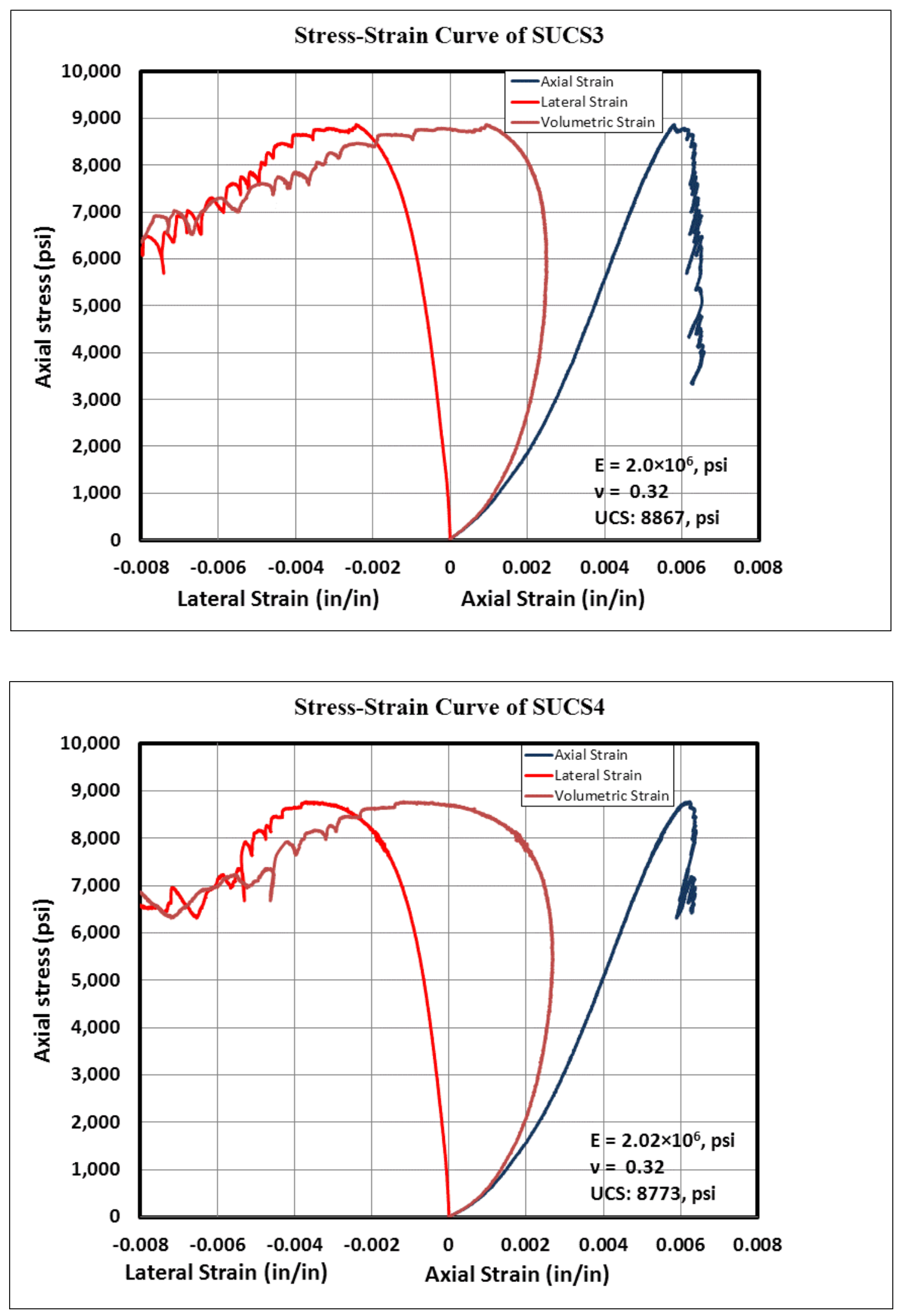

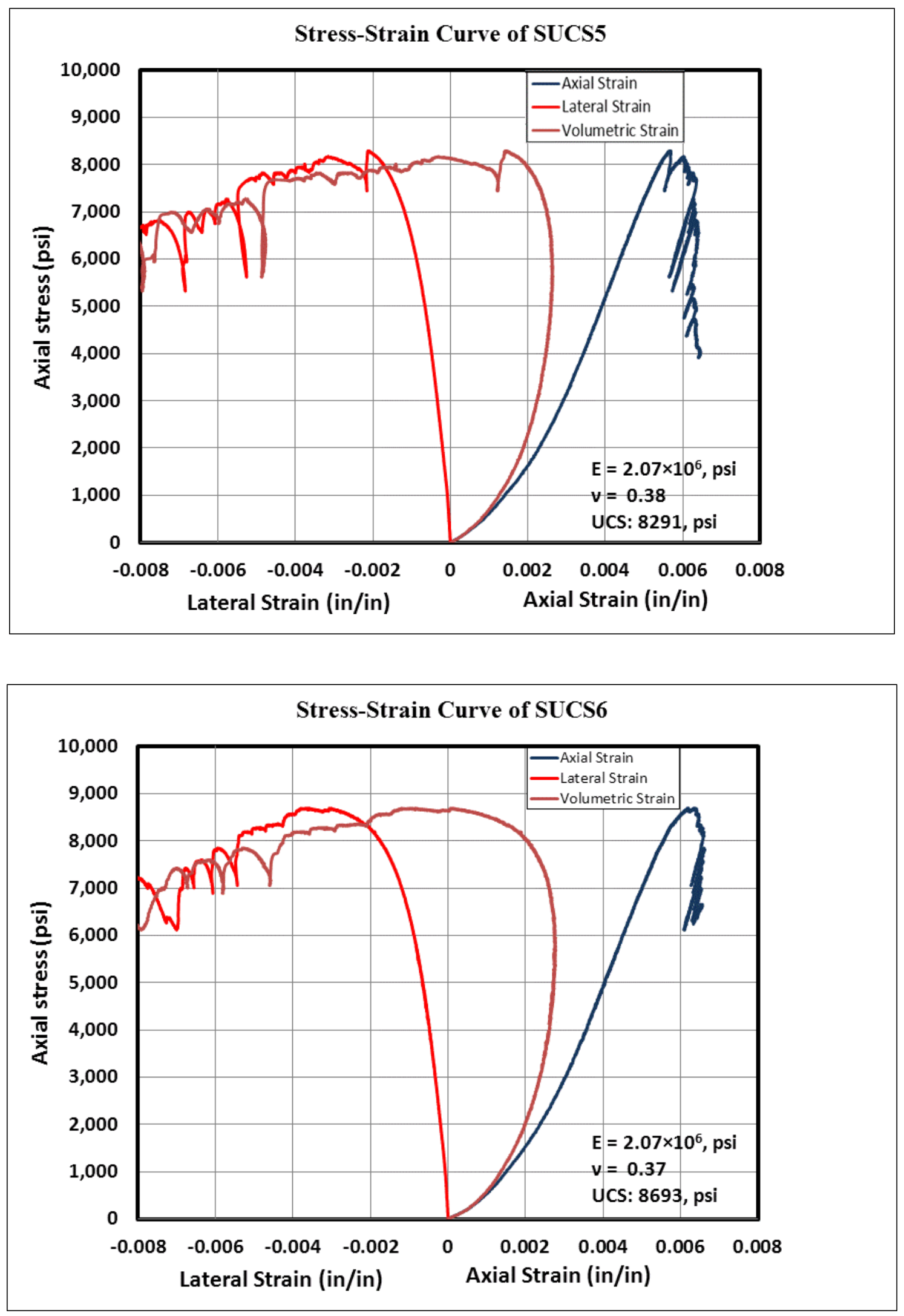
(c) Stress-strain curves of the six different rocks tested under lateral strain control
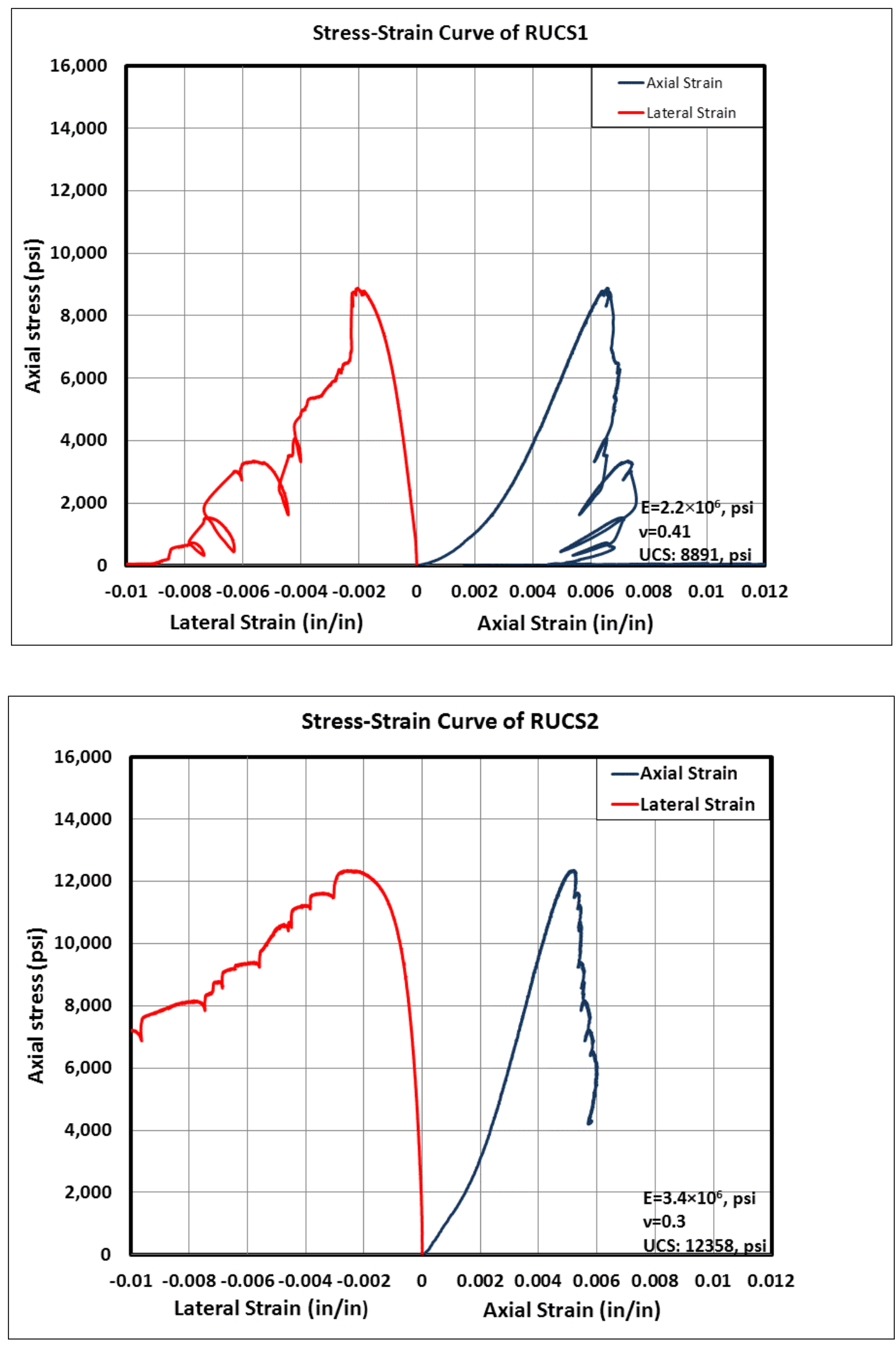

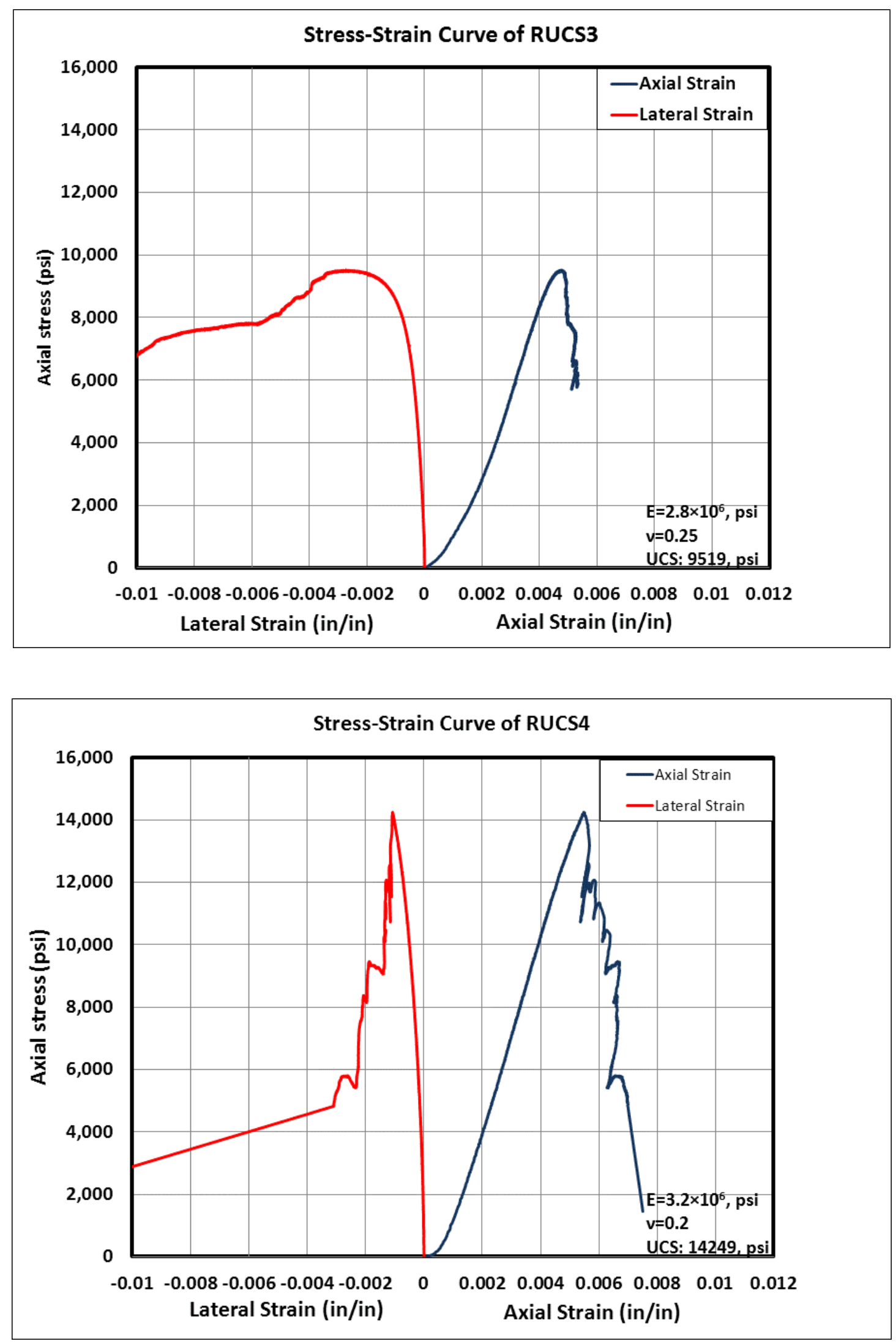

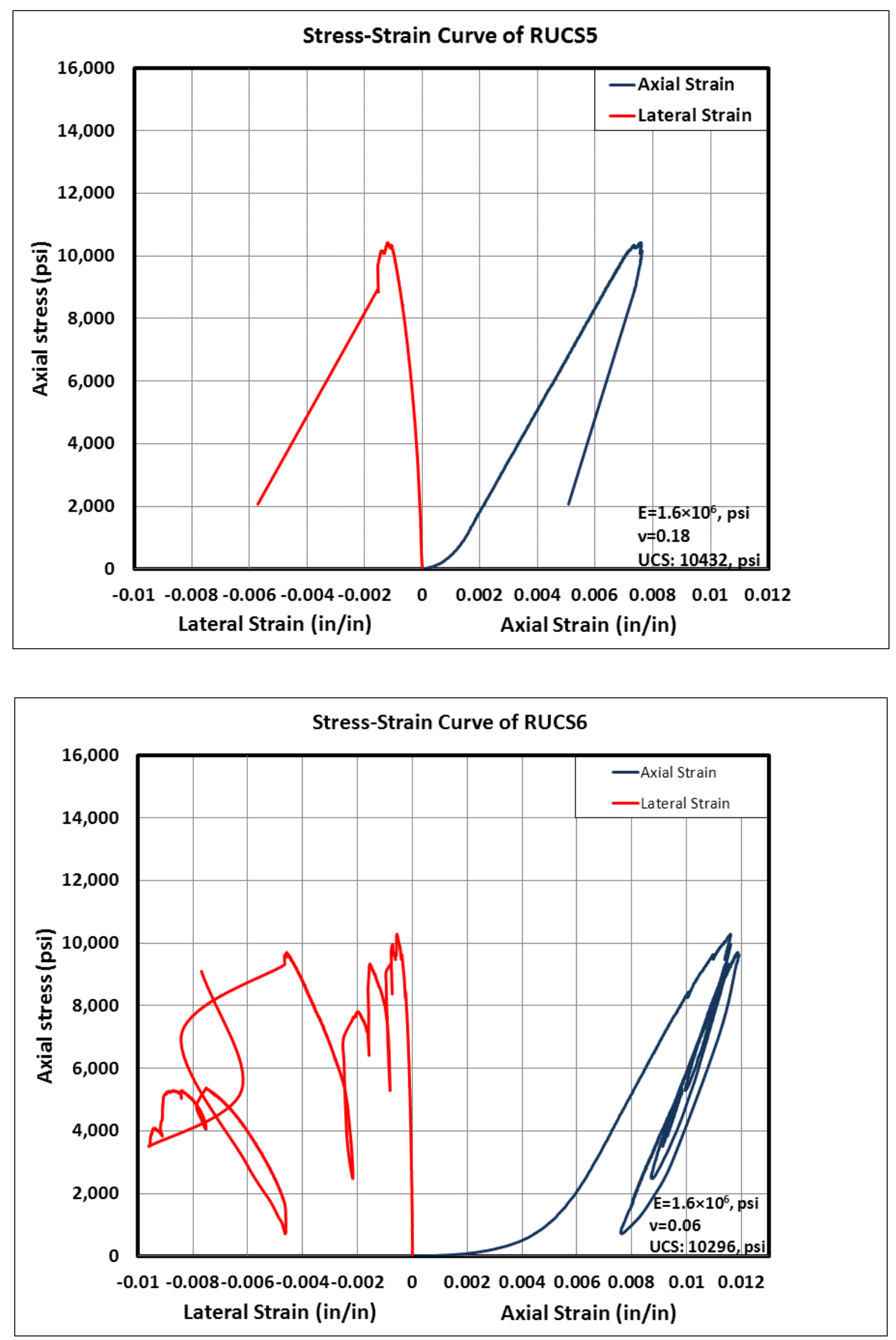
(d)Stress-strain curves of the six different rock specimens tested under axial strain control
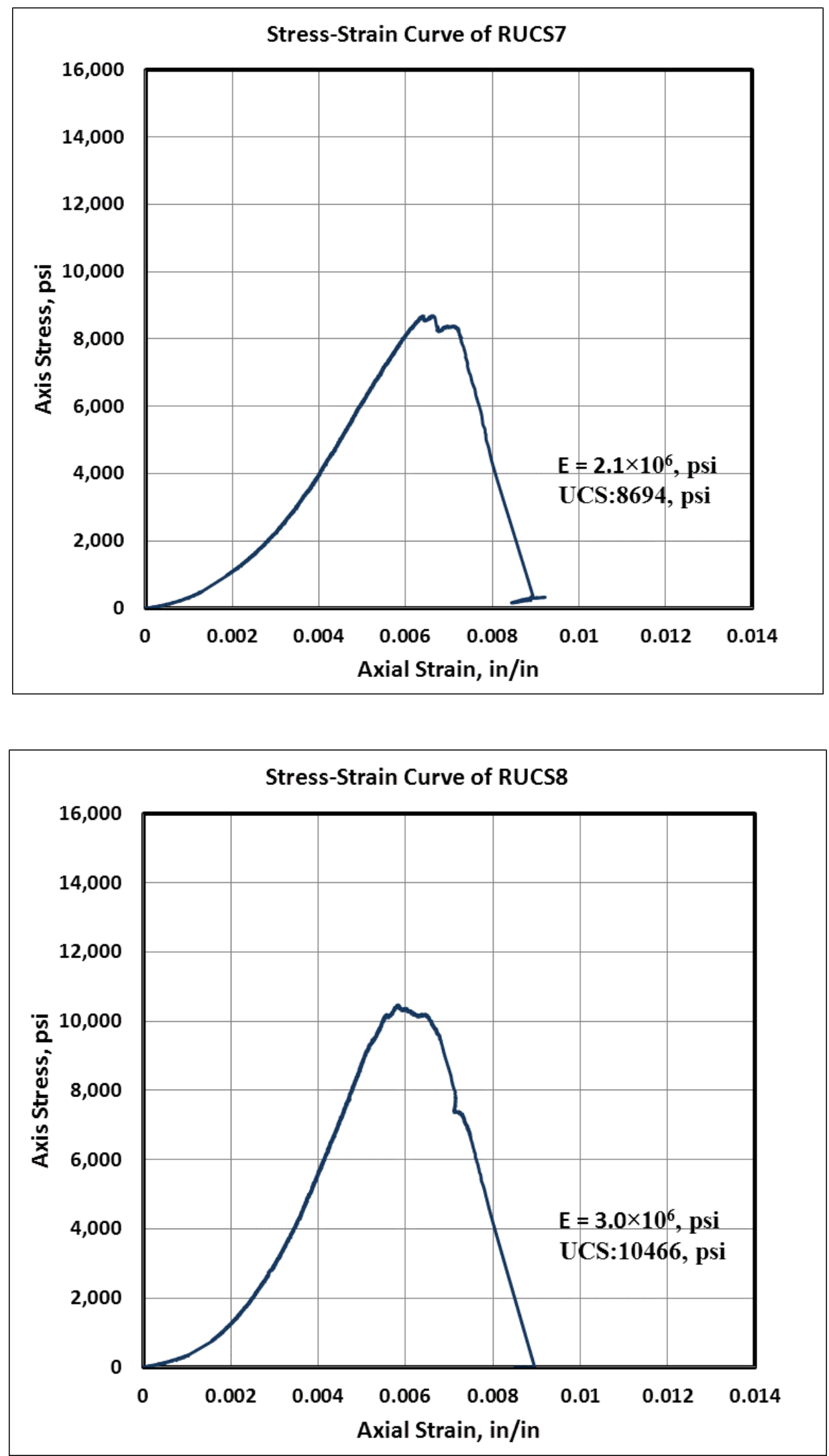

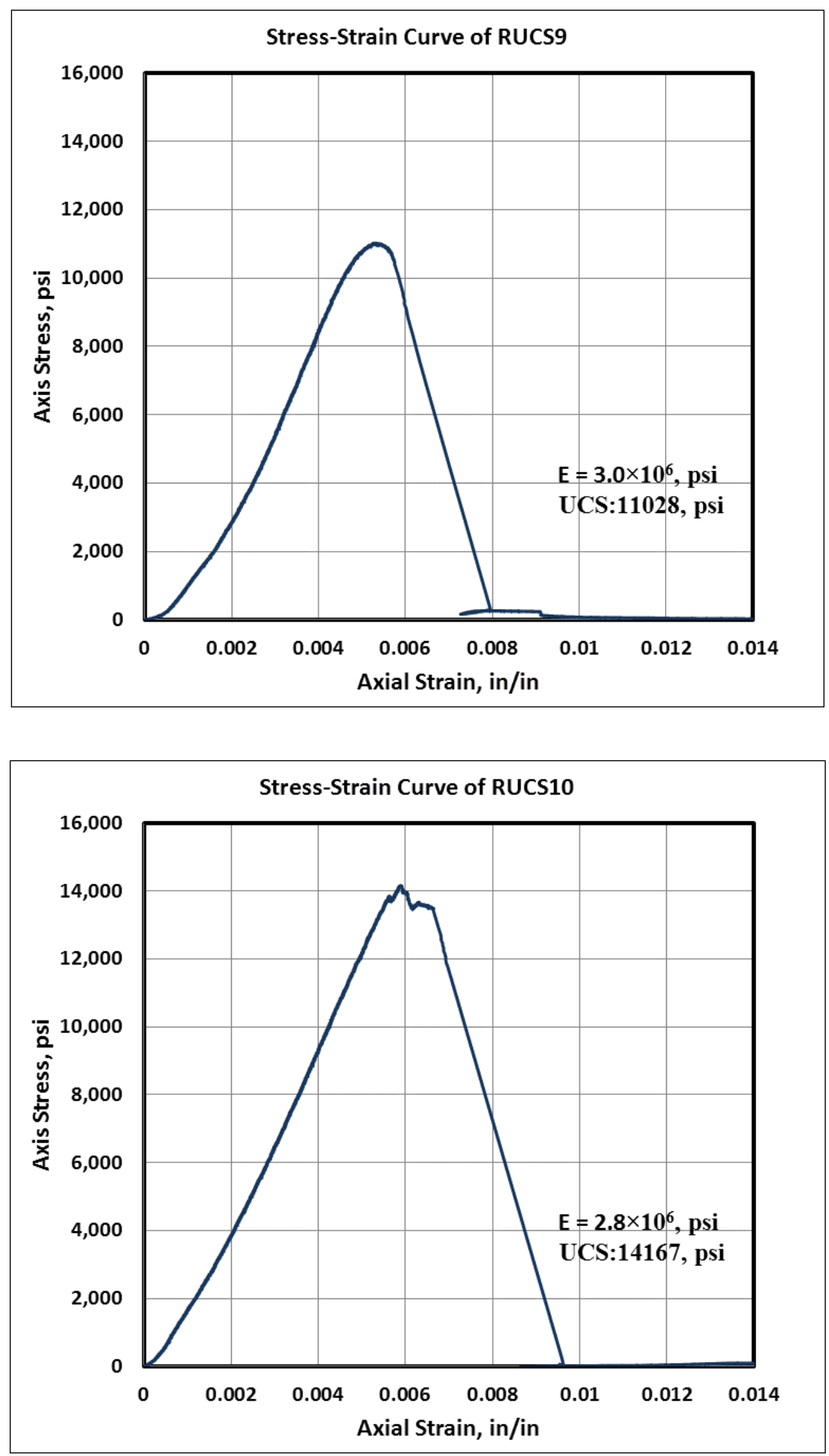

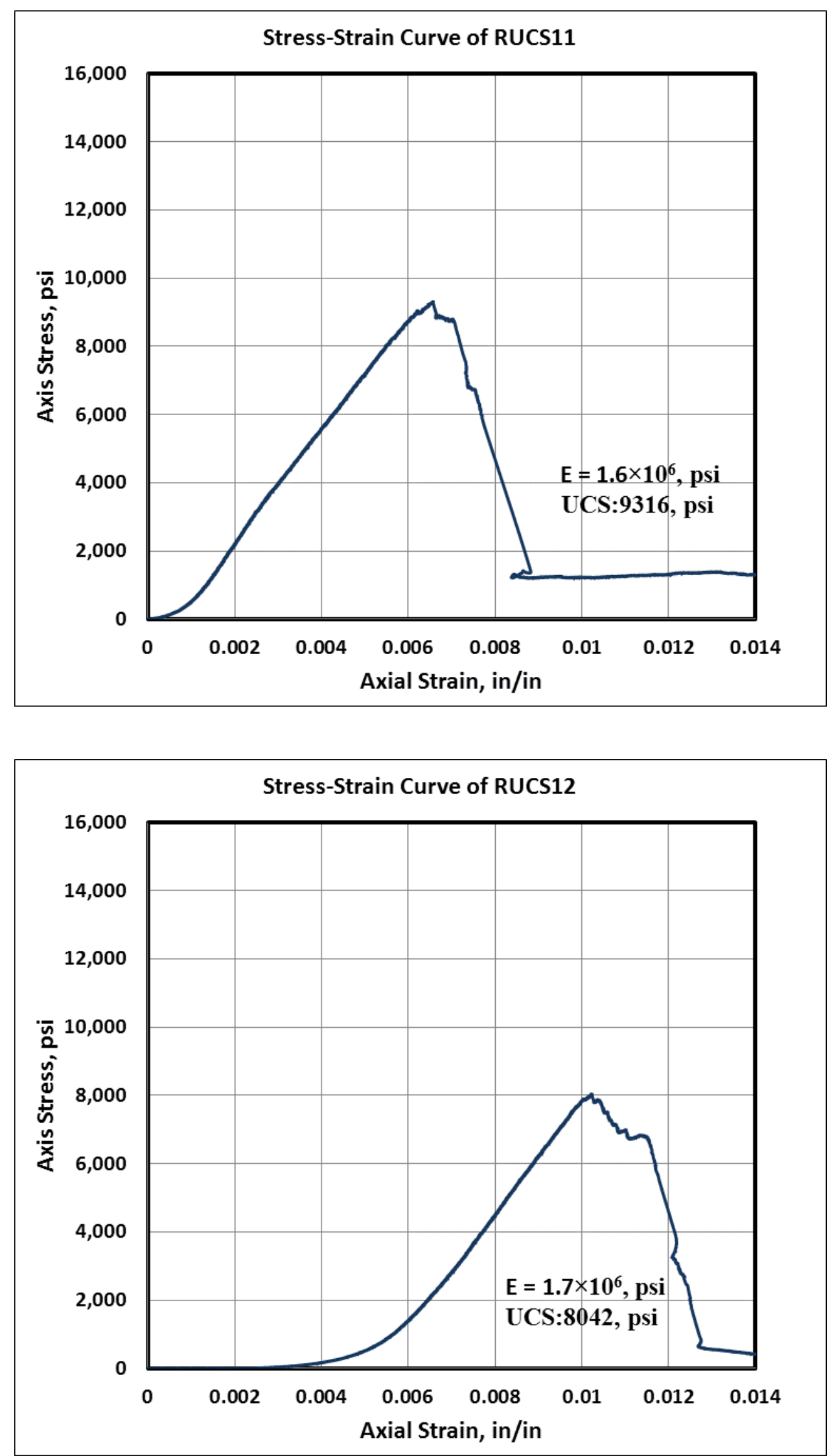
(e) Stress-strain curves of the 6 coal specimens tested under Lateral Strain Control (Pittsburgh Seam)
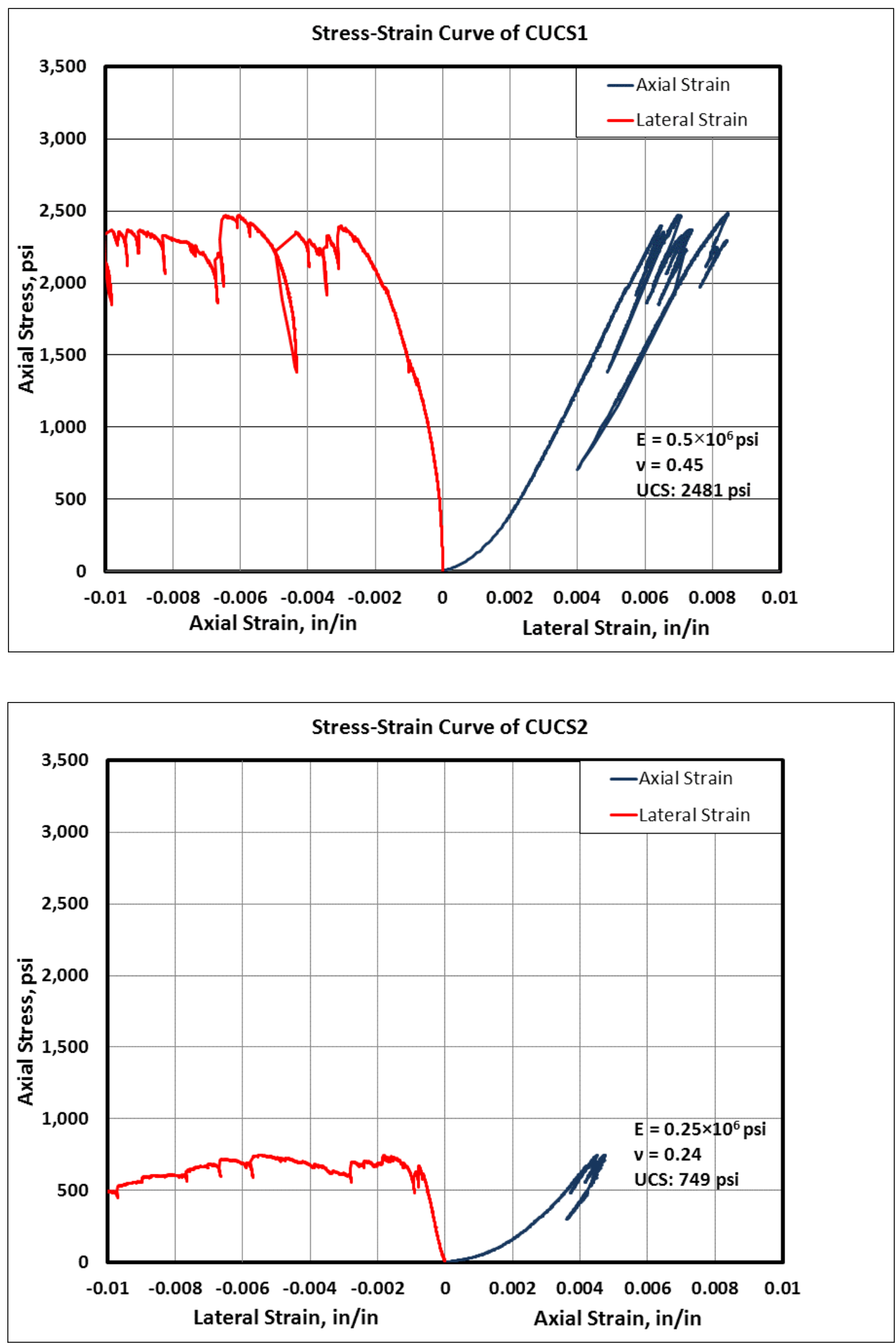

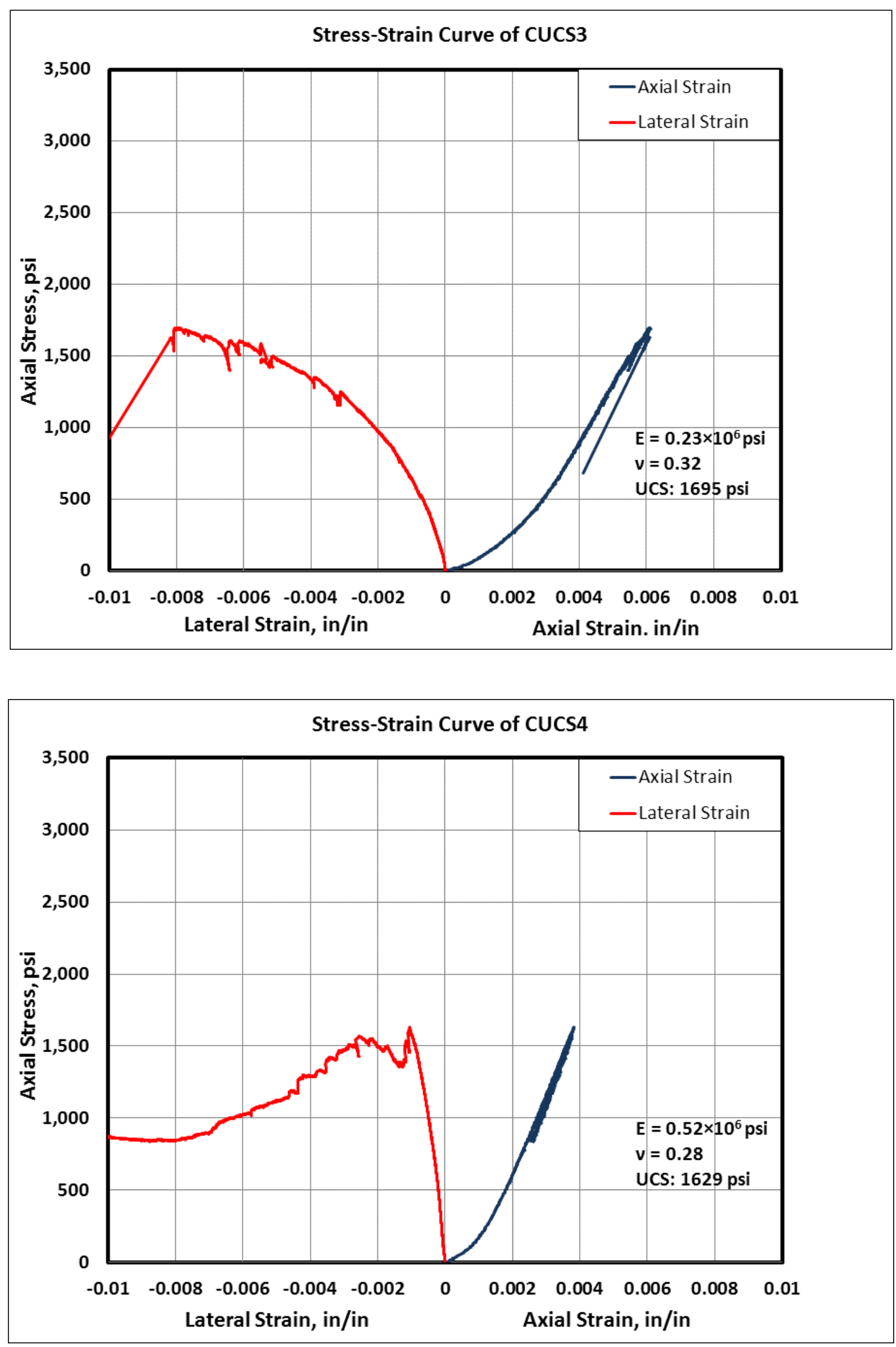

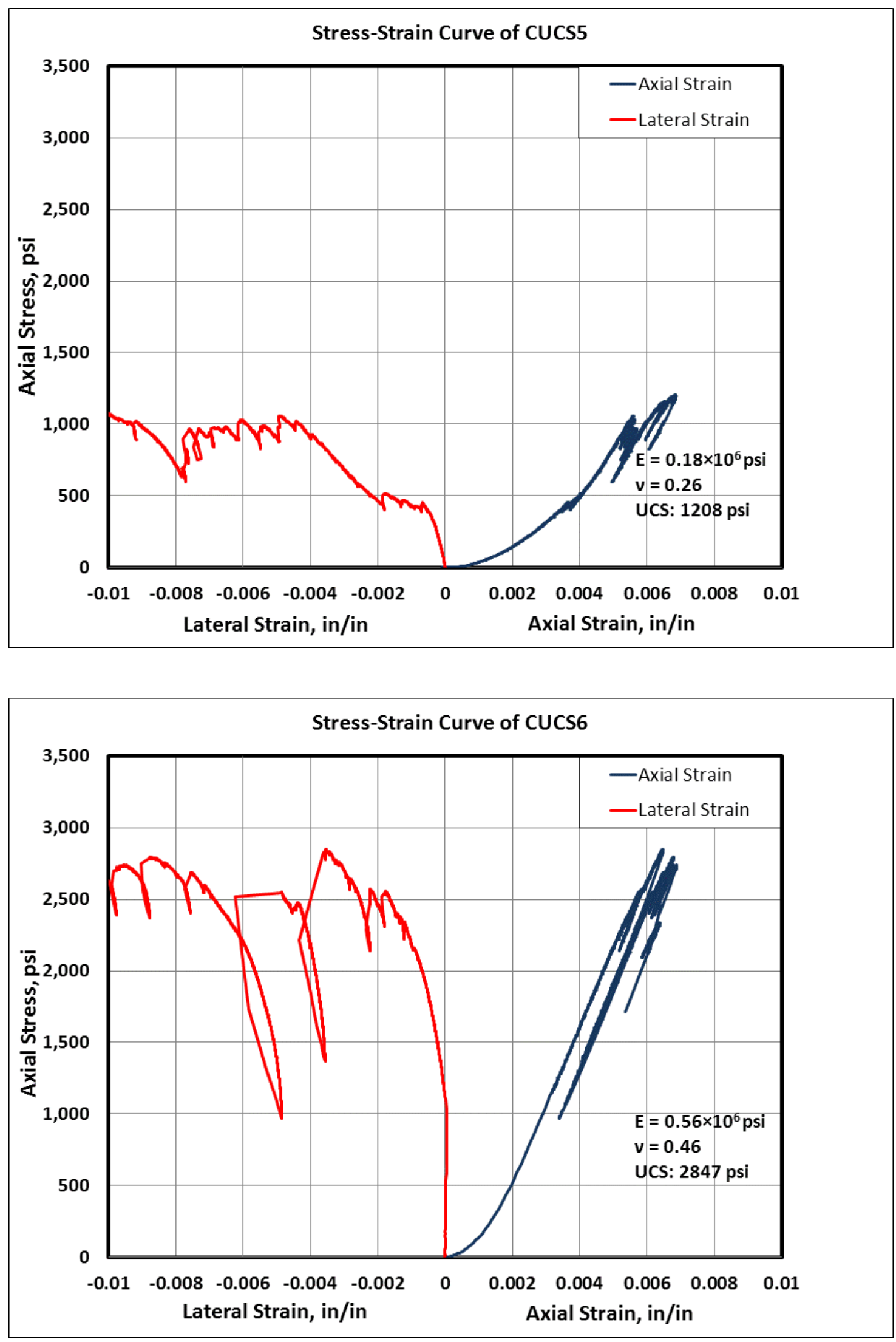
(f) Stress-strain curves of 6 coal specimens tested under Axial Strain Control (Pittsburgh seam)
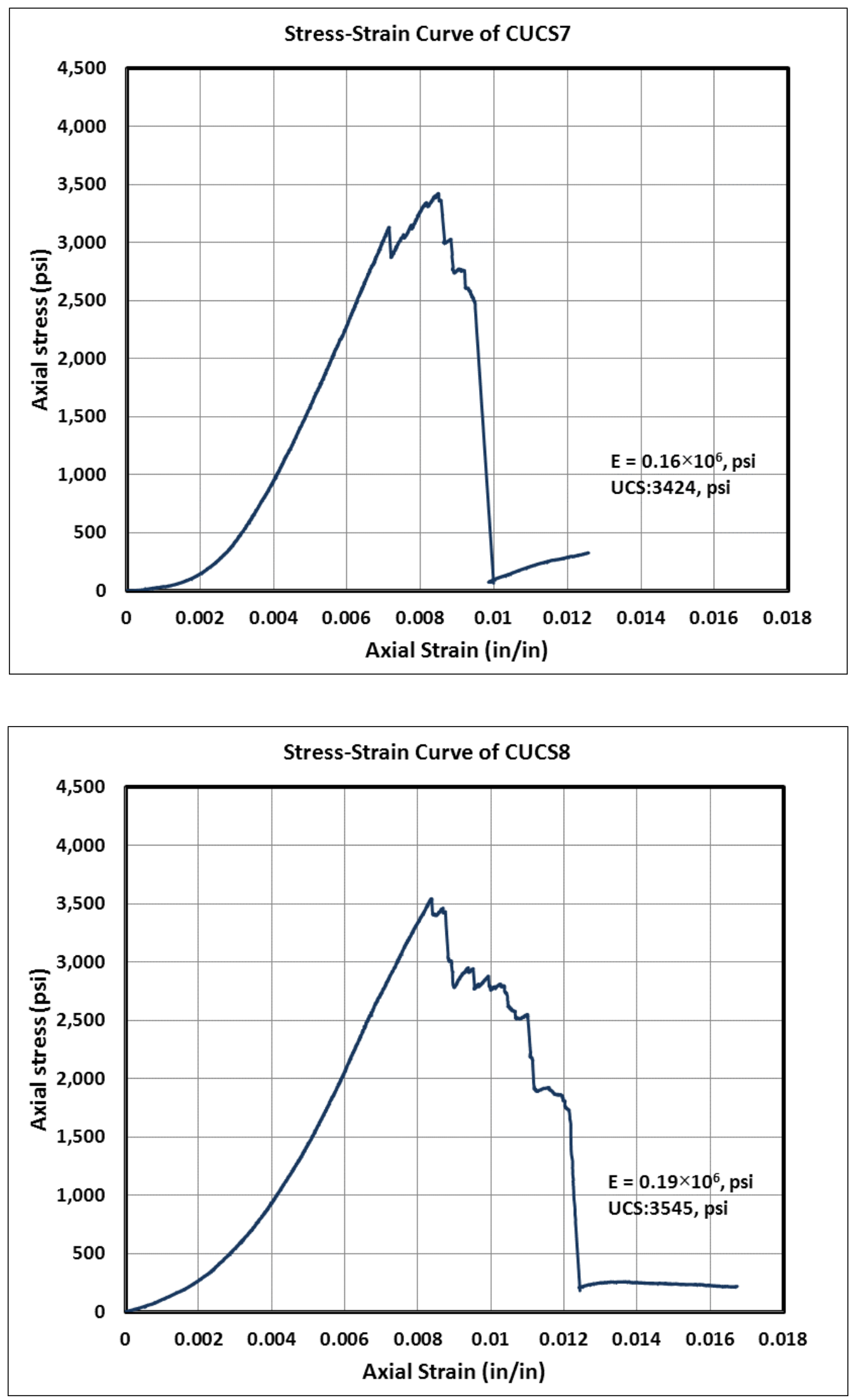

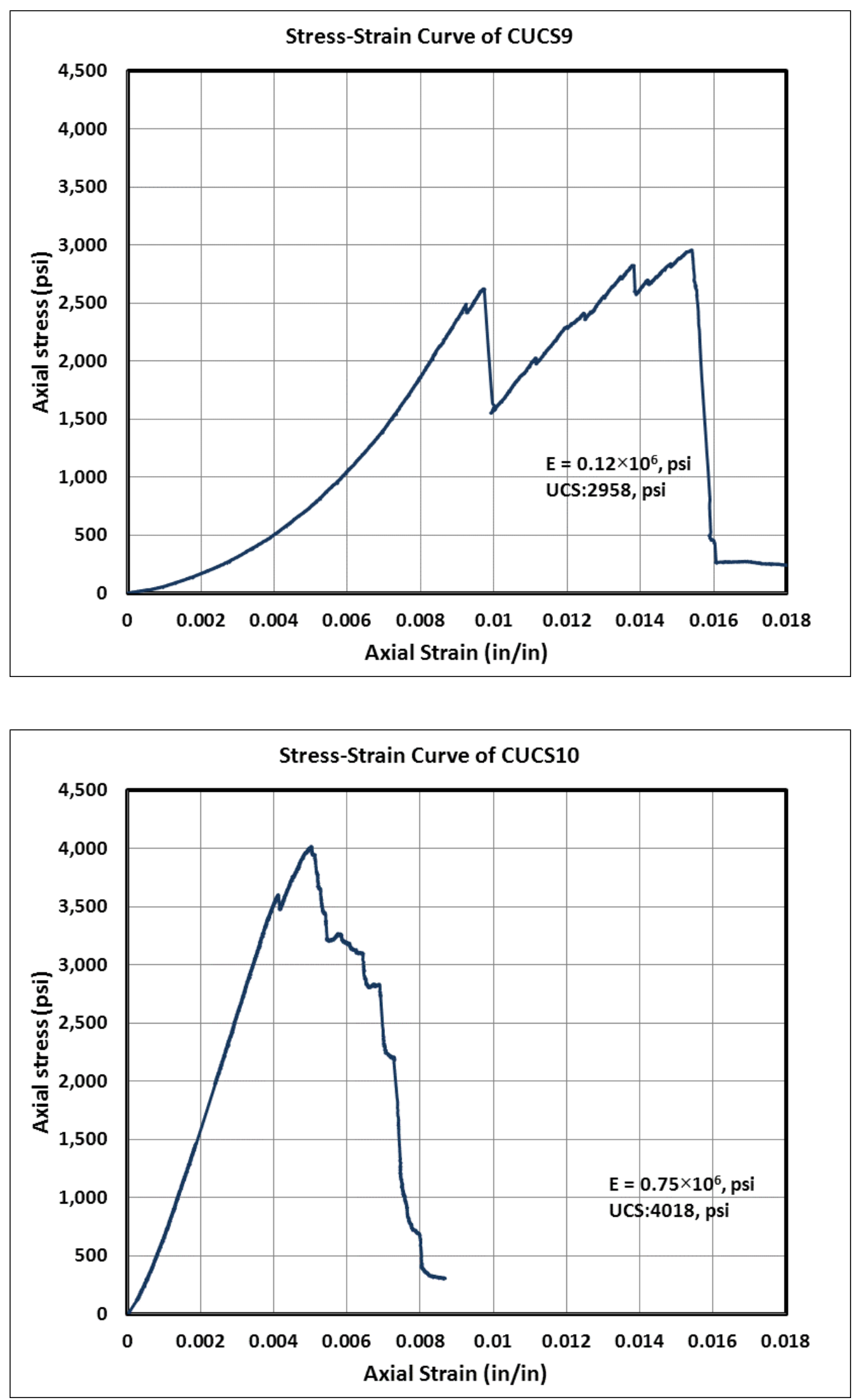

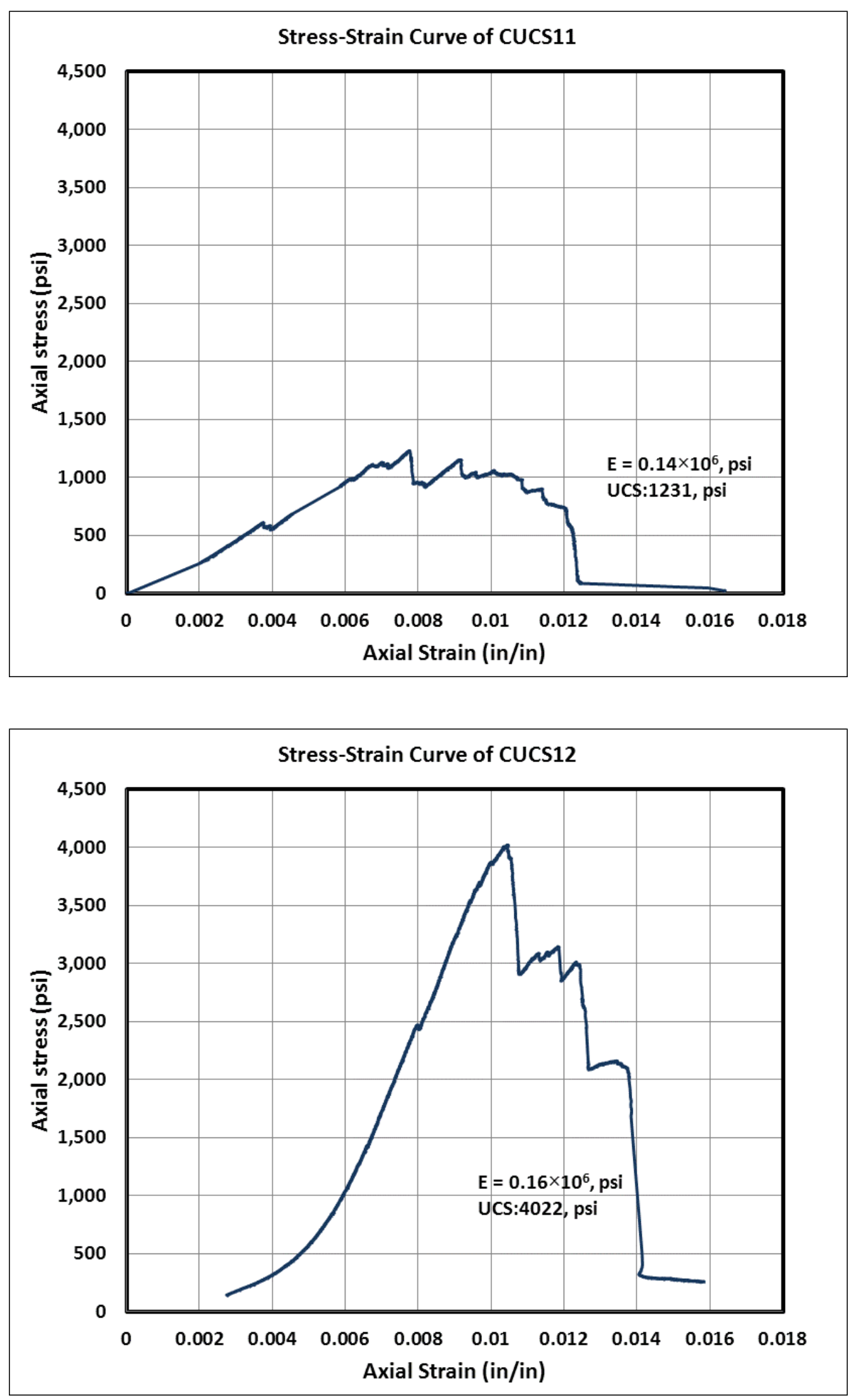
(g) Stress-strain curves of 4 coal specimens tested under Lateral Strain Control (Hiawatha Seam)
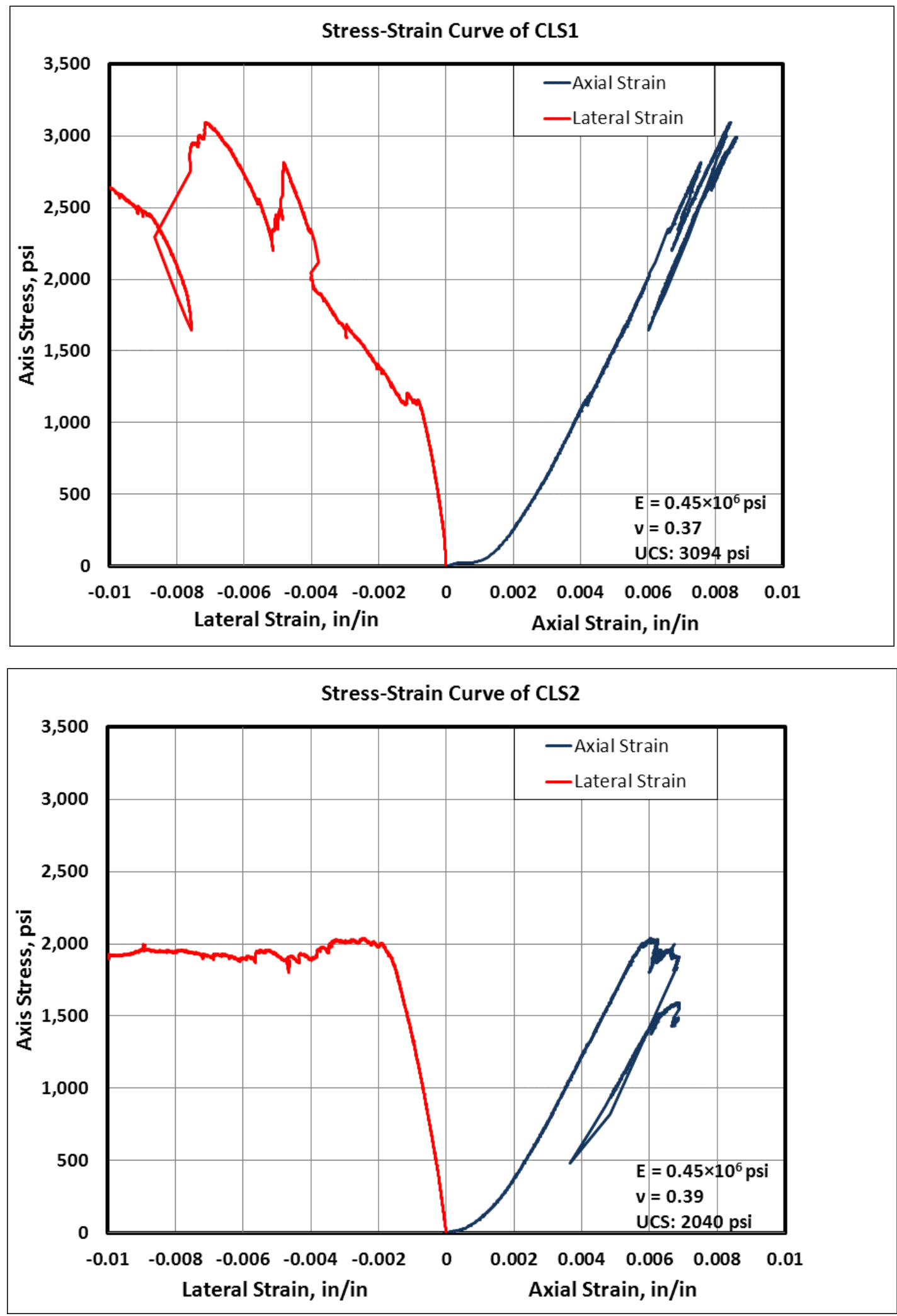

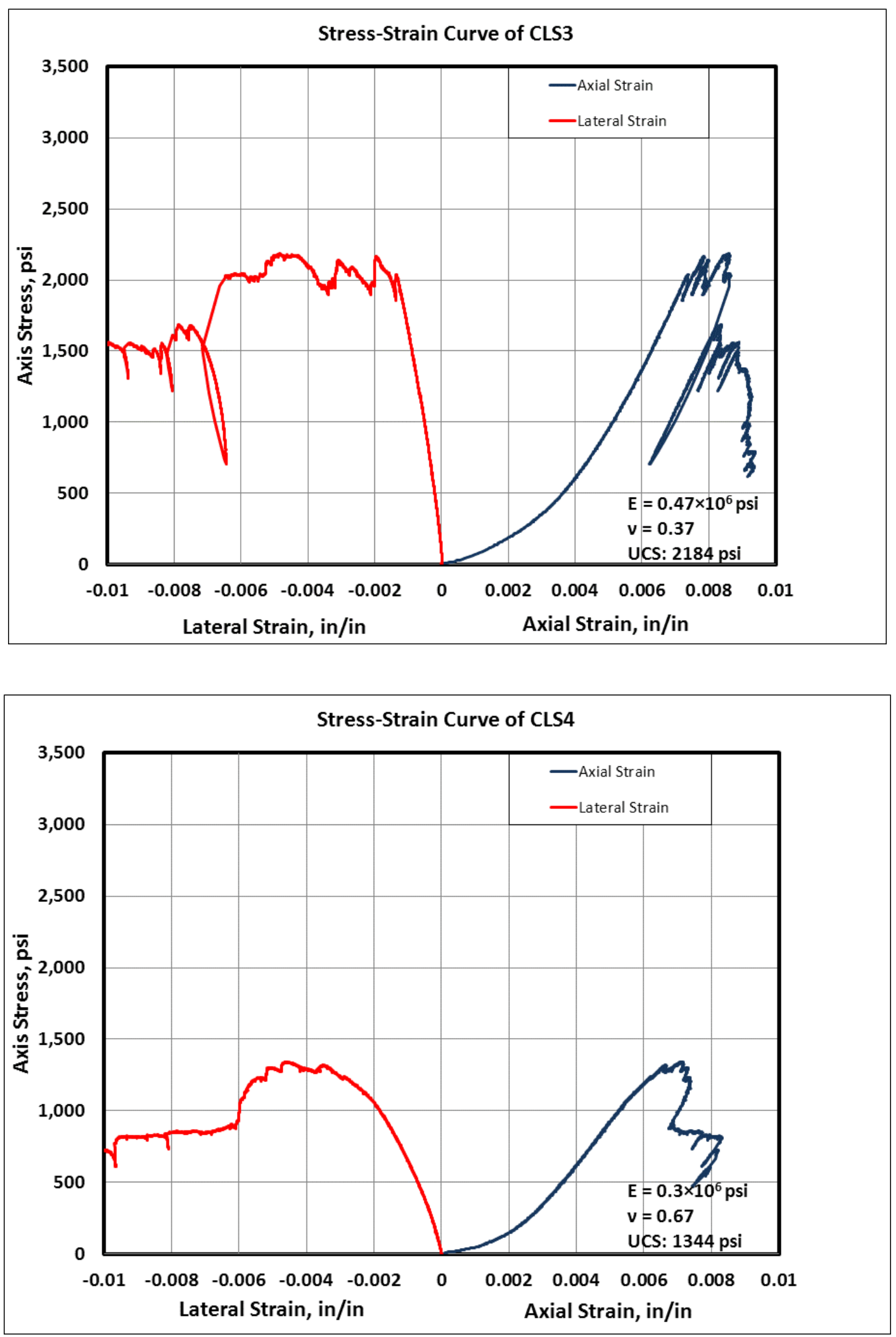
(h) Stress-strain curves of 4 coal specimens tested under Lateral Strain Control (Hiawatha Seam) with Low Confining Pressure
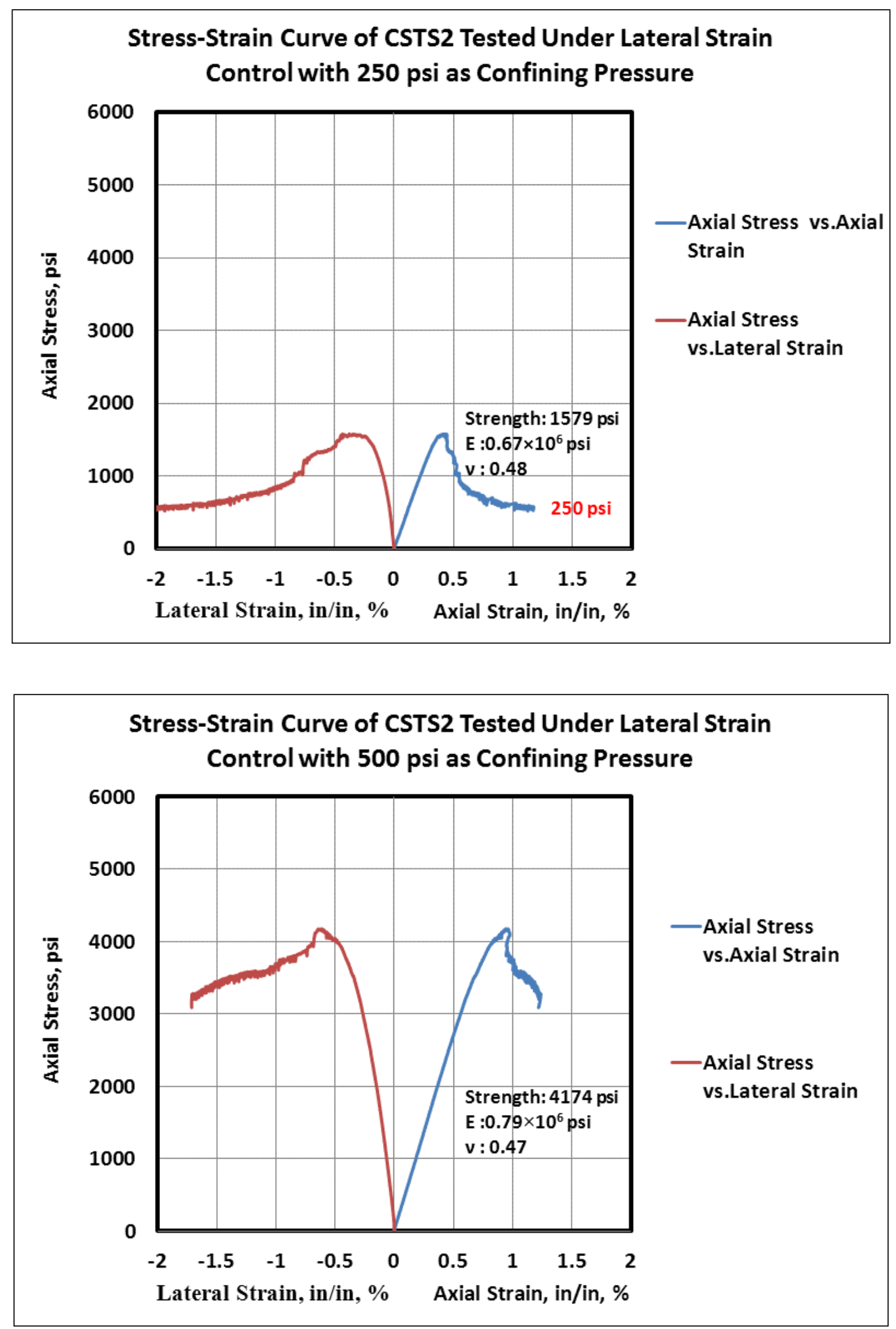

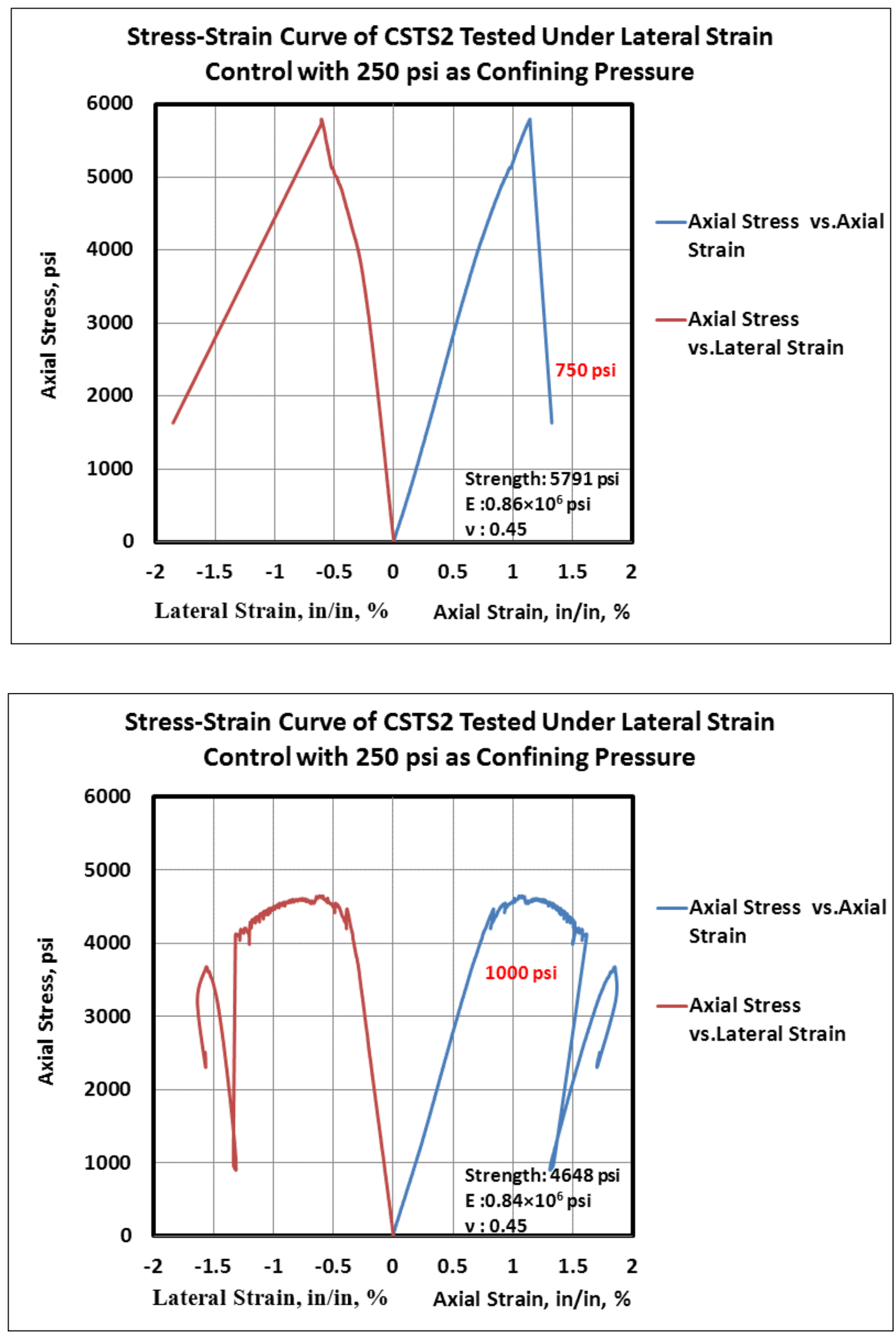
Stress-strain curves of 4 coal specimens tested under Lateral Strain Control (Hiawatha Seam) with Low Confining Pressure, all together.

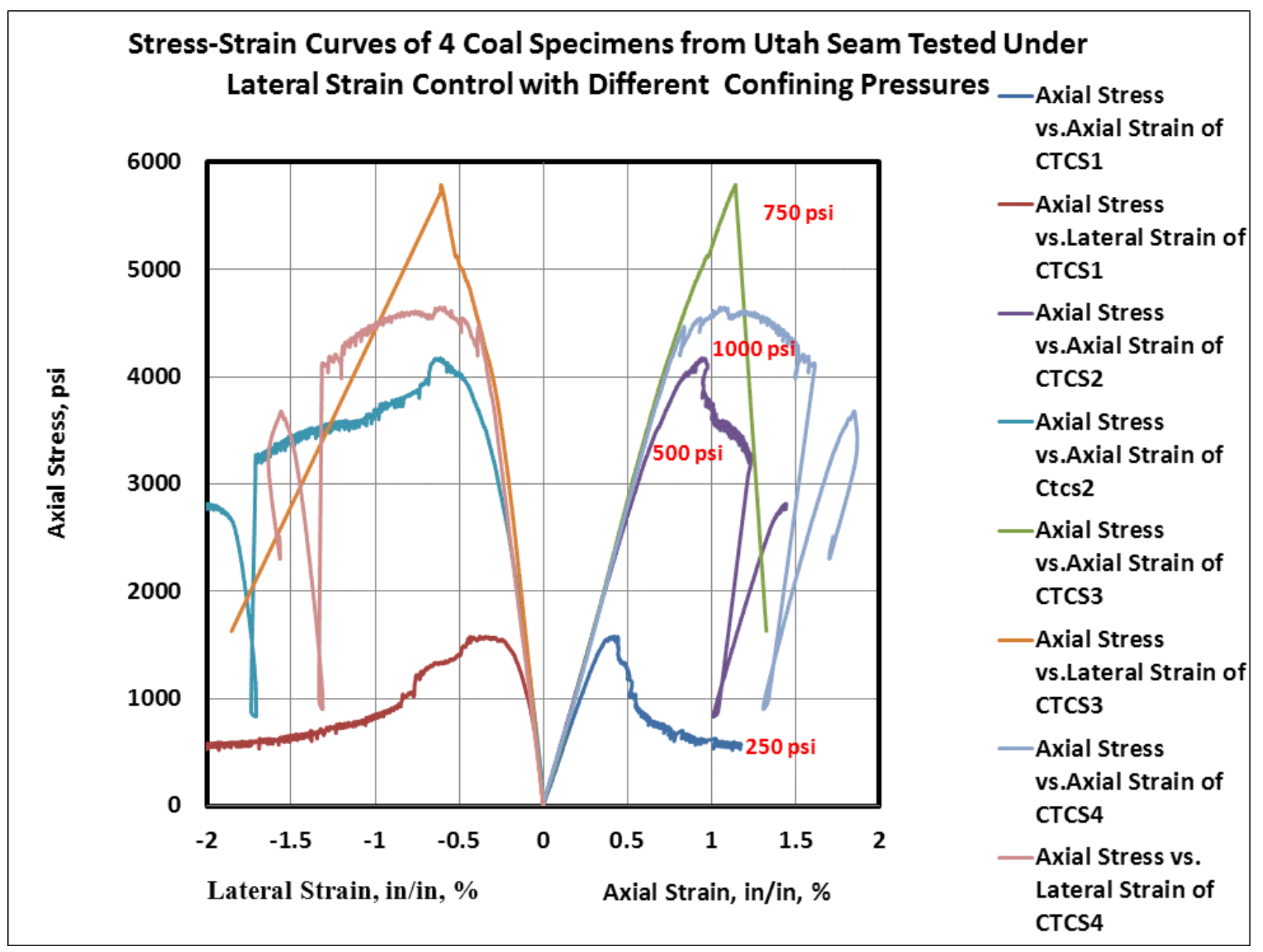




\section{Appendix B: Rock/coal specimens tested under various control modes,}

\section{before and after failure}

(a) Six randomly selected rock samples tested under load control, before failure
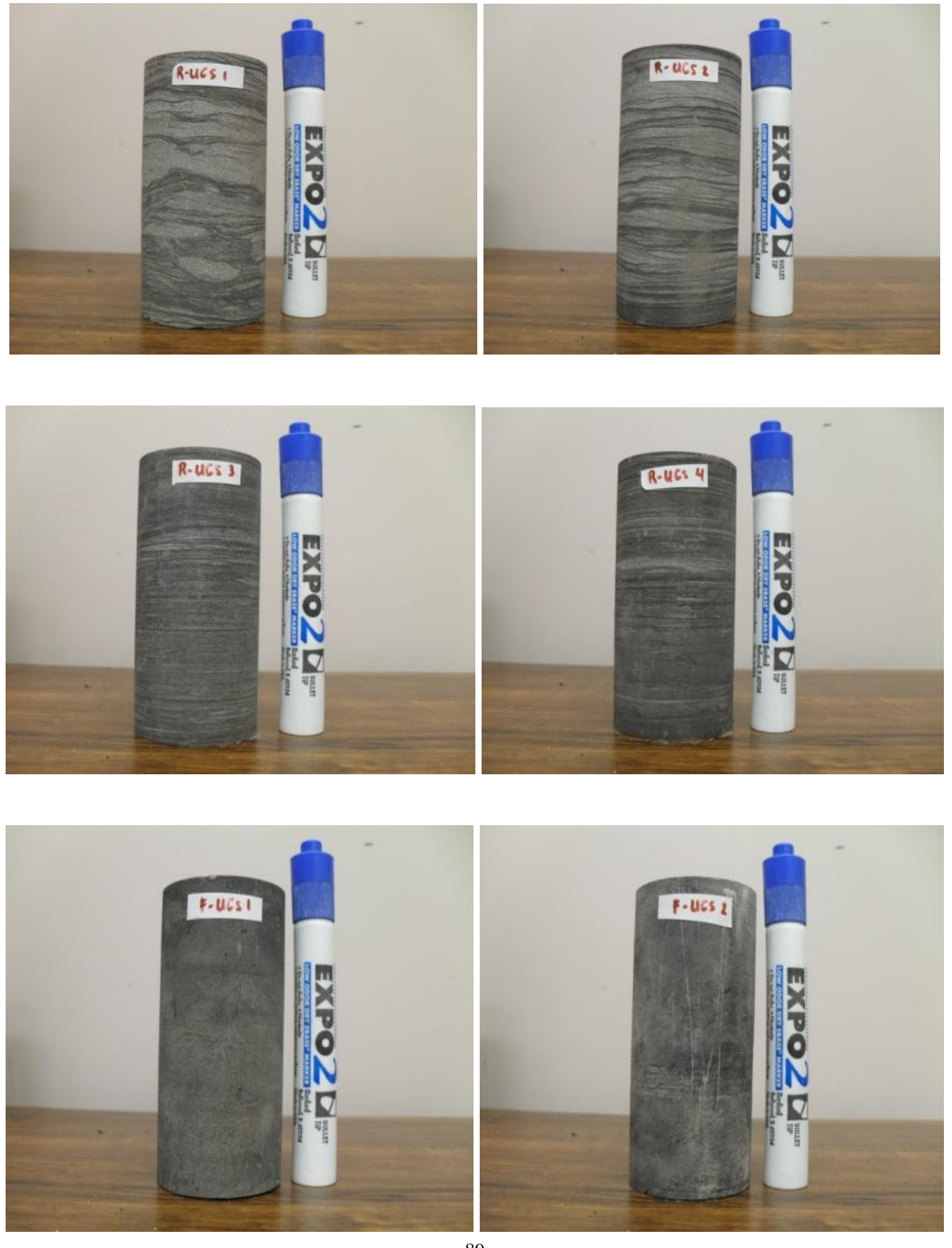
(b) Berea sandstone used for UCS test under lateral strain control mode (before and after failure all together)
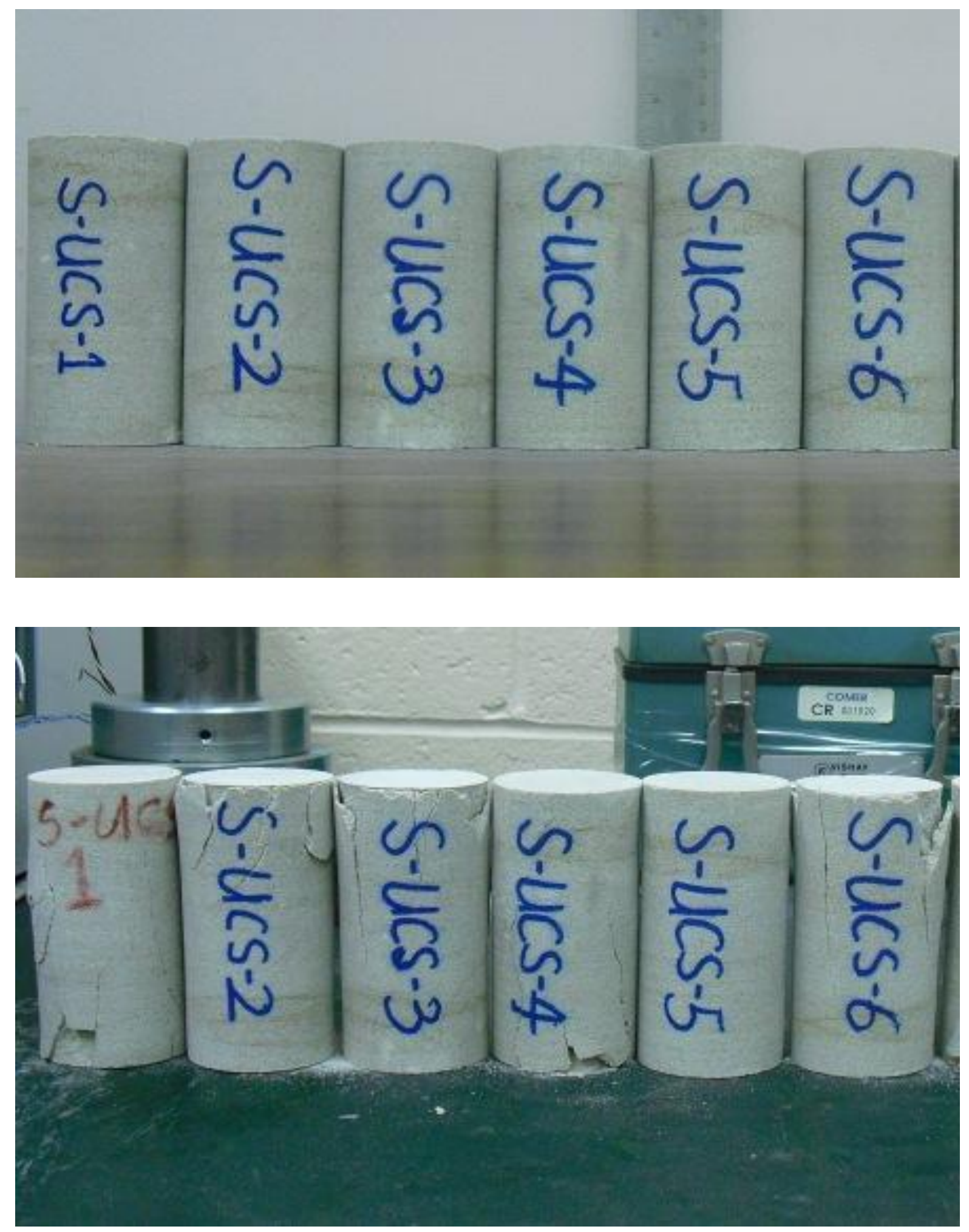
Berea sandstone used for UCS test under lateral strain control mode (before and after failure)
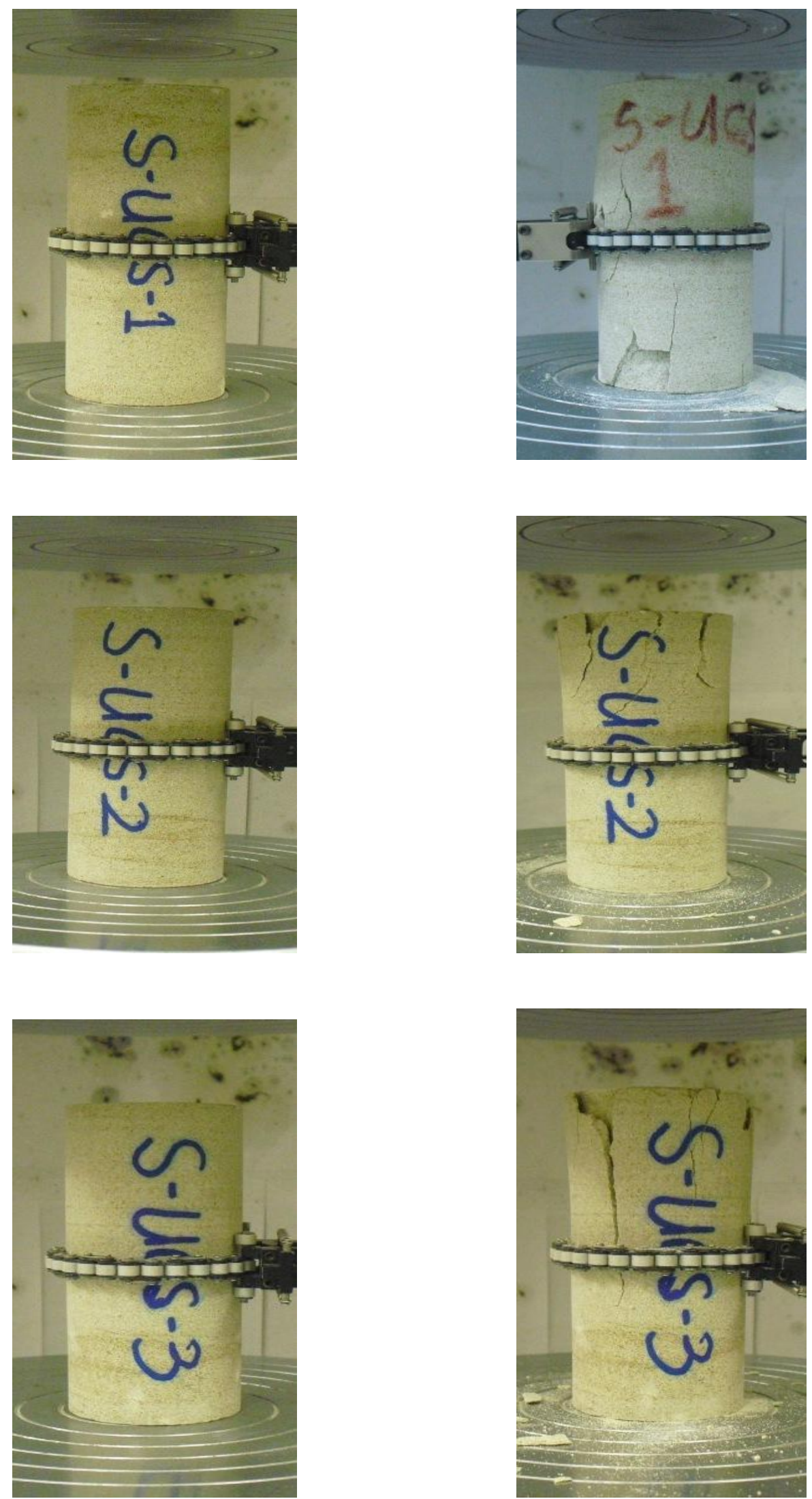

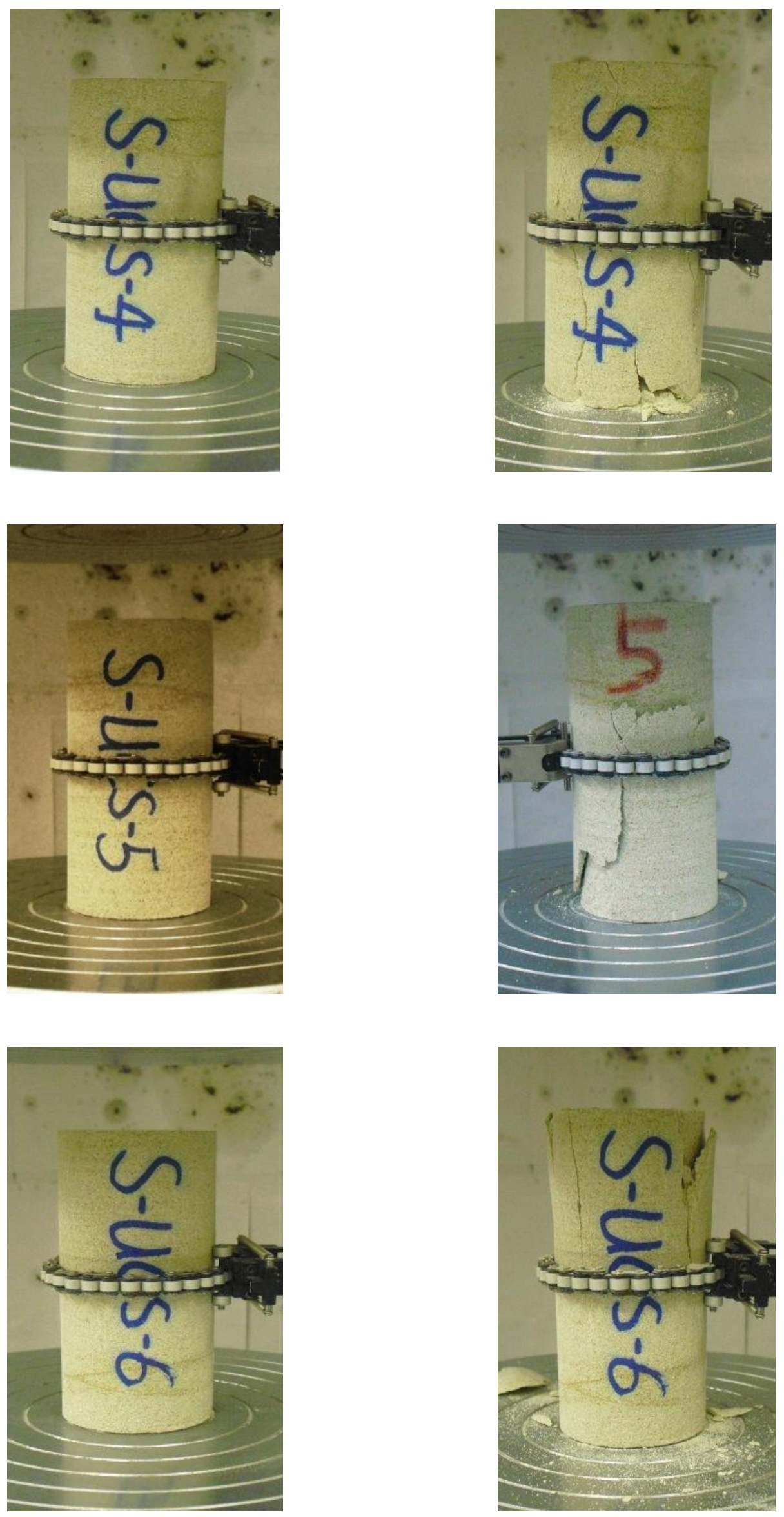
(c) Six different rock specimens tested under lateral strain control mode, (before and after failure all together)
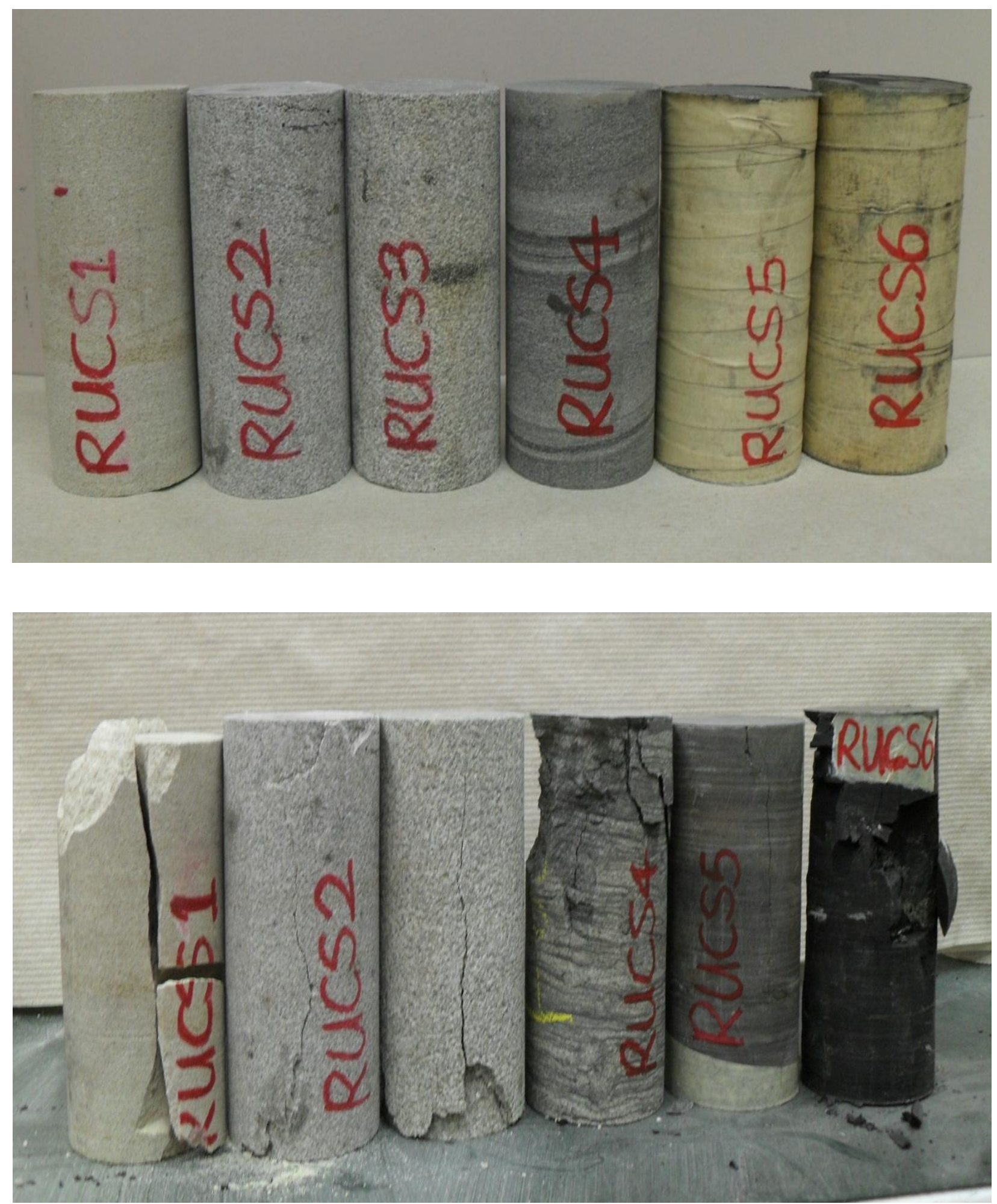
Six different rock specimens tested under lateral strain control mode, (before and after failure)
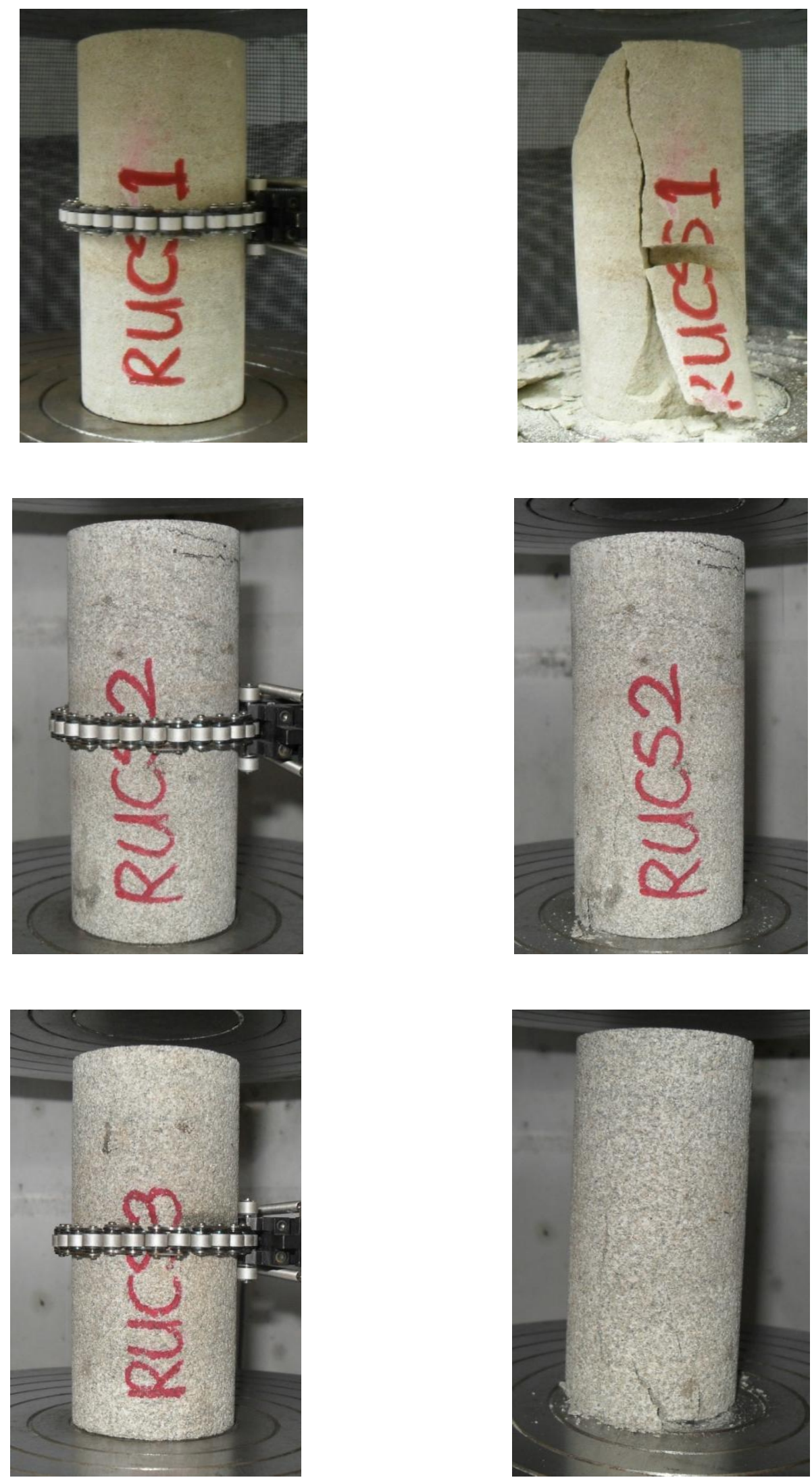

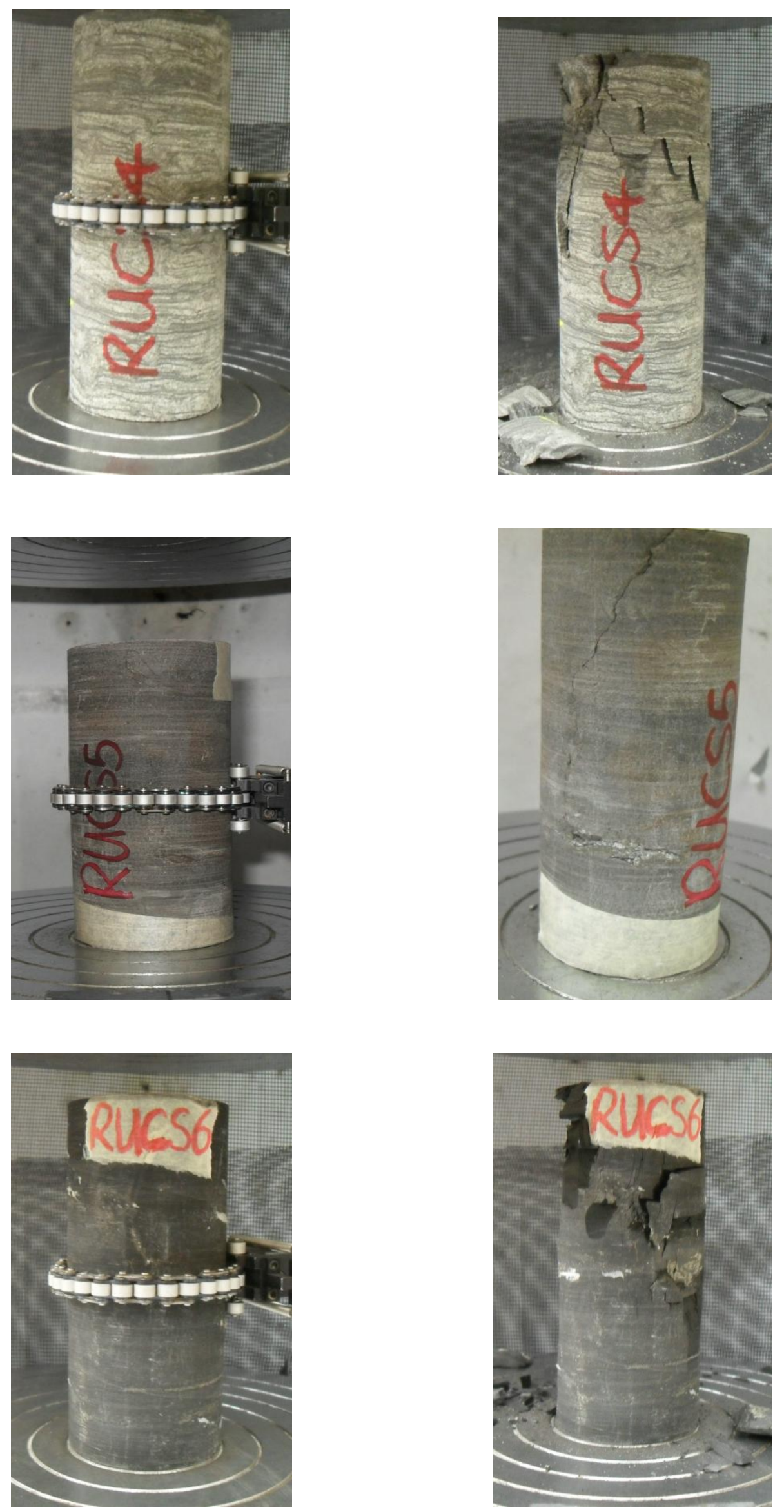
(d) Six different rock specimens tested under axial strain control mode, (before and after

failure, all together)
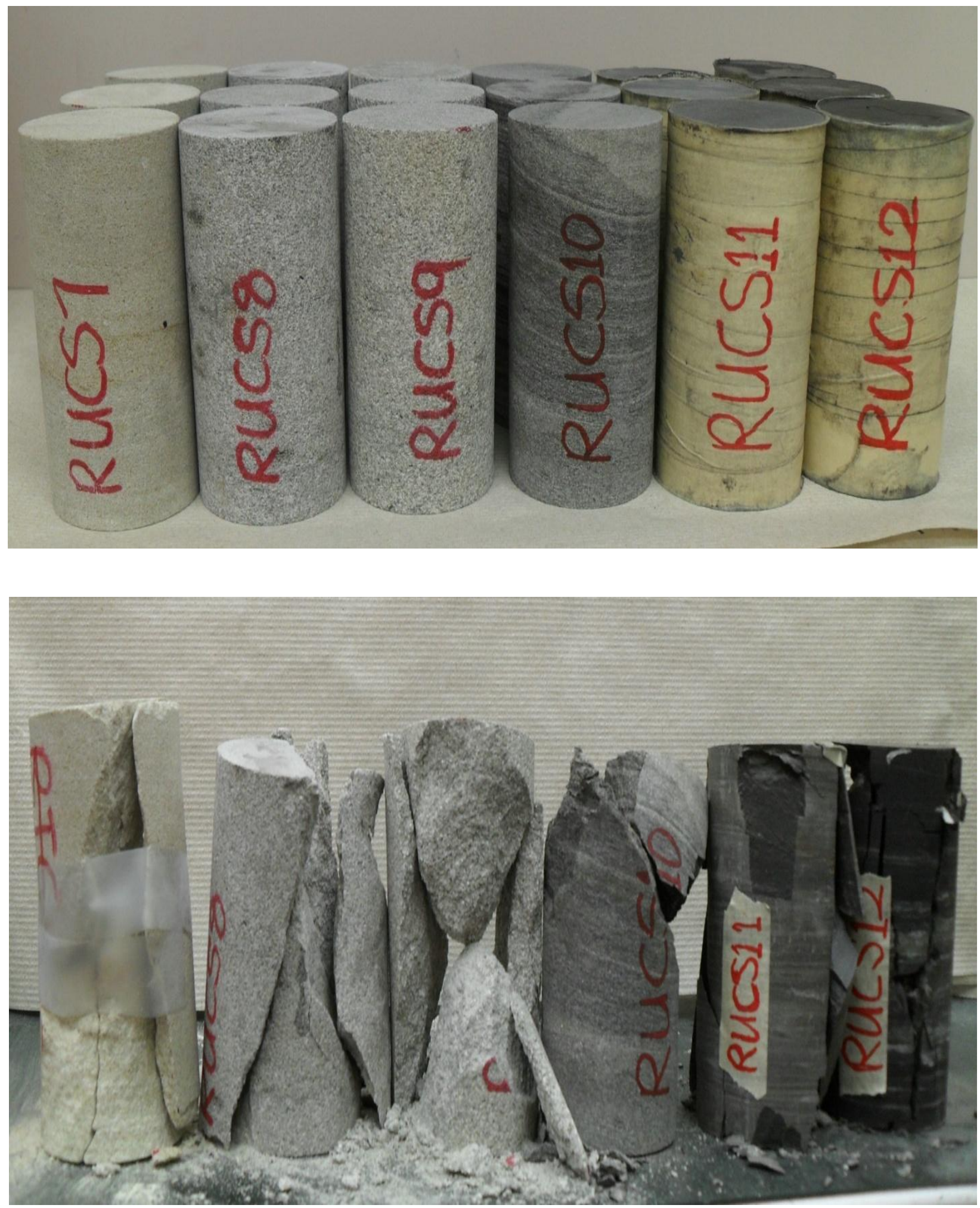
Six different rock specimens tested under axial strain control mode (before and after failure).
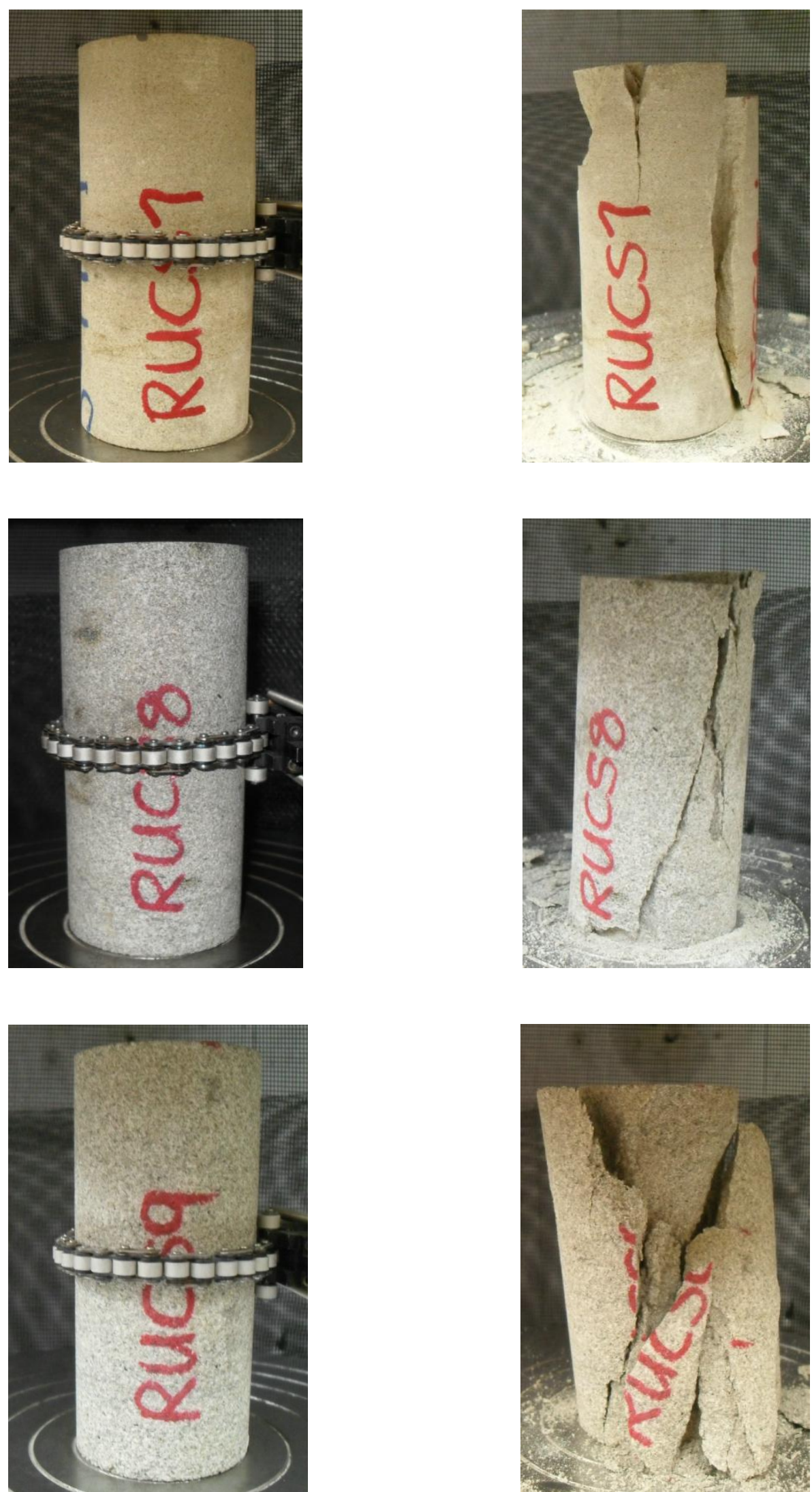

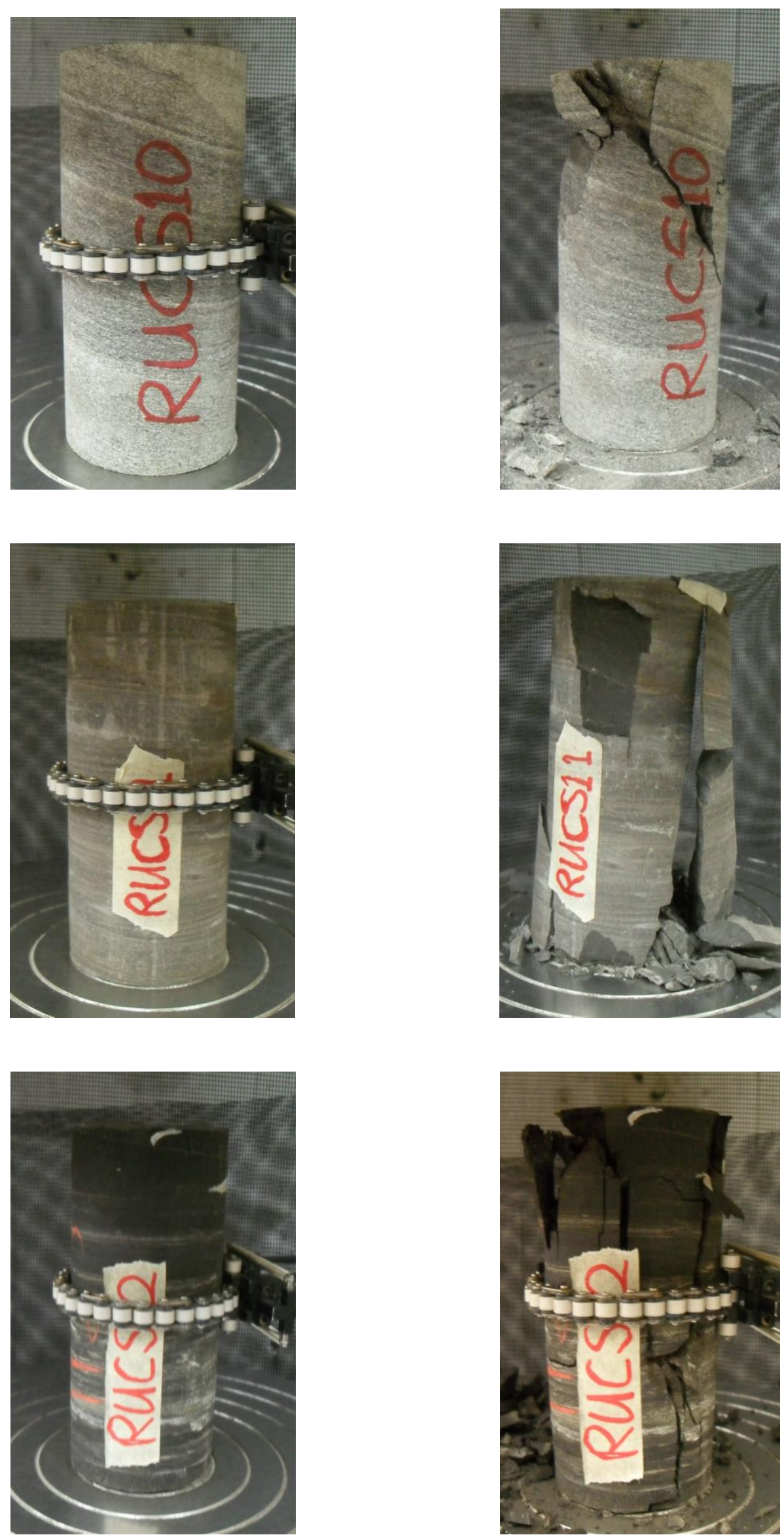
(e) Coal specimens tested under lateral strain control mode from Pittsburgh seam (before and after failure all together)
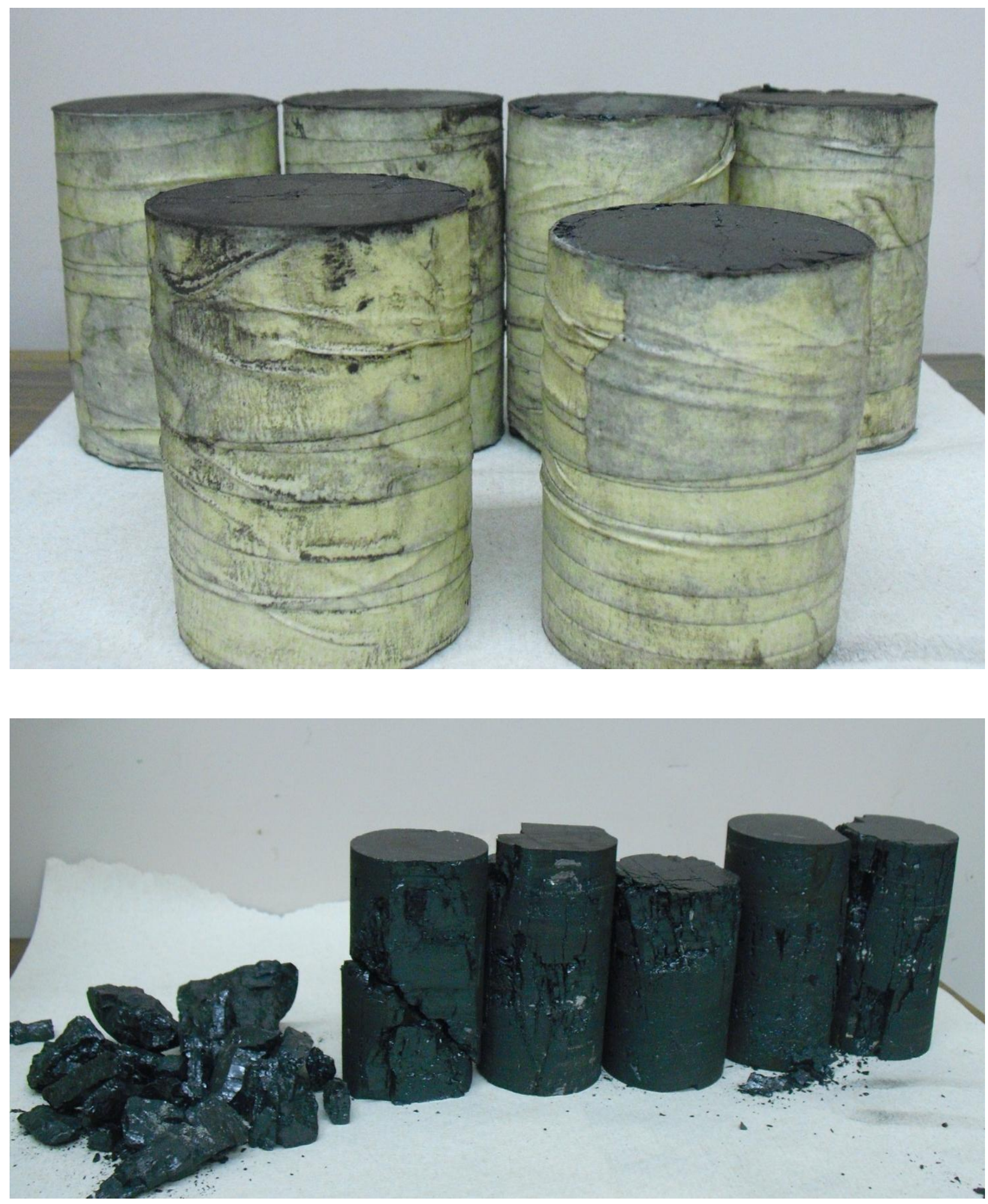
Coal specimens tested under lateral strain control mode, (before and after failure separate)
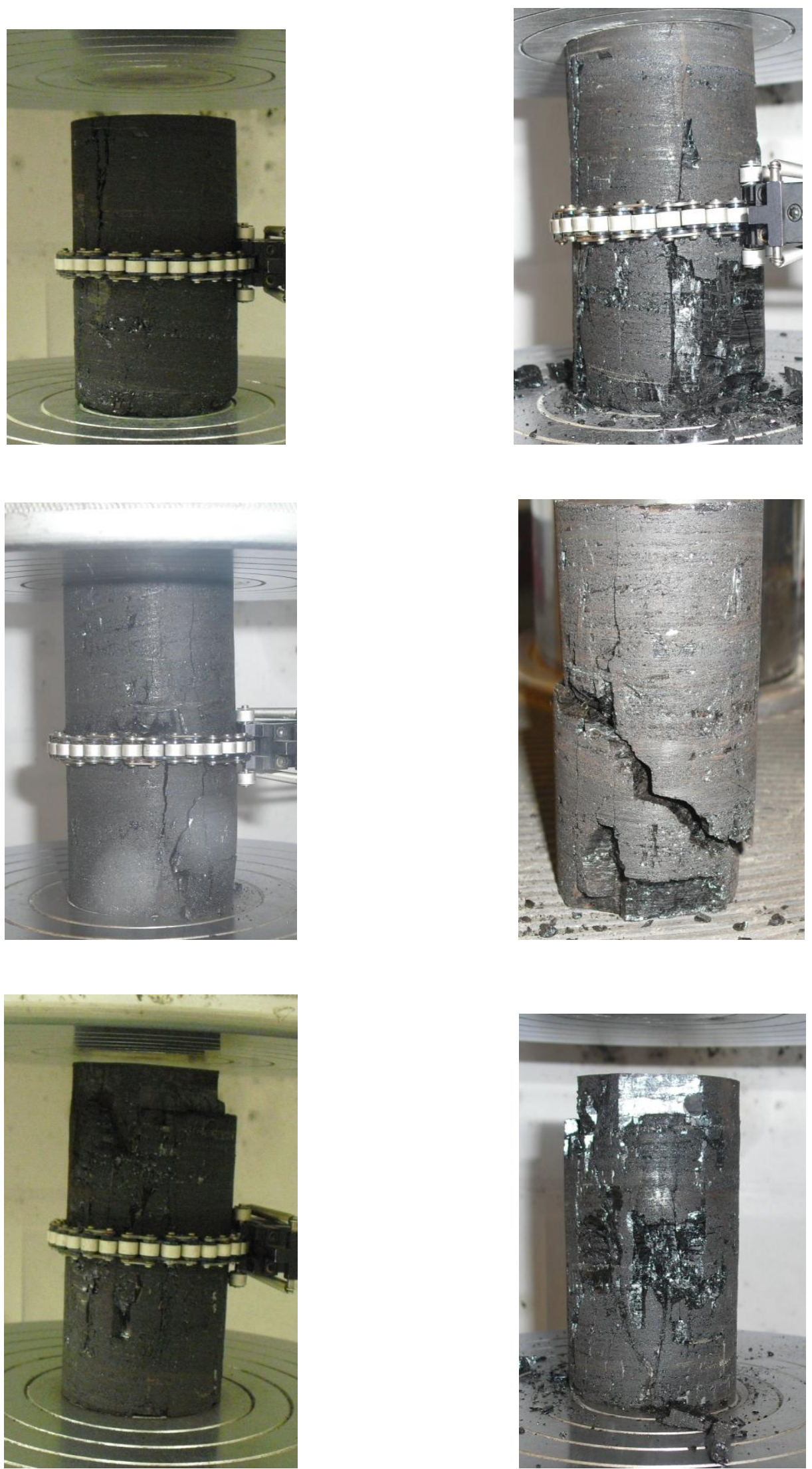

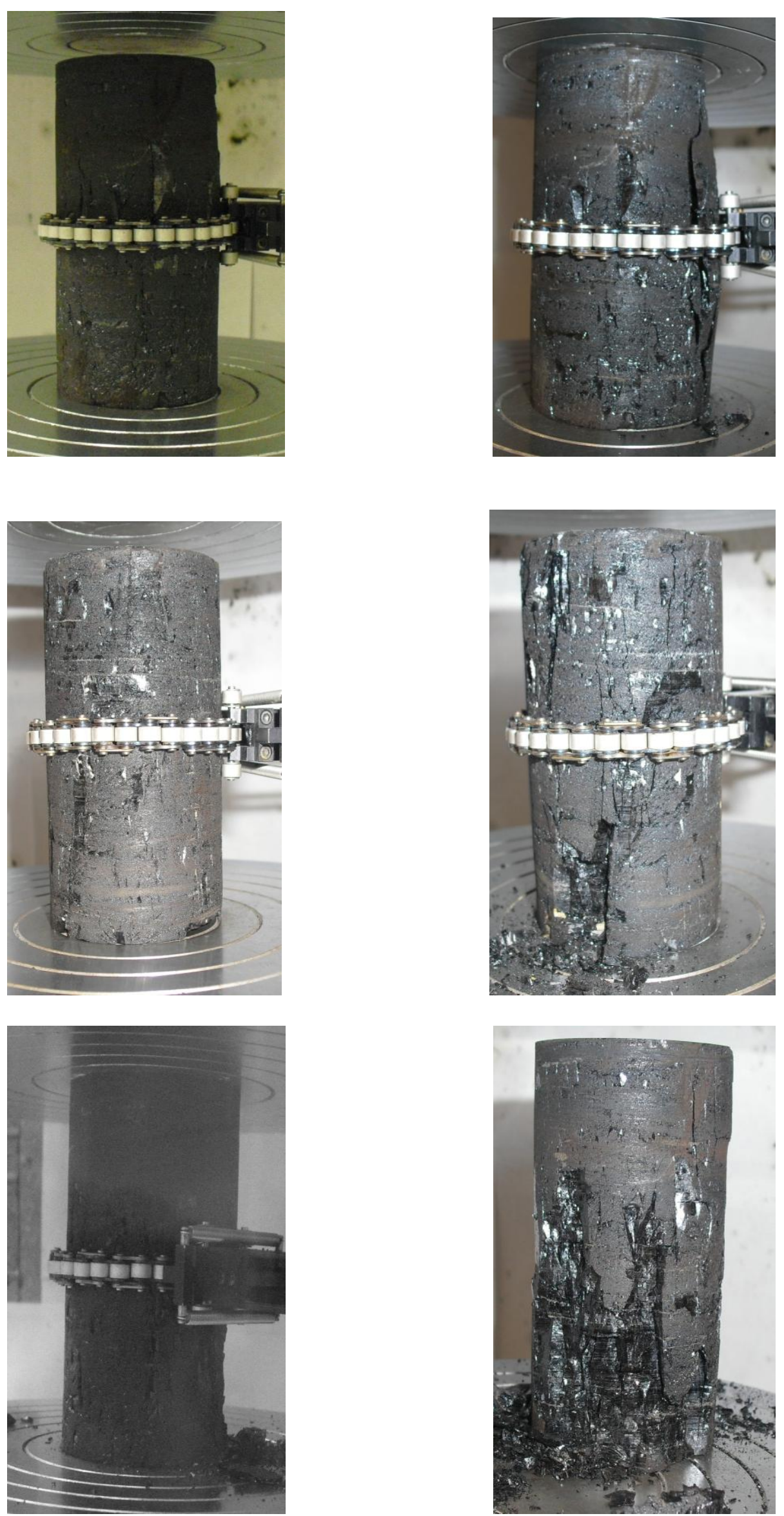
(f) Coal specimens tested under axial strain control mode, (after failure all together)

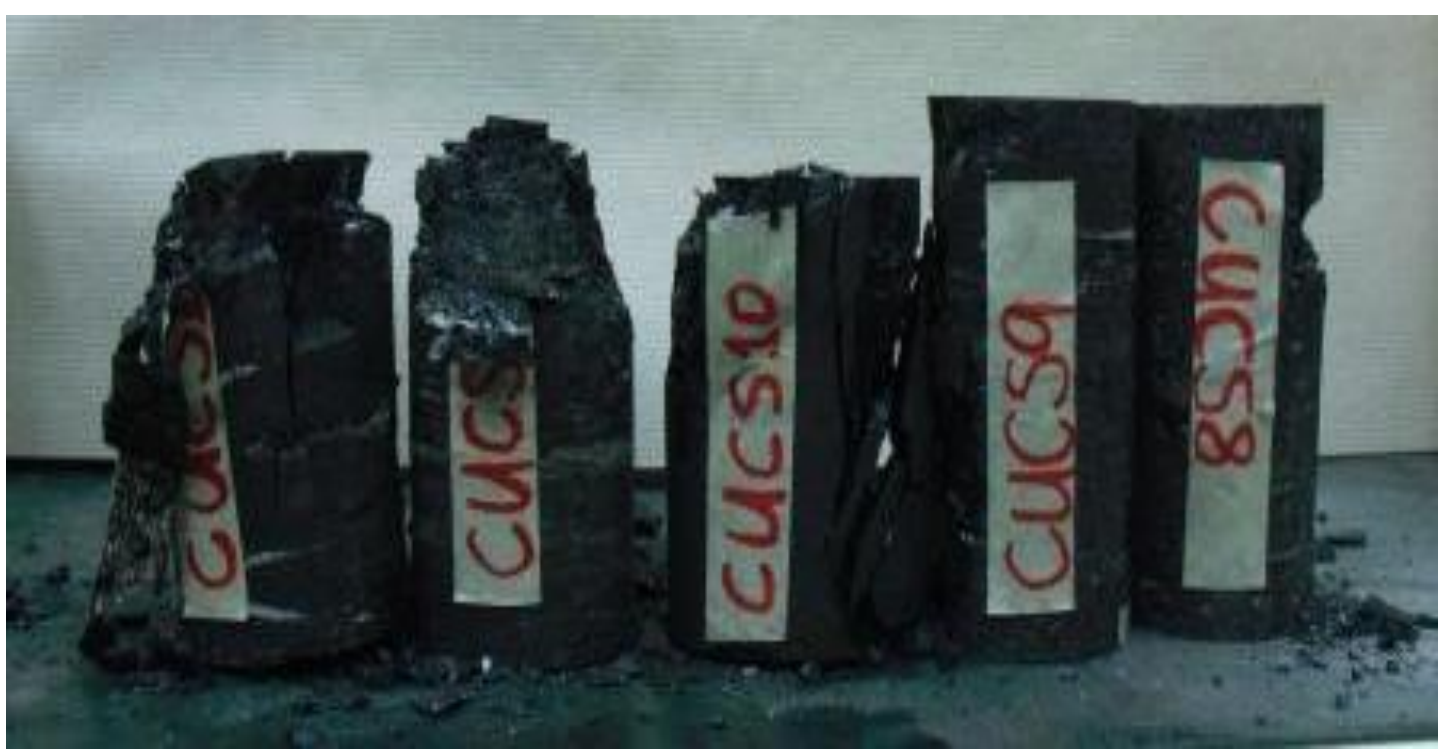


Coal specimens tested under axial strain control mode, CUCS7 is lost, (before and after failure)
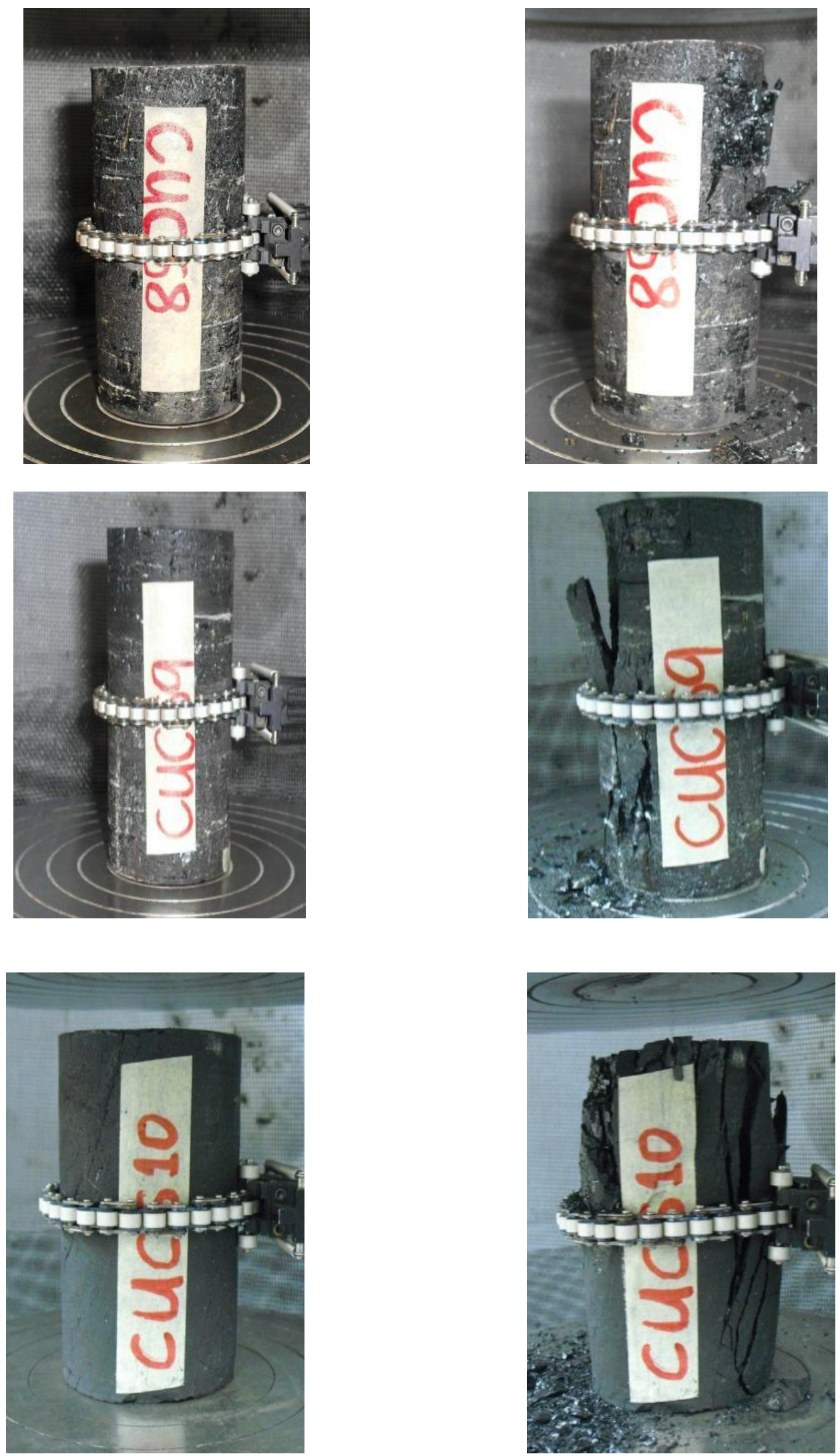

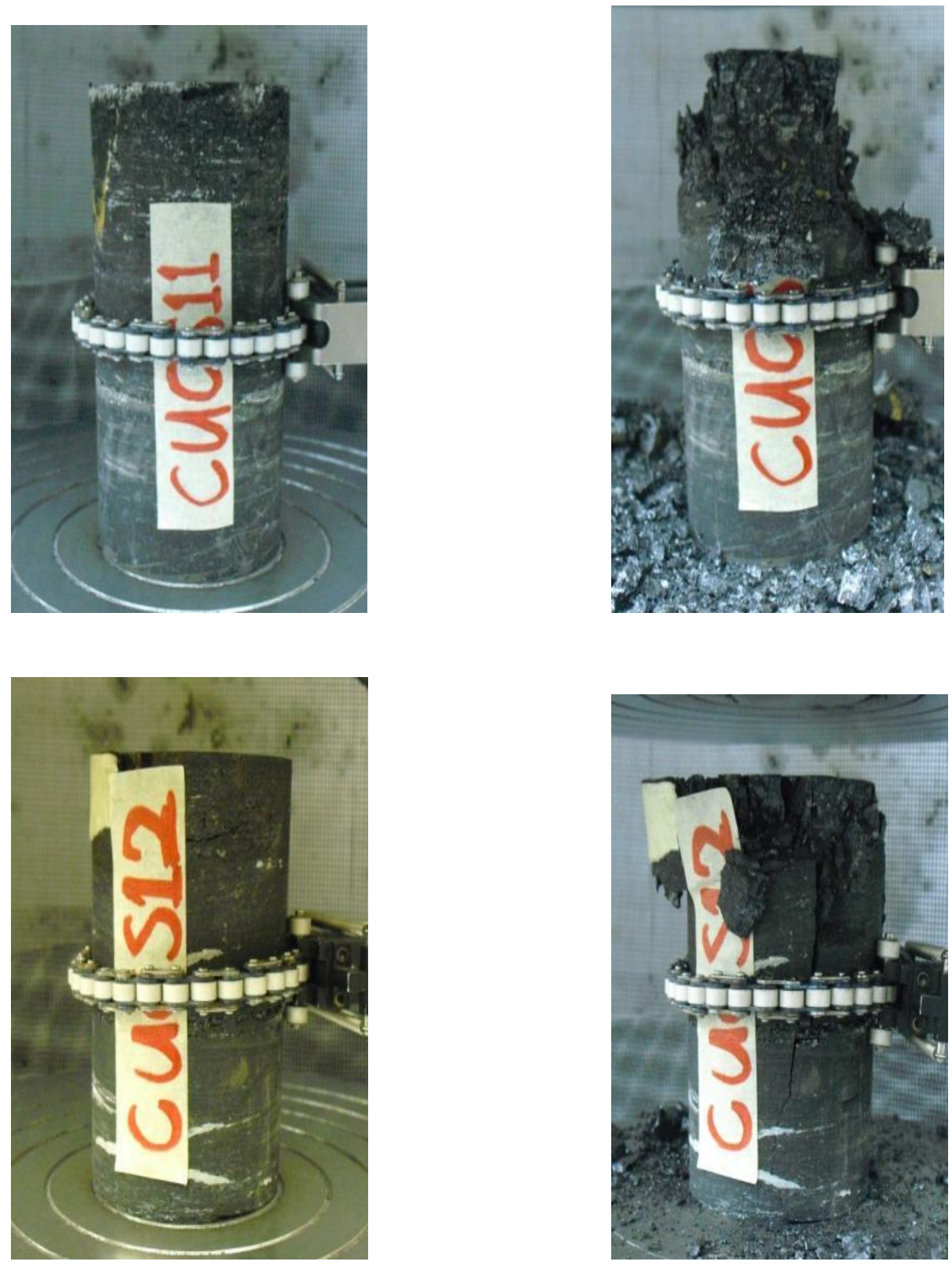
(g) Coal specimens tested under lateral strain control mode, before and after failure (Hiawatha Seam)
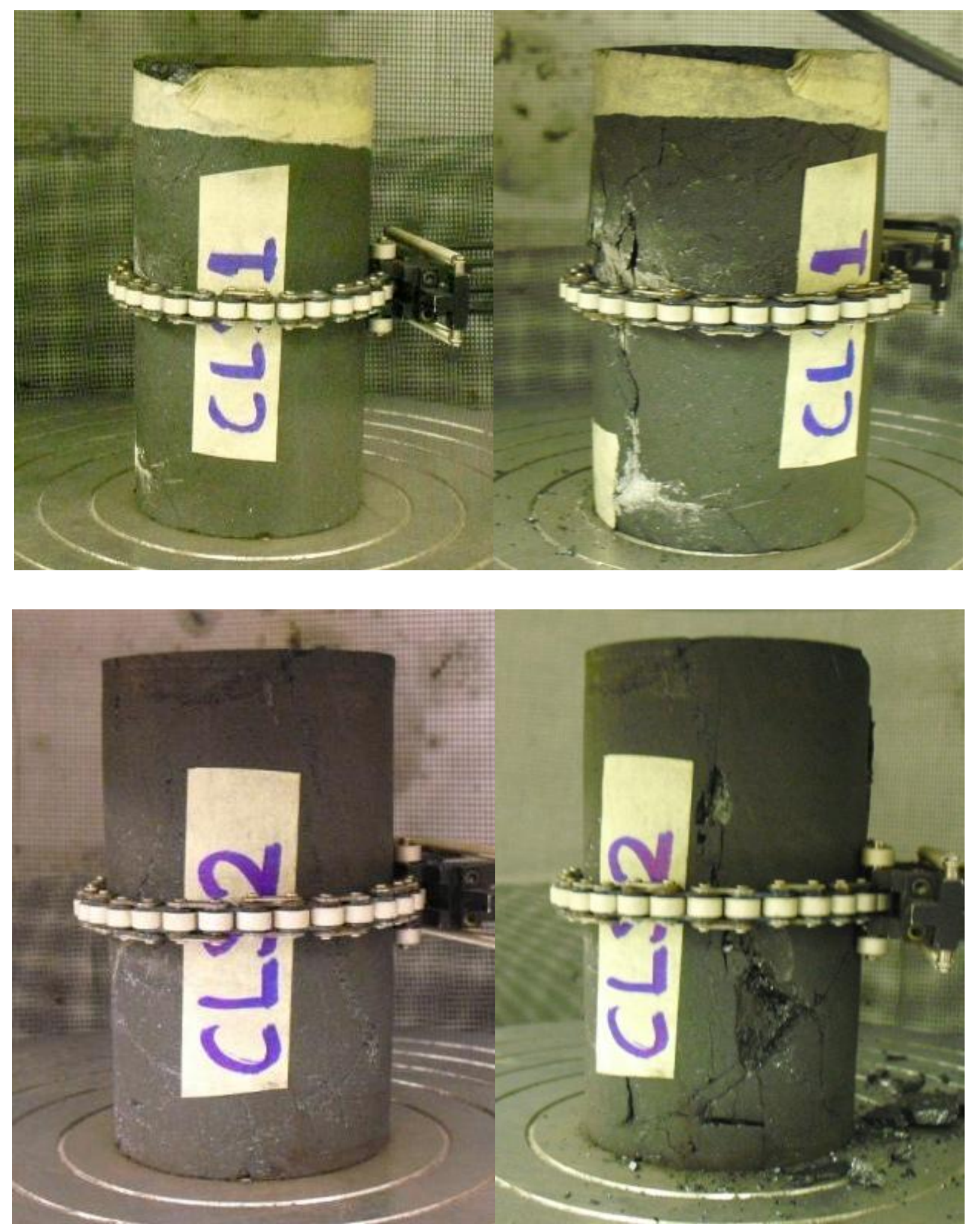

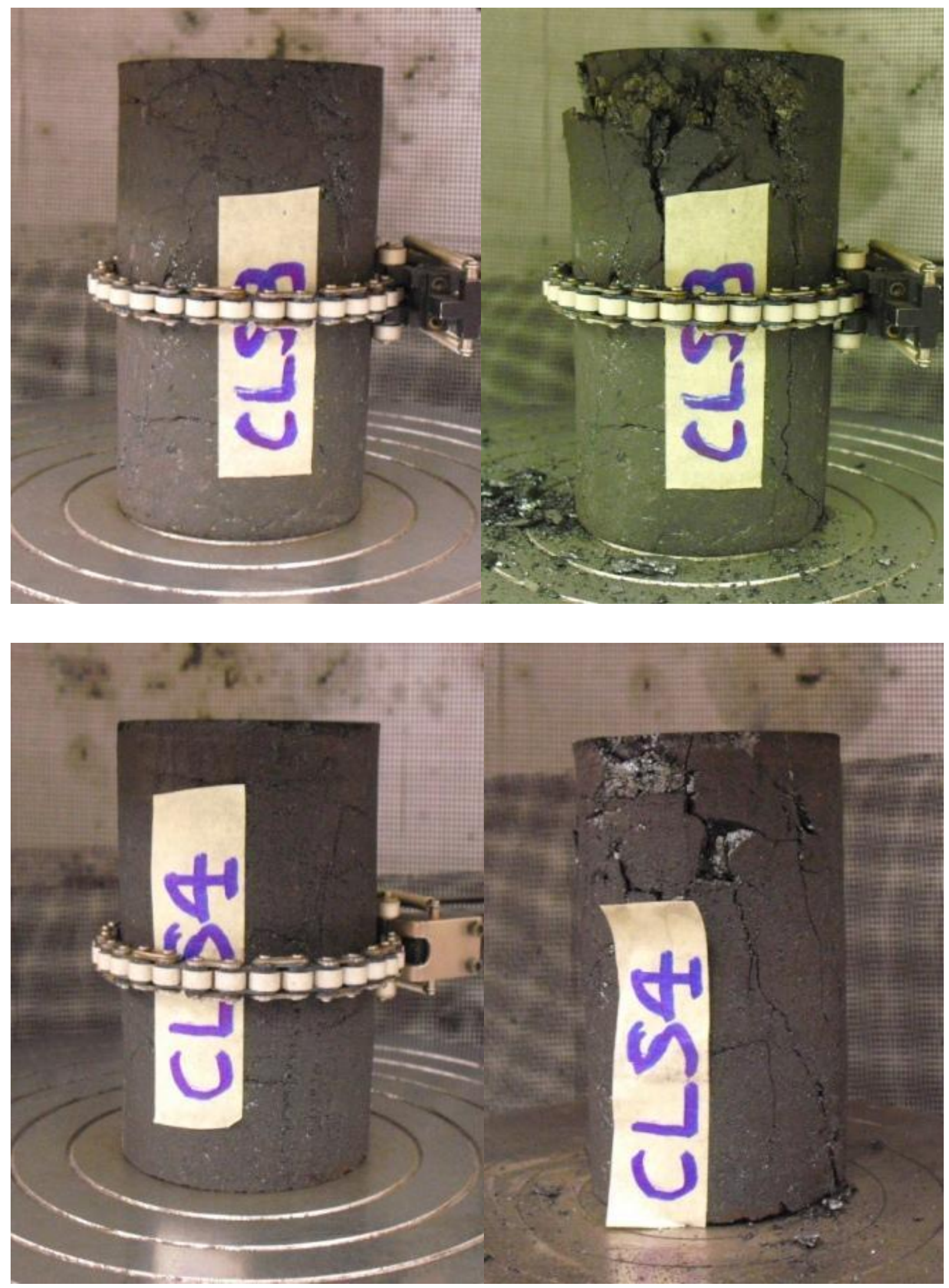
(h) Coal specimens tested under triaxial compression with lateral strain control, before and after failure (Hiawatha Seam)
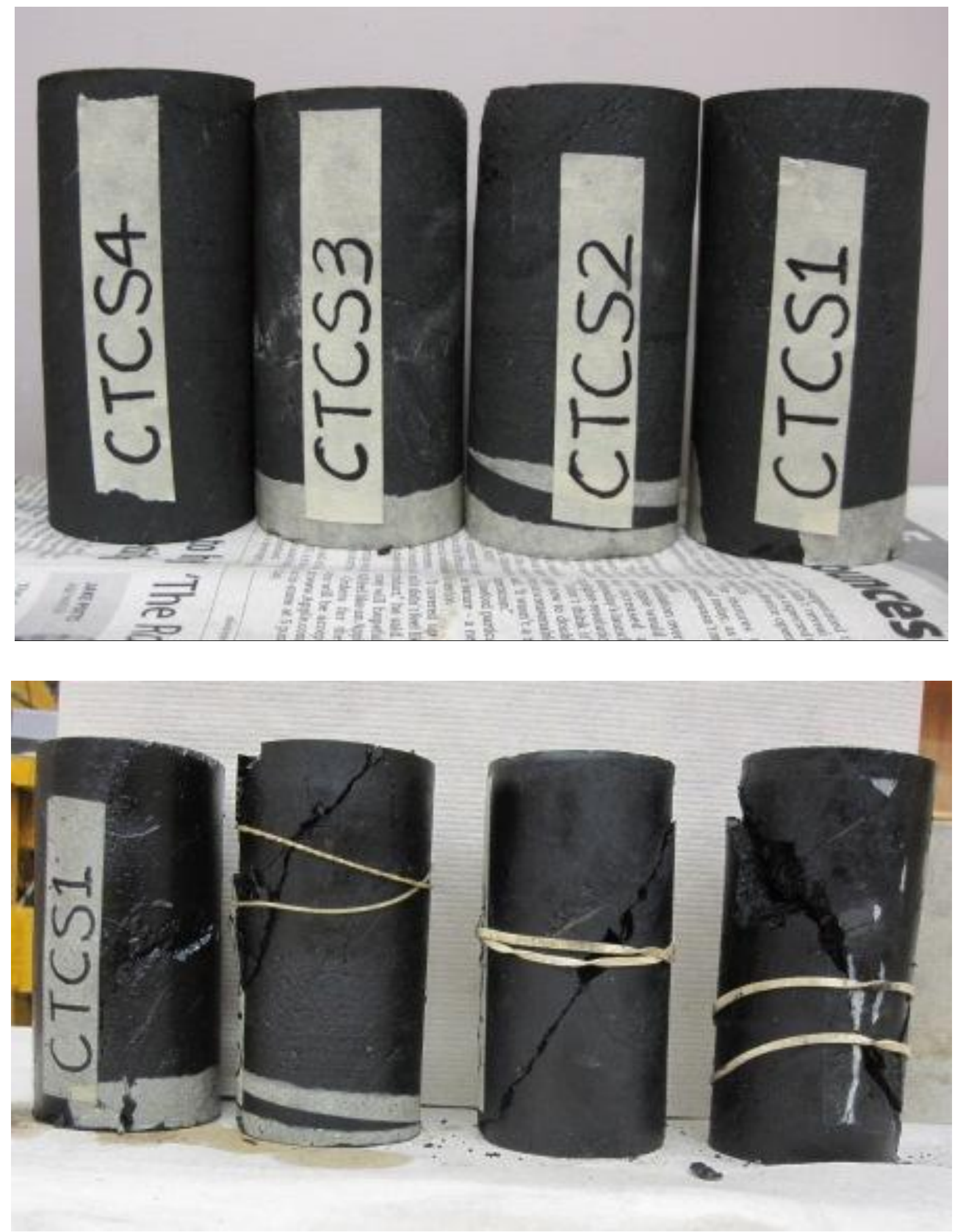

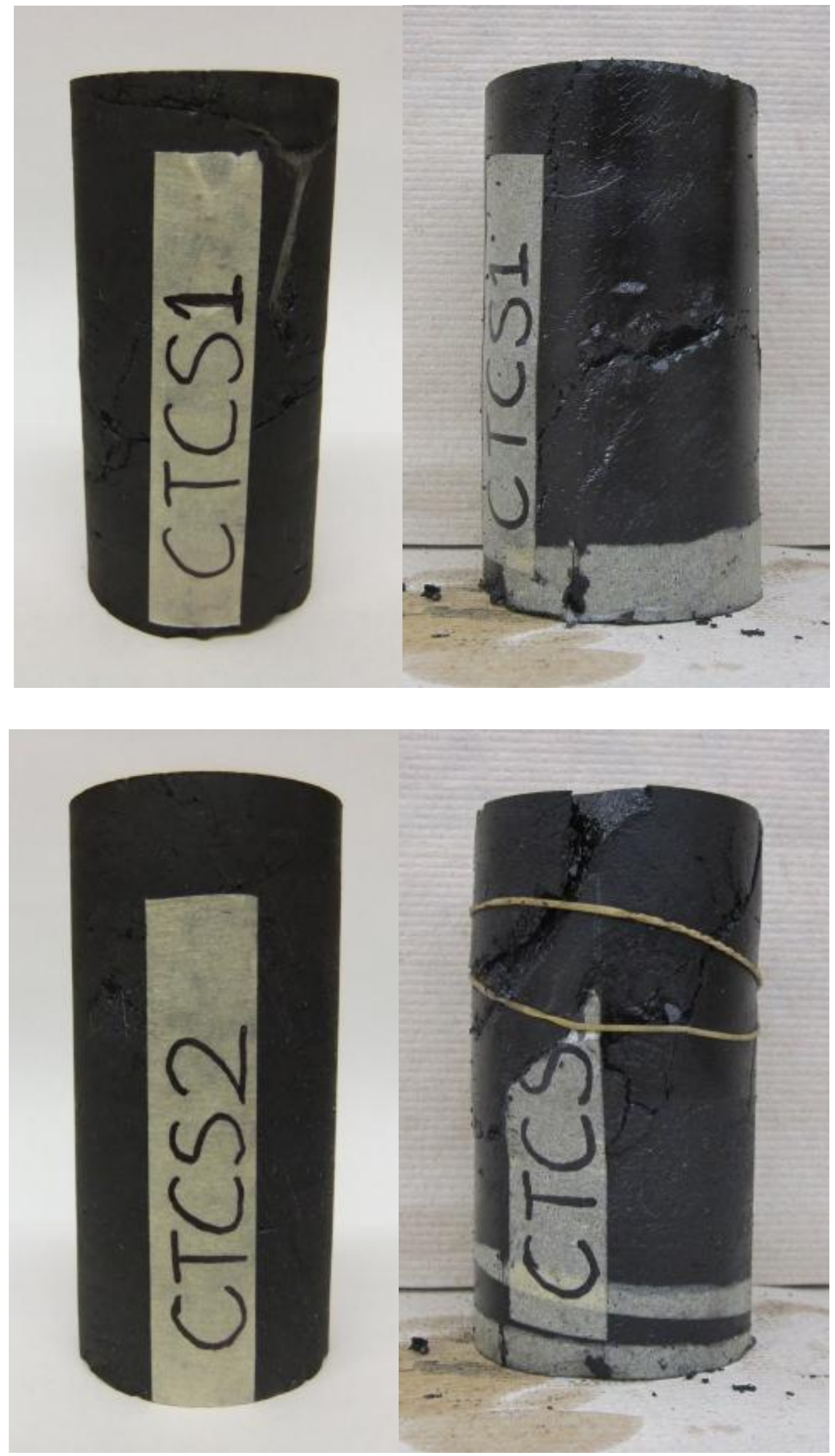

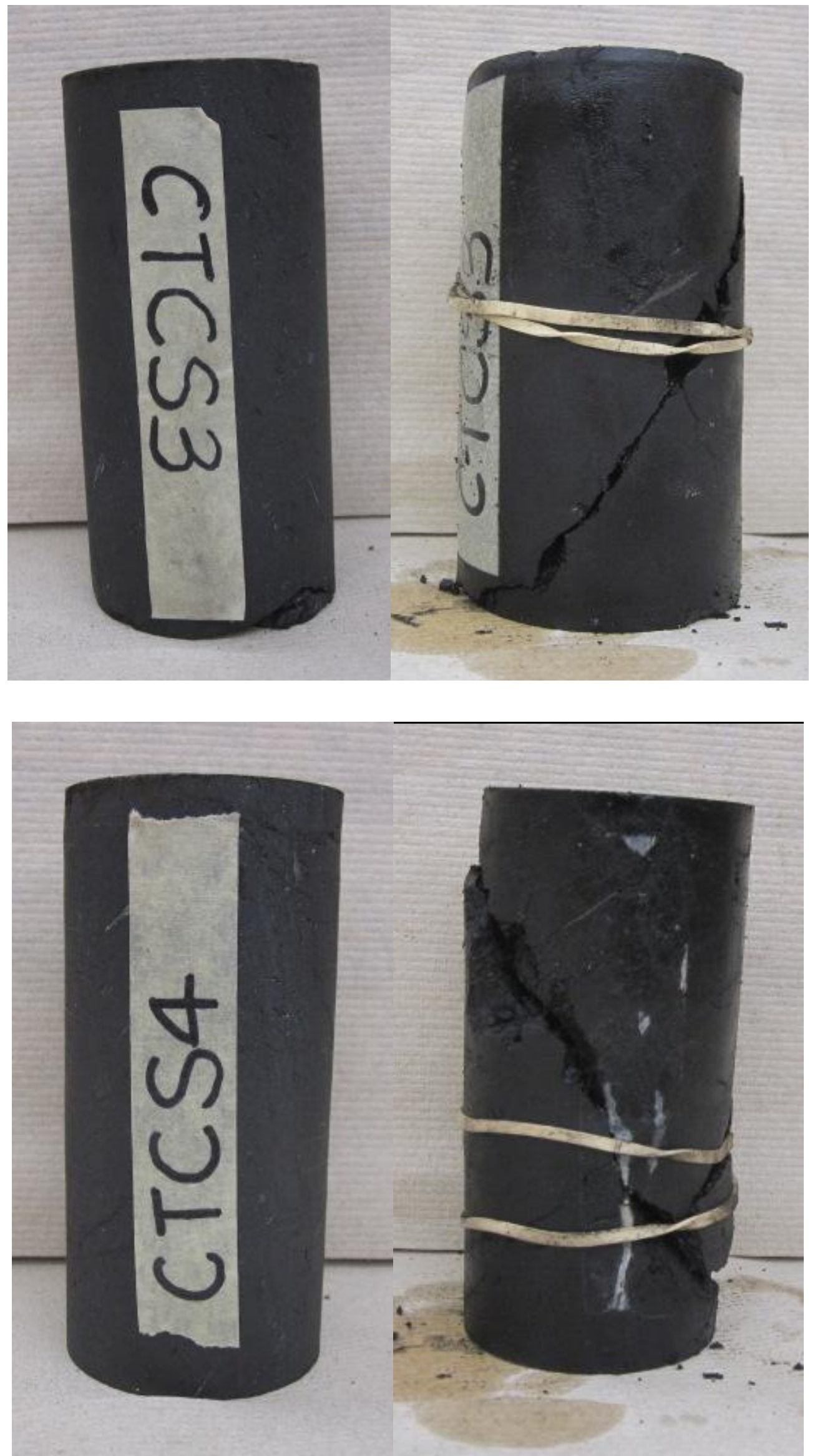


\begin{abstract}
About The Author
Dachao Nie was born in 1986, Nanyang city, Henan province, China. He finished his bachelor's degree in Mining Engineering at the School of Energy Science and Engineering in July 2009 from the first mining university in the Chinese history, Henan Polytechnic University. He came to the United States in August 2009 for his master's degree in Mining Engineering with an emphasis on Rock Mechanics at West Virginia University. He is currently a candidate for the degree of Master of Science in Mining Engineering.
\end{abstract}

